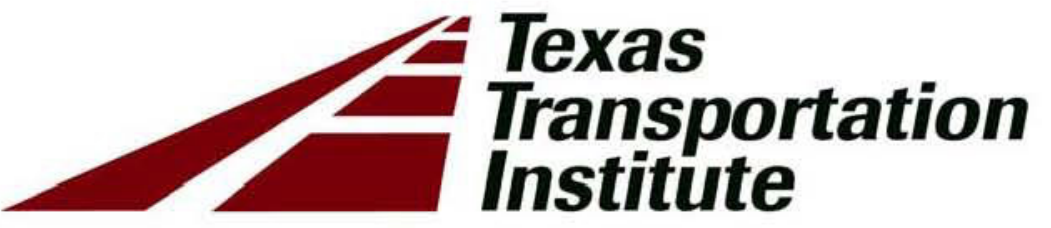

CEnTER for

PORTS and

WATERWAYS

\title{
A MODAL COMPARISON OF \\ DOMESTIC FREIGHT TRANSPORTATION EFFECTS ON THE GENERAL PUBLIC
}

December 2007

CENTER FOR PORTS AND WATERWAYS

TEXAS TRANSPORTATION INSTITUTE

701 NORTH POST OAK, SUITE 430

HOUSTON, TEXAS 77024-3827

for

U.S. DEPARTMENT OF TRANSPORTATION MARITIME ADMINISTRATION

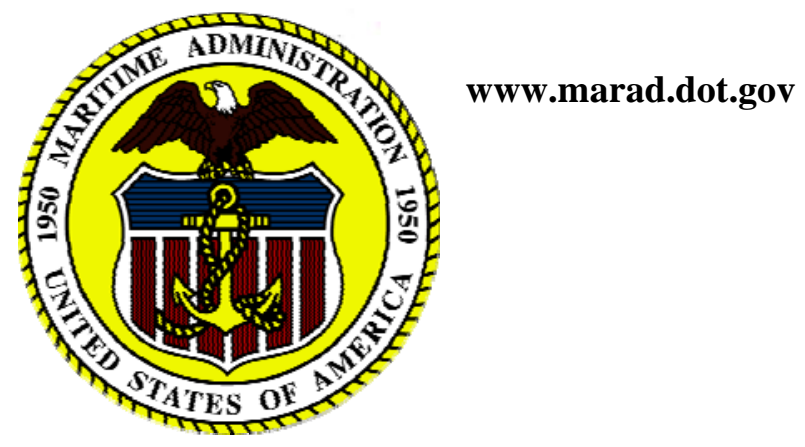

NATIONAL WATERWAYS and FOUNDATION

www.nationalwaterwaysfoundation.org 



\title{
A MODAL COMPARISON OF DOMESTIC FREIGHT TRANSPORTATION EFFECTS ON THE GENERAL PUBLIC
}

\author{
FINAL REPORT
}

\author{
Prepared for \\ U.S. Maritime Administration \\ and \\ National Waterways Foundation
}

by
C. James Kruse, Director, Center for Ports \& Waterways Annie Protopapas, Assistant Research Scientist Leslie E. Olson, Associate Research Scientist David H. Bierling, Assistant Research Scientist

Texas Transportation Institute The Texas A\&M University System

College Station, Texas

December 2007 



\section{DISCLAIMER}

This research was performed in cooperation with the U.S. Maritime Administration (MARAD) and the National Waterways Foundation (NWF). The contents of this report reflect the views of the authors, who are responsible for the facts and the accuracy of the data presented herein. The contents do not necessarily reflect the official view or policies of MARAD or NWF. This report does not constitute a standard, specification, or regulation. 


\section{ACKNOWLEDGMENTS}

This project was conducted in cooperation with MARAD and the National Waterways Foundation.

The authors wish to acknowledge the involvement and direction of Richard Walker of MARAD and Matt Woodruff, representing the National Waterways Foundation.

The authors also wish to acknowledge the involvement and direction of the Advisory Panel established for this project:

Dr. Denver D. Tolliver, Upper Great Plains Transportation Institute, North Dakota State University.

Dr. Arun Chatterjee, Civil \& Environmental Engineering, University of Tennessee, Knoxville.

Dr. Michael Bronzini, Civil, Environmental \& Infrastructure Engineering, George Mason University 


\section{TABLE OF CONTENTS}

Page

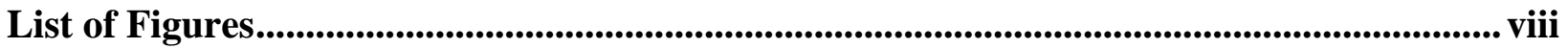

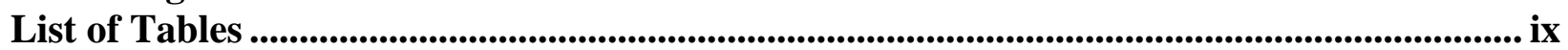

Chapter 1: Background and Significance............................................................................. 1

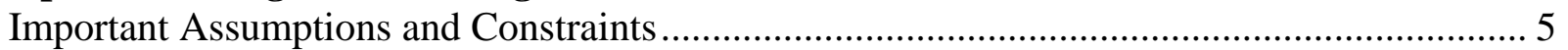

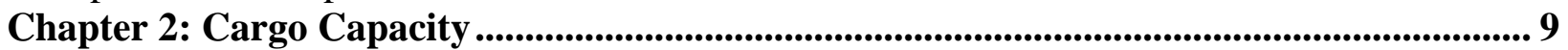

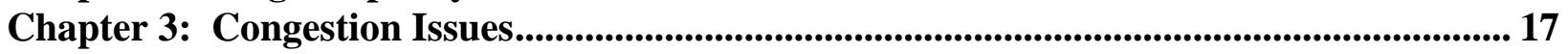

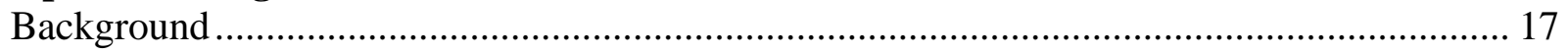

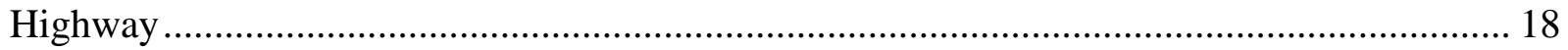

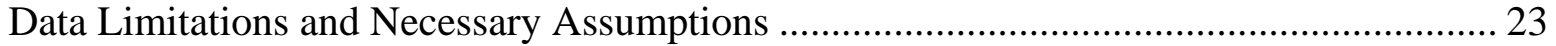

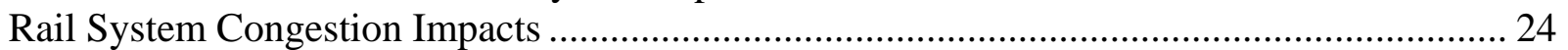

Chapter 4: Emissions Issues.............................................................................................. 29

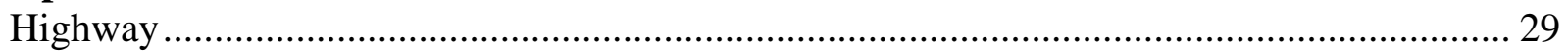

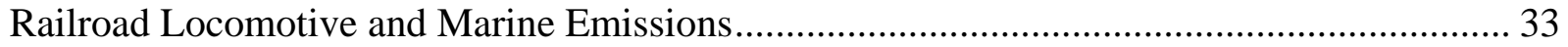

Conversion of Emission Factors to Grams per Gallon ................................................ 33

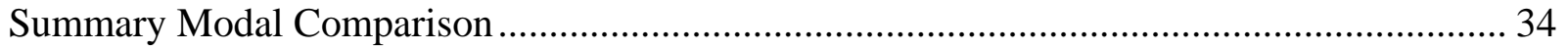

Chapter 5: Energy Efficiency ................................................................................................................. 35

Chapter 6: Safety Impacts......................................................................................................... 39

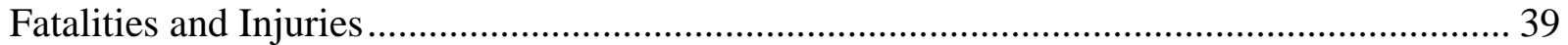

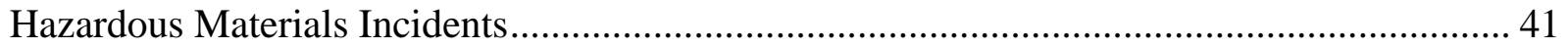

Chapter 7: Infrastructure Impacts......................................................................................... 45

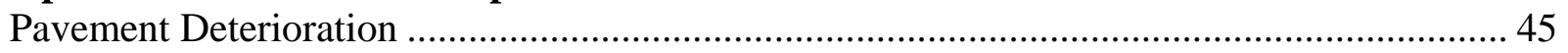

Further Highway Infrastructure Impacts........................................................ 48

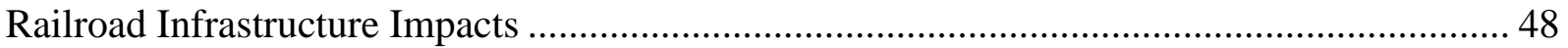

Chapter 8: A Case Study - St. Louis, MO ........................................................................ 53

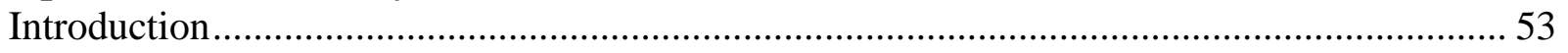

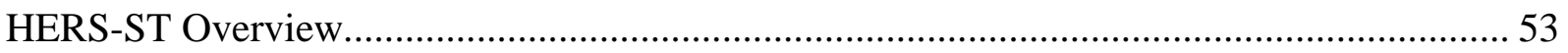

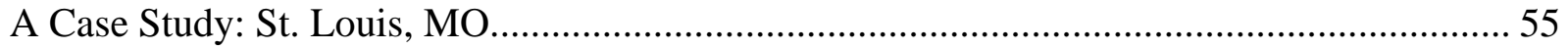




\section{LIST OF FIGURES}

Page

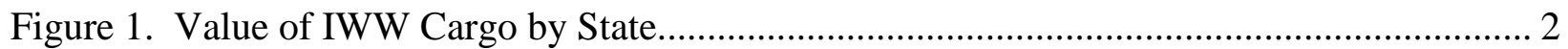

Figure 2. Composition of Internal Tonnage by Waterway................................................................ 3

Figure 3. 2005 Barge Traffic by Commodity Group (in millions of tons). ....................................... 4

Figure 4. Dry Cargo Capacity Comparison .......................................................................... 11

Figure 5. Liquid Cargo Capacity Comparison....................................................................... 12

Figure 6. Wheat Illustration........................................................................................... 13

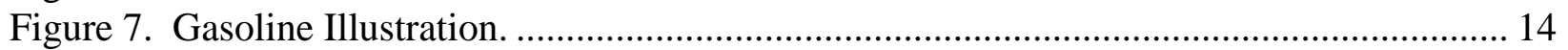

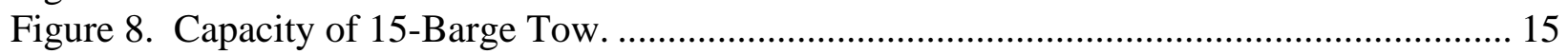

Figure 9. 2005 Barge Traffic by Commodity Group (in millions of tons)................................ 17

Figure 10. Average Daily Vehicles per Lane of Rural Interstate vs. Intercity Truck Ton-miles. 20

Figure 11. Estimated Average Annual Daily Truck Traffic (1998)............................................. 22

Figure 12. Major Highway Interchange Bottlenecks for Trucks. ................................................ 23

Figure 13. Predicted CSX train velocity with addition of Ohio River coal tonnage. ………......... 27

Figure 14. Nonattainment/Maintenance Counties in Study Area................................................. 32

Figure 15. Comparison of Fuel Efficiency......................................................................... 38

Figure 16. Ratio of Fatalities per Bill Ton-Miles Versus Inland Marine....................................... 40

Figure 17. Ratio of Injuries per Bill Ton-Miles Versus Inland Marine......................................... 41

Figure 18. Ratio of Large Spills per Mill Ton-Miles Versus Inland Marine................................. 43

Figure 19. Semitrailer configuration 3-S2: the 18-wheeler. .......................................................... 45

Figure 20. CSX map section for Indiana and Illinois along the Ohio River illustrating the CSX railroad tracks and coal powered electric generating plants....................................... 49

Figure 21. St. Louis Nonattainment/Maintenance Area. .............................................................. 57

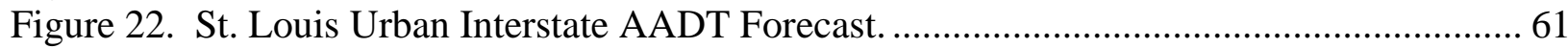




\section{LIST OF TABLES}

Page

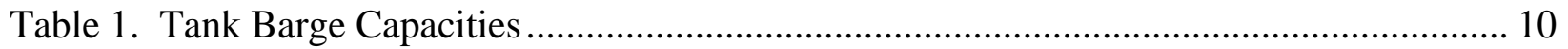

Table 2. Standard Modal Freight Unit Capacities. .............................................................. 10

Table 3. Modal Cargo Capacity Comparison. ...................................................................... 14

Table 4. Waterway and Truck Equivalents - 2005 Tonnage and Ton-miles............................. 18

Table 5. Intercity Truck Ton-Miles vs. Rural Interstate Vehicle Traffic................................... 19

Table 6. CSX Railroad Performance Measures. ................................................................. 26

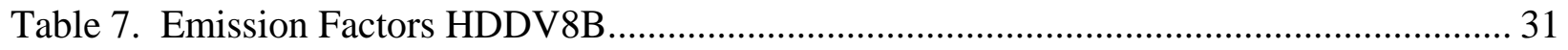

Table 8. Conversion Factors for Emissions in g/gal of Fuel Use. ......................................... 34

Table 9. Summary of Emissions - Grams per Ton-Mile........................................................ 34

Table 10. Calculated Railroad Fuel Efficiency............................................................... 36

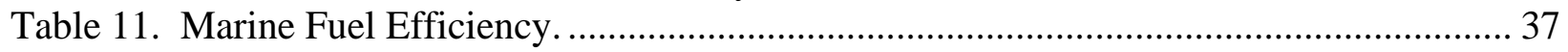

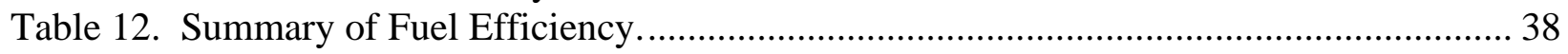

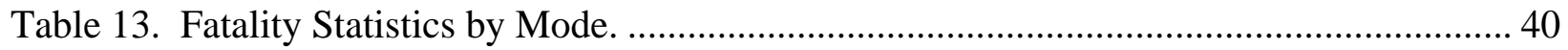

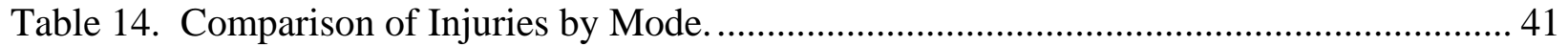

Table 15. Comparison of Large Spills Across Modes. ......................................................... 42

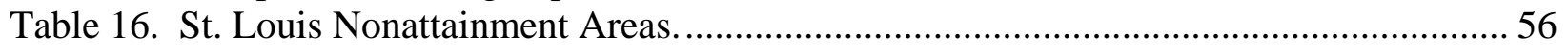

Table 17. St. Louis Lock Tonnage and Truck Traffic Equivalent.......................................... 58

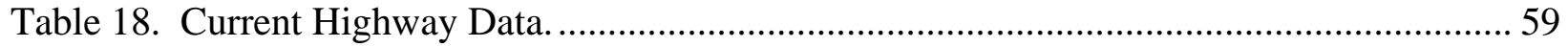

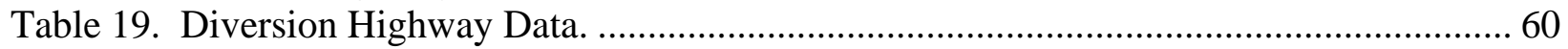

Table 20. HERS Results: Current and Diversion System Conditions - with Improvements....... 63

Table 21. HERS Results: Current and Diversion System Deficiencies - with Improvements.... 64

Table 22. HERS Results: Current and Diversion Improvement Statistics............................... 65

Table 23. HERS Results: Current and Diversion System Conditions - w/o Improvements........ 66

Table 24. HERS Results: Current and Diversion System Deficiencies - w/o Improvements. .... 67

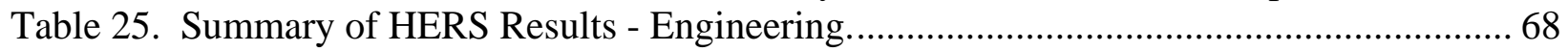

Table 26. Summary of Significant Impacts - General Public ................................................ 69 



\section{CHAPTER 1: BACKGROUND AND SIGNIFICANCE}

The Inland Waterway System (IWWS) is a key element in the nation's transportation system. The IWWS includes approximately 12,000 miles of navigable waterways and 240 lock sites that incorporate 275 lock chambers. It handles shipments to/from 38 states each year. The system is part of a larger system referred to as "America's Marine Highways" which encompasses both deep draft and shallow draft shipping.

In 2005, inland waterways maintained by the U.S. Army Corps of Engineers (Corps) handled over 624 million tons of freight (274 billion ton-miles) ${ }^{1}$ valued at over $\$ 70$ billion, $^{2}$ resulting in an average transportation cost savings of $\$ 11$ ton (as compared to other modes). ${ }^{3}$ This translates into more than $\$ 7$ billion annually in transportation savings to America's economy. In 2003, barges moved $14 \%$ of intercity freight ton-miles for $3 \%$ of the freight bill. ${ }^{4}$ Virtually all American consumers benefit from these lower transportation costs.

Thirty-one states are served by the Mississippi River System and the Gulf Intracoastal Waterway. States on the Gulf Coast and throughout the Midwest and Ohio Valley especially depend on the inland and intracoastal waterways. Texas and Louisiana each ship over \$10 billion worth of cargo annually, while Illinois, Pennsylvania, West Virginia, Kentucky, Mississippi, and Alabama, each ship between $\$ 2$ billion and $\$ 10$ billion annually. ${ }^{5}$ Over $60 \%$ of the nation's grain exports move by barge. ${ }^{6}$ The Inland Waterway System is the primary artery for more than half of the nation's grain and oilseed exports, for about $20 \%$ of the coal for utility plants, and for about $22 \%$ of domestic petroleum movements. ${ }^{7}$ Figure 1 shows the level to which the various states use the waterway system.

\footnotetext{
${ }^{1}$ The U.S. Waterway System — Transportation Facts, Navigation Data Center, U.S. Army Corps of Engineers, February 2007.

2 "Value to the Nation: Navigation", website maintained by U.S. Army Corps of Engineers, accessible at http://www.corpsresults.us/navigation/naveconomic.htm as of August 2007.

${ }^{3}$ Based on data produced by the Tennessee Valley Authority using 2001 statistics.

4 "Transportation in America”, $20^{\text {th }}$ Edition, ENO Foundation, 2007.

5 "Inland Waterway Navigation: Value to the Nation", brochure by U.S. Army Corps of Engineers, Institute for Water Resources, May 2000, accessible at http://www.iwr.usace.army.mil/docs/InlandNavigation.pdf as of September 2007.

6 “A Reliable Waterway System Is Important to Agriculture”, United States Department of Agriculture, Agricultural Marketing Service, August 2007, accessible at http://www.ams.usda.gov/tmd/TSB/WaterwaysFacts08-07.pdf as of September 2007.

7 “The Declining Reliability of the U.S. Inland Waterway System”, David V. Grier, U.S. Army Corps of Engineers, Institute for Water Resources, presented at 7th Marine Transportation System Research \& Technology Coordination Conference, November 16-17, 2004, accessible at http://trb.org/Conferences/MTS/4A\%20GrierPaper.pdf as of August 2007.
} 


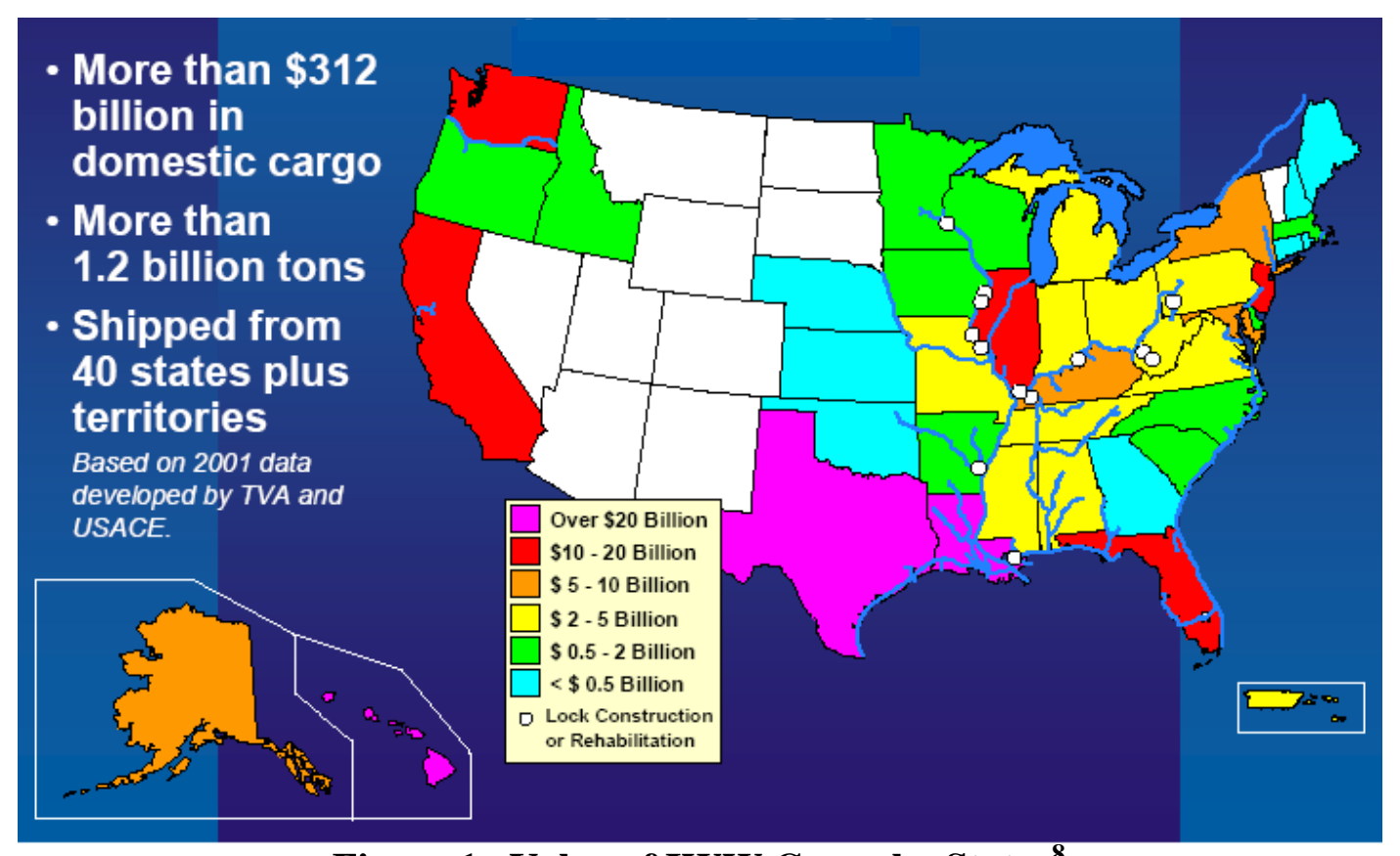

Figure 1. Value of IWW Cargo by State. ${ }^{8}$

Source: U.S. Army Corps of Engineers, Institute for Water Resources.

A wide variety of public, semi-public, and private entities is involved in the maintenance and operation of the waterway. The following list illustrates the types of enterprises that directly depend on the waterways:

- Ports

- Ocean-going ships

- Towboats and barges

- $\quad$ Ship-handling tugs

- Marine terminals

- $\quad$ Shipyards

- Offshore supply companies

- Brokers and agents

- Consultants, maritime attorneys

- Cruise services

- $\quad$ Suppliers and others

The federal agencies most directly involved with the inland waterways are the U.S. Department of Transportation, the Corps, and the U.S. Coast Guard.

The Inland Waterway System is one modal network within the entire pool of domestic transportation systems networks that include truck and rail modal networks. The entire surface transportation system is becoming increasingly congested. The ability to expand this system in a

\footnotetext{
${ }^{8}$ This figure was produced by David V. Grier, U.S. Army Corps of Engineers, Institute for Water Resources.
} 
timely fashion is constrained by both funding and environmental issues. Many proponents of the inland waterway system point out that it provides an effective and efficient means of expanding capacity with less funding, has virtually unlimited capacity, and impacts the environment much less than the other modes of transportation.

Initially, this study was designed to focus on certain segments of the IWWS. However, for certain types of analyses, it is not feasible to segregate components of the system, i.e., river segments, rail segments, etc. In these cases, the analysis is performed on a system-wide level and includes the entire system. When it is desirable or necessary to focus on only certain segments, this study focuses primarily on the Mississippi River Basin, Ohio River Basin, the Gulf Intracoastal Waterway, and the Columbia/Snake River System. These segments limit the number of data sets that must be analyzed, but include a high percentage of the total cargo traffic and represent a diversity of waterway segment types. The level of analysis is noted in the body of the report, as appropriate. Figure 2 illustrates the dominance of these waterways in terms of the national tonnage totals for internal domestic freight movements.

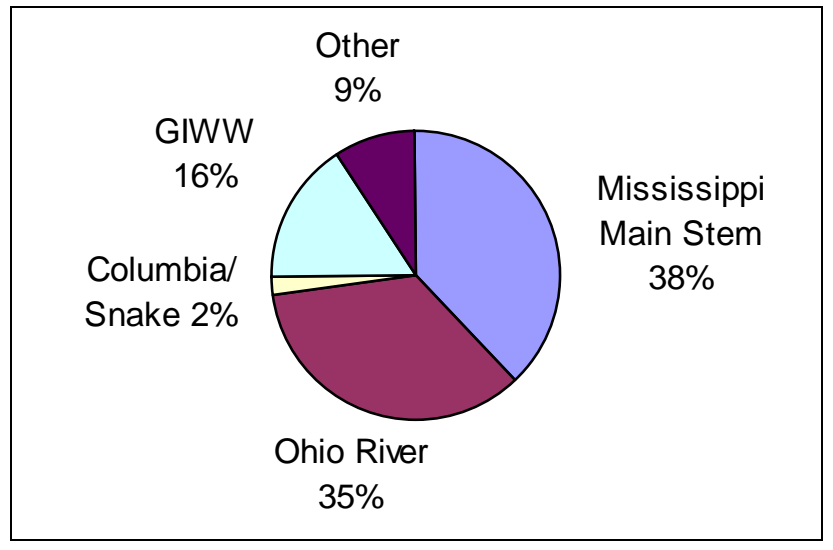

Figure 2. Composition of Internal Tonnage by Waterway.

Source: Waterborne Commerce of the United States, Calendar Year 2005, Part 5-National Summaries, U.S. Army Corps of Engineers

The Mississippi River System stretches from Minneapolis, Minnesota to New Orleans, Louisiana. The Illinois, Missouri, and Ohio River systems all empty into the Mississippi. Further south, the Arkansas and Ouachita Rivers also flow into the Mississippi. The Mississippi main stem runs for 1,800 miles; the entire system is 9,000 miles $^{9}$. Approximately 513 million tons of domestic and coastwise freight were shipped on this system in $2005 .^{10}$

The Ohio River System contains 2,800 miles of navigable waterways, flowing from Pittsburgh, Pennsylvania to Cairo, Illinois. This system--which encompasses seven other rivers that flow through nine states--is part of the larger Mississippi River system. Approximately 2/3 of the traffic on the Ohio River System originates and terminates on the system.

\footnotetext{
${ }^{9}$ U.S. Army Corps of Engineers, Institute for Water Resources. An Overview of the U.S. Inland Waterway System. IWR Report 05-NETS-R-12, November 1, 2005.

${ }^{10}$ Source: Waterborne Commerce of the United States, Calendar Year 2005, Part 5-National Summaries, accessible at http://www.iwr.usace.army.mil/ndc/wcsc/pdf/wcusnatl05.pdf as of August 2007.
} 
The Gulf Intracoastal Waterway (GIWW) consists of 1,109 miles of navigable waterway along the Gulf Coast. The GIWW is part of a larger waterway system (1,992 miles) that includes various small rivers, bayous, and channels. In 2005, approximately 116 million tons of freight was shipped on the GIWW ${ }^{11}$.

The Columbia/Snake River System includes 596 navigable miles of waterway. It is not connected to any other waterway system; instead it flows directly into the Pacific Ocean. Approximately 18 million tons of freight moved on this system in 2005.

Figure 3 shows the composition of 2005 domestic freight tonnage by principal commodity groups. This figure illustrates that a very high percentage of domestic freight traffic is composed of bulk commodities - commodities that are low in value per ton and very sensitive to freight rates.

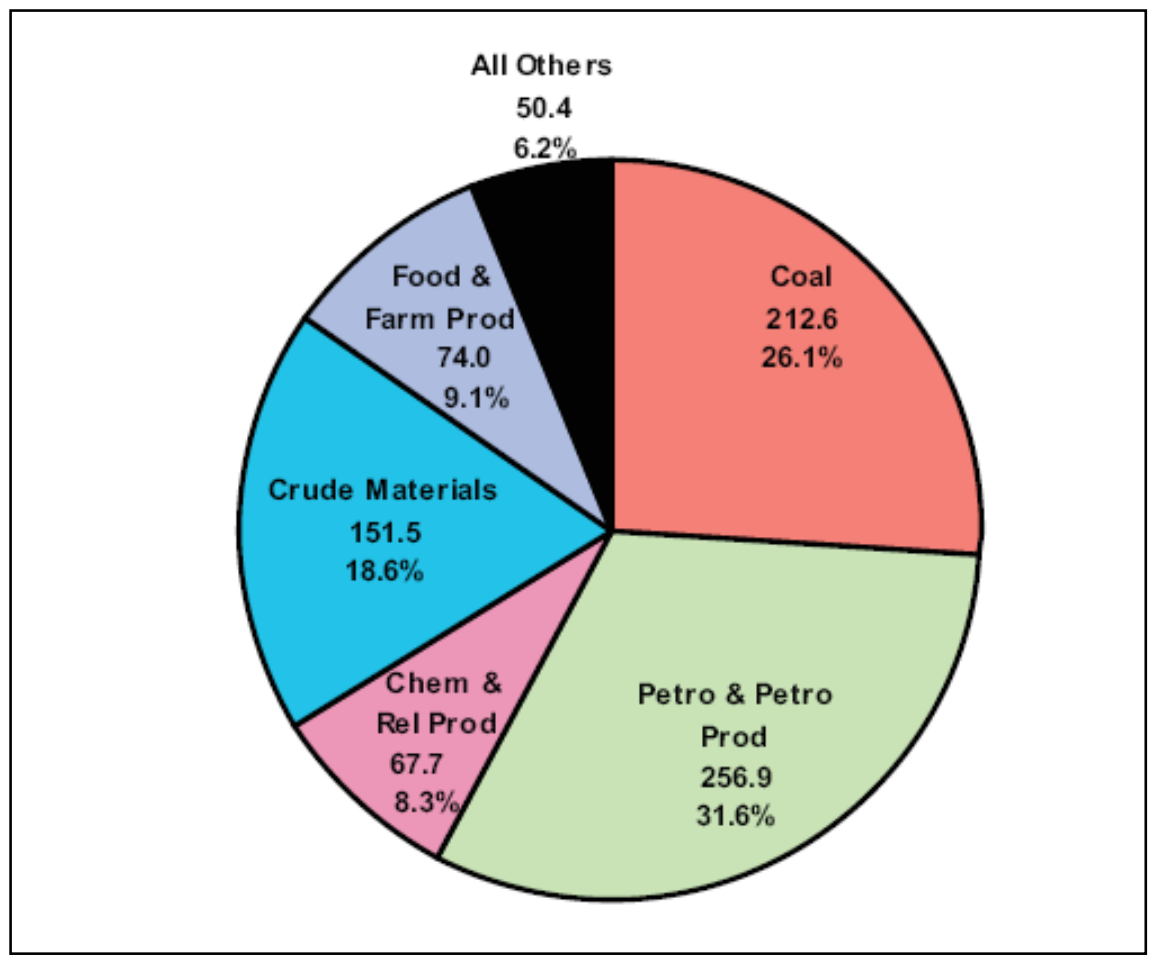

Figure 3. 2005 Barge Traffic by Commodity Group (in millions of tons). Source: Waterborne Commerce of the United States, Calendar Year 2005, Part 5-National Summaries, U.S. Army Corps of Engineers

The economics of barge transportation are easily understood and well documented. This report updates and quantifies the environmental, selected societal, and safety impacts of utilizing barge transportation and compares these impacts to highway and rail transportation.

\footnotetext{
${ }^{11}$ Source: Waterborne Commerce of the United States, Calendar Year 2005, Part 5-National Summaries, accessible at http://www.iwr.usace.army.mil/ndc/wcsc/pdf/wcusnatl05.pdf as of August 2007.
} 
In 1994, the Maritime Administration released a document titled "Environmental Advantages of Inland Barge Transportation.” Using the best available data at the time, the document laid out the benefits of barge transportation compared to other modes with an emphasis on the following areas:

- $\quad$ Energy efficiency

- Safety

- Congestion

- Air/noise pollution

- Land use/social impacts

- Environmental aspects

Since that study, technology has advanced, operating conditions have changed, and new and updated data are available. This report examines many of the same aspects as the 1994 report, but using more current data, and—in some cases—new data sources.

Based on available data sources and existing research documents, these topical study areas were identified for this research:

- Cargo capacity

- Congestion

- Emissions

- Energy efficiency

- Safety impacts

- Infrastructure impacts

These topics are very similar to the topics covered in the 1994 MARAD report. They were selected because:

- $\quad$ They are issues associated with all modes, enabling their comparison across modes.

- Data availability allows the conduct of a scientifically sound and defensible analysis.

- The importance of these issues has been verified by industry contacts.

- $\quad$ They can be summarized and presented in ways the general public can understand.

\section{IMPORTANT ASSUMPTIONS AND CONSTRAINTS}

The hypothetical nature of this comparative study requires certain assumptions in order to enable valid comparisons across the modes.

The analysis is predicated on the assumption that cargo will be diverted to rail or highway (truck) modes in the event of a major waterway closure. The location of the closure and the alternative rail and highway routes available for bypass will determine any predominance in modal share. The geographical extent of the waterway system network does not allow for any realistic predictions to be made in regards to a closure location, the alternate modal routes available for bypass, or the modal split. As a result, this analysis adopts the all-or-nothing modal assignment principle. The analysis considered the possible impacts resulting from either a theoretical diversion of $100 \%$ of the current waterborne cargo to the highway mode OR a theoretical diversion of $100 \%$ of the current waterborne cargo to the rail mode. 
This report presents a snapshot in time in order to focus on several vital issues. Analysis of the broad spectrum of economic consequences that could potentially result from any deviation from existing conditions is beyond the scope of this study. The data utilized in this research are publicly available and can be independently verified and utilized to support various analyses.

This analysis uses values of ton-miles of freight as the "common denominator" to enable a crossmodal comparison that takes into account both the shipment weight as well as the shipping distance. However, water and rail ton-mile data are available through 2005, whereas truck tonmiles are only available through 2004; therefore, data for 2001-2004 are used to provide a common time frame for comparison of ton-miles. Four sources were used for ton-mile data: National Transportation Statistics - 2006, Table 1-46a: U.S. Ton-Miles of Freight (Millions); National Transportation Statistics - 2006, Table 1-46b, Special Tabulation (highway data); Association of American Railroads Website (2005 ton-miles); Waterborne Commerce Statistics 2005.

Most of the issues related to a theoretical waterborne freight diversion are examined on a national or system-wide level. The level of detail of the available data does not permit any disaggregation, for example, to the state level. In addition, a microscopic examination of individual pairs of origins and destinations of waterborne trips is beyond the objectives of this research project. The system-wide level of analysis cannot support reasonable traffic assignment on specific highway links. It only permits a reasonable allocation of the truck traffic that would replace waterborne freight transportation to the highest class of long haul roadway, the rural segments of the interstate system.

Detailed data for train fuel consumption or composition are generally proprietary, hence not publicly available. Therefore, the research team developed methodologies for cross-referencing available train data with compiled statistics in order to support the comparative analysis among modes.

Barge transportation is characterized by the longest haul operations, followed by rail, then by truck. This study is macroscopic in nature and focuses on the main stems of the major river systems. Considerable effort took place to investigate for possible differences in route lengths ("circuity") among the three modes, in particular between the water and highway modes. Obviously, the water and rail modes have to follow fixed routes. The highway mode is highly flexible due to the expanse of the network, but it is known that truckers have their preferred routes, and aim to minimize the total trip length, especially in longer hauls. Geographic Information Systems, using data from the National Transportation Atlas Database (NTAD) ${ }^{12}$, are used to map and compare the lengths of the major river main stems with the most logical route that would most likely be chosen by trucks transporting barge commodities from an origin at one extreme of a river to a destination at the other extreme. Educated assumptions are made in regard to which truck routes would likely be preferred, with assistance from the Federal

\footnotetext{
${ }^{12}$ U.S. Department of Transportation, Research and Innovative Technology Administration, Bureau of Transportation Statistics. National Transportation Atlas Databases 2007.
} 
Highway Administration's (FHWA) Estimated Average Annual Daily Truck Traffic ${ }^{13}$, shown in Chapter 3. Conventional wisdom prescribes circuity factors of 1.3:1 for water trip length and 1.1:1 for rail trip length, with respect to the highway trip length from the same origin to the same destination. These ratios, though, are based on microscopic evaluations of individual trips. The comparative analysis found that trip length differences are minimal between trips of length approximately equal to an entire river's length and the corresponding long haul highway route that would be followed. In some instances the highway trip length is actually longer due to the absence of highway routes closely parallel to the adjacent river, simply because the presence of the latter makes the presence of the former redundant. For example, approximately 1,700 river miles have to be traveled by a barge along the Mississippi from Minneapolis to New Orleans. The corresponding south bound truck trip would most likely take place along Interstate 94, then Interstate 90, then Interstate 39, and finally Interstate 55, a total distance of about 1,900 miles, which is nominally longer than the Mississippi river route. Also according to NTAD, the Gulf Intracoastal Waterway, from Apalachee Bay, Florida to the Louisiana-Texas border is 640 miles long. The stretch of Interstate 10 that runs parallel to this stretch of GIWW is more than 600 miles long, indicating that the two modal routes are very similar in length. The comparative analysis was also conducted for the remaining waterways under study and led to similar conclusions. Allowing for possible deviations from the assumed preferred highway route, the long haul routes on the river and respective highway would be very comparable in total length. Therefore, any attempt to compensate for possible differences in modal route circuity was deemed unnecessary for the purposes of this study.

Further, it is assumed that in the event of a waterborne freight diversion to either truck or rail, the short haul, usually by truck, from the site to any mode's trunk line would still be present, at the same levels and on classes of roads similar to the current ones used for waterway access. These roads would most likely be major, four lane arterials (for example, U.S. or state highway routes). A diversion of all waterway freight to either truck or rail would require a truck haul of similar length from the site to the respective mode's major artery. Existing short hauls associated with access to the waterways would be offset by similar ones, to either the highway or the rail main line. Therefore, any compensation for differences relating to any aspect of short haul movements is considered unnecessary.

A logical consequence of a hypothetical waterborne freight diversion to either highway or rail would be a change in the transloading or intermodal facilities required. For example, in the absence of waterways, port facilities would become obsolete. At the same time the need for transloading facilities between local truck and long haul truck, between local truck and rail, or between long haul and shorter haul rail would arise. However, investigation of the chain reaction effects of a hypothetical freight diversion in regards to forecasting facility requirements is beyond the scope of this research study.

\footnotetext{
${ }^{13}$ Source: Federal Highway Administration, Office of Freight Management and Operations, Freight Analysis Framework, accessible at http://ops.fhwa.dot.gov/freight/freight_analysis/nat_freight_stats/nat_stat.htm as of August 2007.
} 


\section{CHAPTER 2: CARGO CAPACITY}

The dimensions of the units used to transport freight vary widely within each of the three modes (rail, truck, and inland waterway). In order to facilitate a meaningful cross-modal comparison, "standard" dimensions of the units used by each mode were defined. In comparing the modes, the capacity of the unit of transport was analyzed, not the average load. In this manner, all three modes were evaluated on the same scale.

The typical bulk commodity truck's body type, axle configuration, fuel, gross, tare, and cargo weight used in this report were confirmed by the Texas Motor Transportation Association ${ }^{14}$. This truck is a Heavy Duty Diesel Vehicle with a Gross Vehicle Weight Rating (GVWR) of $80,000 \mathrm{lbs}$ which includes $50,000 \mathrm{lbs}$ of cargo weight. The typical axle configuration is that of a typical tractor-trailer truck, i.e. an 18-wheeler, with a steering axle and two tandem axles, or five total axles.

This cargo weight is assumed to be roughly equal for liquid or dry bulk cargo. The densities of representative bulk commodities were investigated to ensure that the volume of a 50,000 lb net cargo weight is commensurate with the maximum tank truck volume of about 8,500 gallons. For example, 50,000 lbs of gasoline, at a density of $6.2 \mathrm{lbs} / \mathrm{gal}$, would occupy a volume of 8,065 gallons. The process was repeated for a number of representative bulk commodities commonly transported by barge. The results confirmed that trucks carrying these heavy liquid or dry bulk commodities weigh out before cubing out. Therefore, this study assumes that the trucks that would transport this cargo in case of a waterway closure will be constrained by weight limits; thus, the maximum allowable cargo weight is assigned.

For the same reason, only railcars used for carrying bulk commodities are taken into consideration. Even among this type of railcars, there is significant variation in carload capacities depending on the specific commodity. According to the Association of American Railroads the average carload for coal, which is the dominant non-liquid commodity for both rail and inland barge traffic, was 112.5 tons in 2006. Industry statistics also show that general purpose tank cars carry up to 125 tons. The expert panel assembled as a part of this research effort reached the conclusion that with the wide range of capacities in the existing railcar fleet, these figures should be adjusted downward to 110 tons per car.

Barge data were acquired from the Corps of Engineers’ Navigation Data Center (NDC) Vessel Characteristics File for 2005. The most common dimensions of barges carrying dry bulk (either covered or open) are $200 \mathrm{ft}$ x $35 \mathrm{ft}$, followed by $195 \mathrm{ft}$ x $35 \mathrm{ft}$. These two types represent $49 \%$ and $43 \%$ of the dry bulk barge population in the database respectively. Industry contacts report that the trend in recent years has been to construct larger barges, so the $200 \mathrm{ft}$ barges are used as the "standard" barge in this report. The average cargo capacity for these barges is 1,757 short tons, rounded down to 1,750 tons for use in this study.

\footnotetext{
${ }^{14}$ Telephone consultation with TMTA staff. March 2007. http://www.tmta.com.
} 
Also according to the same database, $195 \mathrm{ft}$ x $35 \mathrm{ft}$ barges constitute 22\% of the total tank barge fleet while $300 \mathrm{ft} \times 54 \mathrm{ft}$ barges constitute $21 \%$ of the total barges carrying liquid bulk.

Capacities are reported in tons, which can be converted to barrels by using the weight of each commodity per barrel (lbs/bbl). Using a range of $6 \mathrm{lbs} / \mathrm{gal}$ to $7.3 \mathrm{lbs} /$ gal, barrel weights may range from $252 \mathrm{lbs} / \mathrm{bbl}$ to $307 \mathrm{lbs} / \mathrm{bbl}$ respectively. Table 1 shows approximate carrying capacities for tank barges:

Table 1. Tank Barge Capacities

\begin{tabular}{|c|c|c|c|}
\hline \multirow{2}{*}{ Dimensions (feet) } & \multirow{2}{*}{$\begin{array}{c}\text { Average Cargo Weight } \\
\text { (tons) }\end{array}$} & \multicolumn{2}{|c|}{ Number of Barrels } \\
\cline { 2 - 4 } & 1,487 & Minimum & Maximum \\
\hline $195 \times 35$ & 3,935 & 9,687 & 11,802 \\
\hline$\sim 300 \times 54$ & & 25,635 & 31,230 \\
\hline
\end{tabular}

Discussions with a leading tank barge operator revealed that new tank barge construction is primarily of the $\sim 300 \mathrm{ft} x 54 \mathrm{ft}$ barge. This type of barge can hold an average of 28,433 barrels. An examination of barges operated by Kirby Inland Marine indicated that this may be slightly too high; therefore, this study uses a more conservative 27,500 barrels as the capacity of a typical tank barge.

The "standard" capacities for the various freight units across all three modes that are used in this analysis are summarized in Table 2.

Table 2. Standard Modal Freight Unit Capacities.

\begin{tabular}{|c|c|}
\hline Modal Freight Unit & Standard Cargo Capacity \\
\hline Highway - Truck Trailer & 25 tons \\
\hline Rail - Bulk Car & 110 tons \\
\hline Barge - Dry Bulk & 1,750 tons \\
\hline Barge - Liquid Bulk & $27,500 \mathrm{bbl}$ \\
\hline
\end{tabular}


Barges obviously have a higher cargo carrying capacity per unit than do trucks or railcars. Figure 4 illustrates the carrying capacity of a dry cargo barge in comparison with the rail and truck modes.

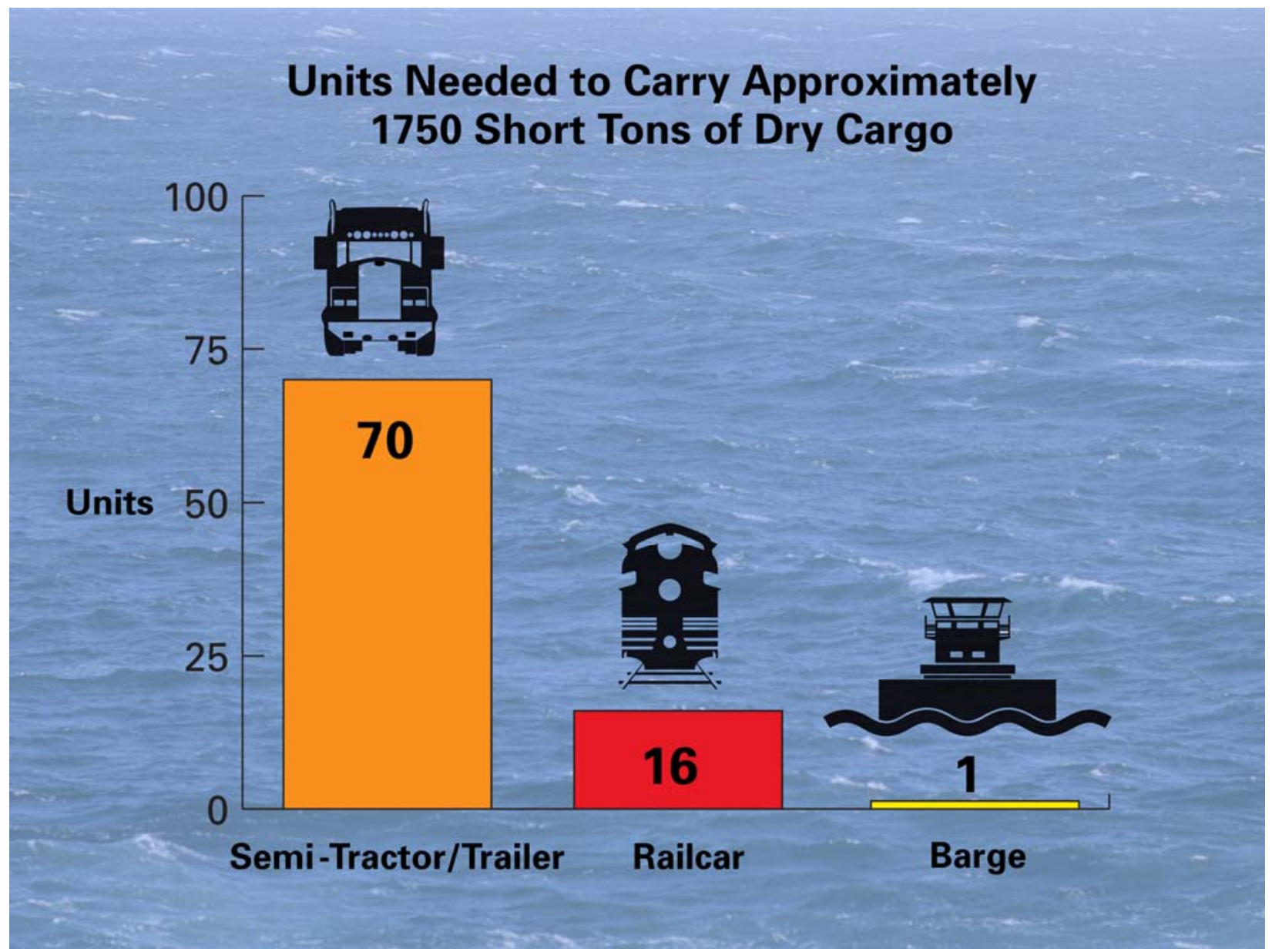

Figure 4. Dry Cargo Capacity Comparison. 
Figure 5 illustrates the carrying capacity of a liquid cargo barge in comparison with the rail and truck modes.

\section{Units Needed to Carry Approximately 27,500 BBL of Liquid Cargo}

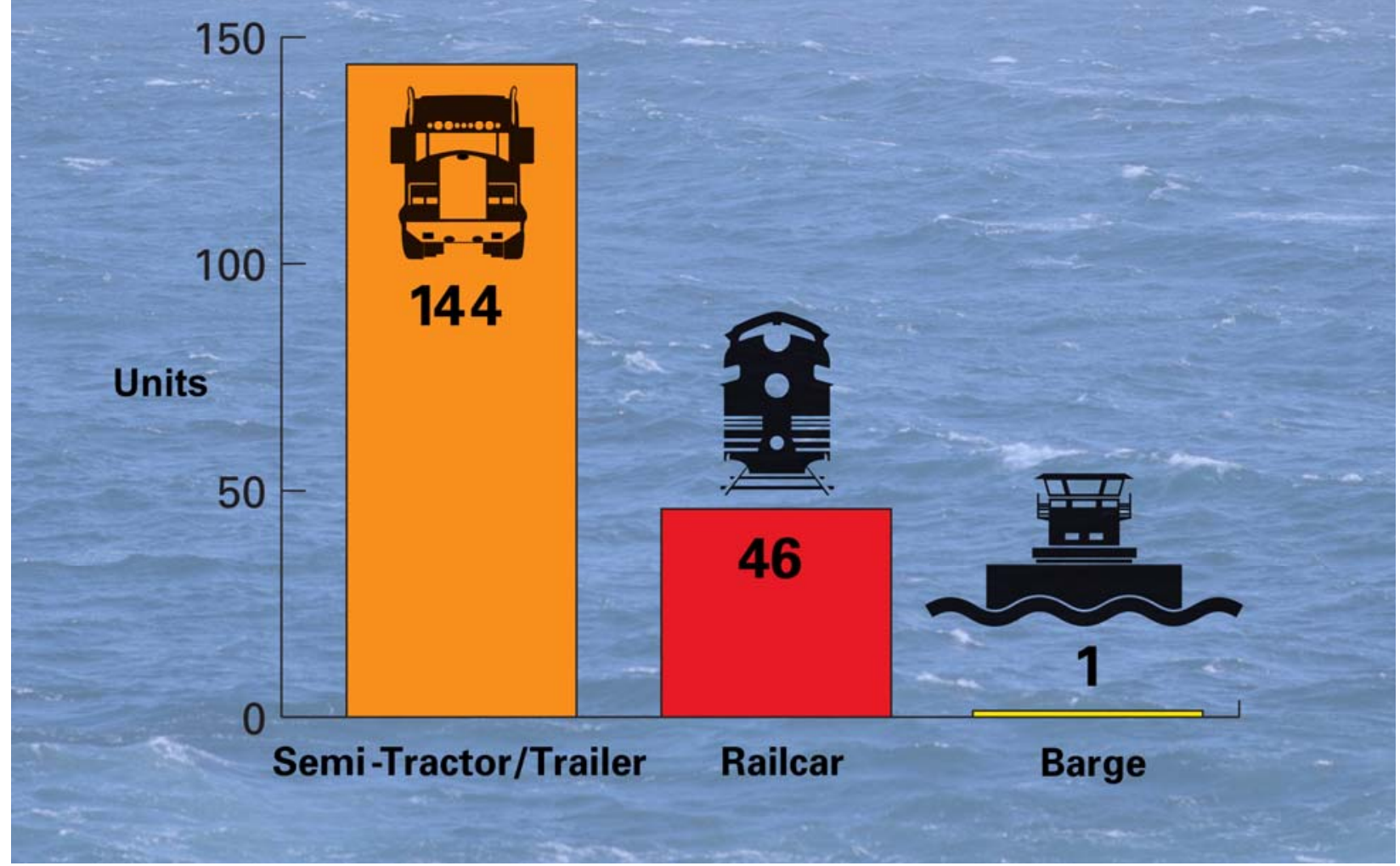

Figure 5. Liquid Cargo Capacity Comparison. 
It is difficult to appreciate the carrying capacity of a barge until one understands how much demand a single barge can meet. For example, a loaded covered hopper barge carrying wheat carries enough product to make almost 2.5 million loaves of bread, or the equivalent of one loaf for almost every person in the state of Kansas. (See Figure 6.)

\section{Dry Cargo Capacity}

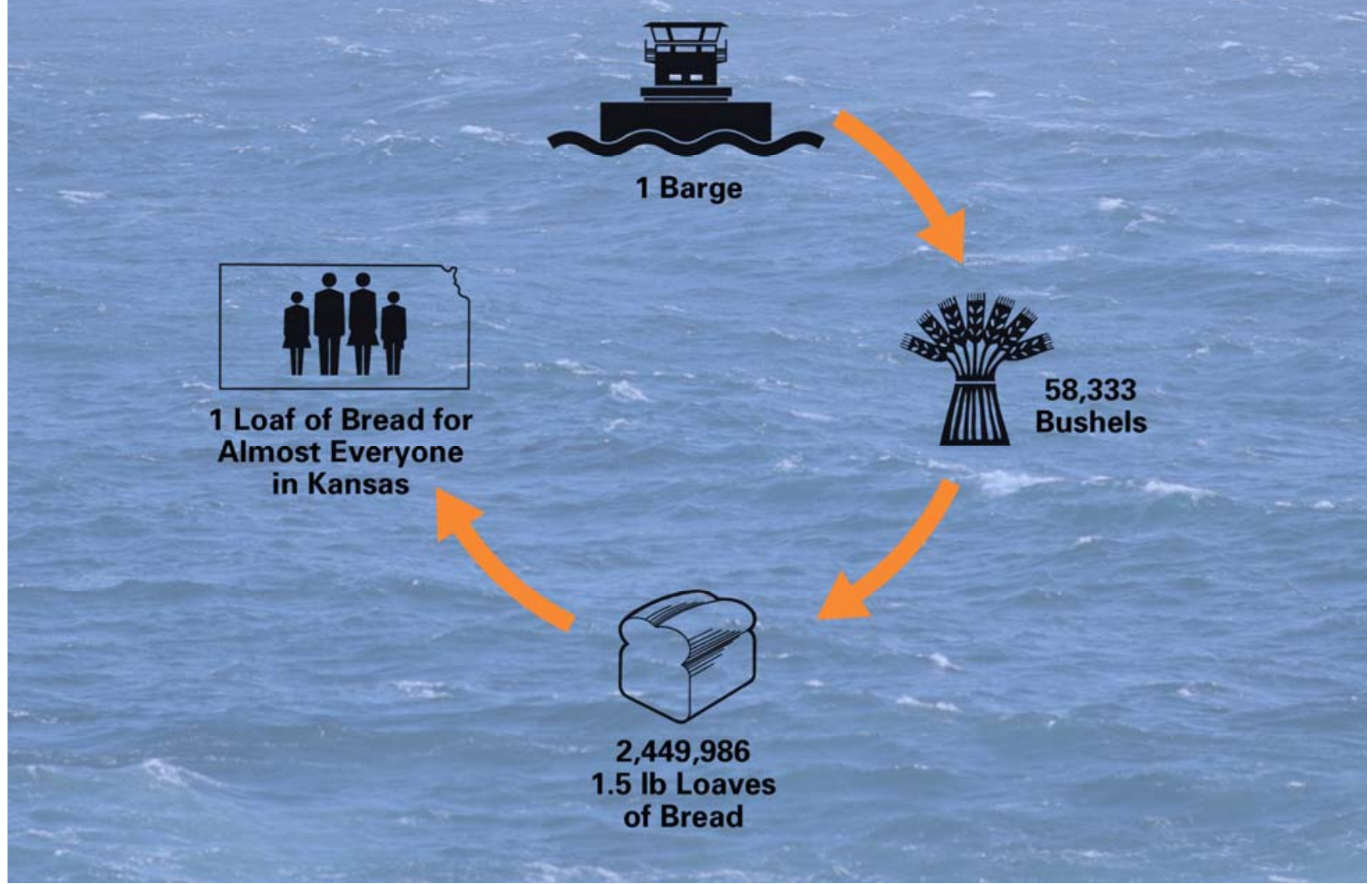

Figure 6. Wheat Illustration. 
A loaded tank barge carrying gasoline carries enough product to satisfy the current annual gasoline demand of approximately 2,500 people. (See Figure 7.)

\section{Liquid Cargo Capacity}

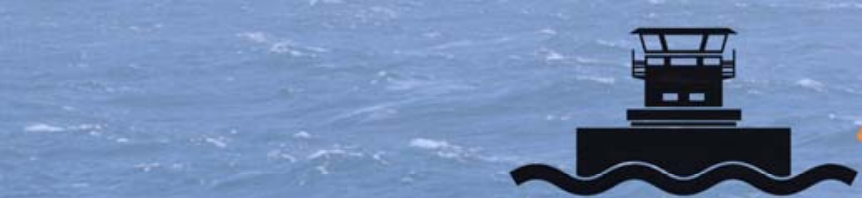

1 Barge
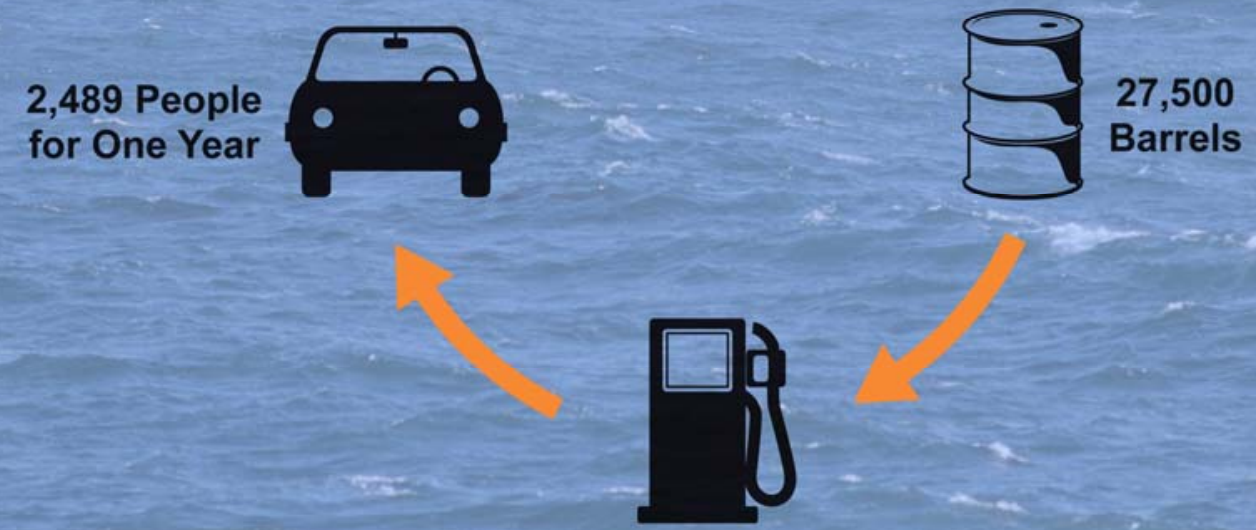

$1,155,00$ Gallons

Figure 7. Gasoline Illustration.

Table 3 presents a tabulated comparison of the dimensions and capacities of the modal freight units to better understand the differences in the order of magnitude among the three modes:

Table 3. Modal Cargo Capacity Comparison.

\begin{tabular}{|c|c|c|c|}
\hline Modal Freight Unit & Freight Unit Configuration & Length (feet) & Cargo Capacity (tons) \\
\hline Tow (Dry Cargo) & 15-barge tow (5x3) & 1,072 & 26,250 \\
\hline Unit Train & 108 cars, 3 locomotives & 6,054 & 11,880 \\
\hline Truck & One tractor with a 53 ft trailer & 70 & 25 \\
\hline
\end{tabular}


It is common to see tows of 15 barges or more on the major river systems. Figure 8 illustrates the carrying capacity of a 15-barge tow of dry cargo.

\section{Cargo Capacity Comparison}

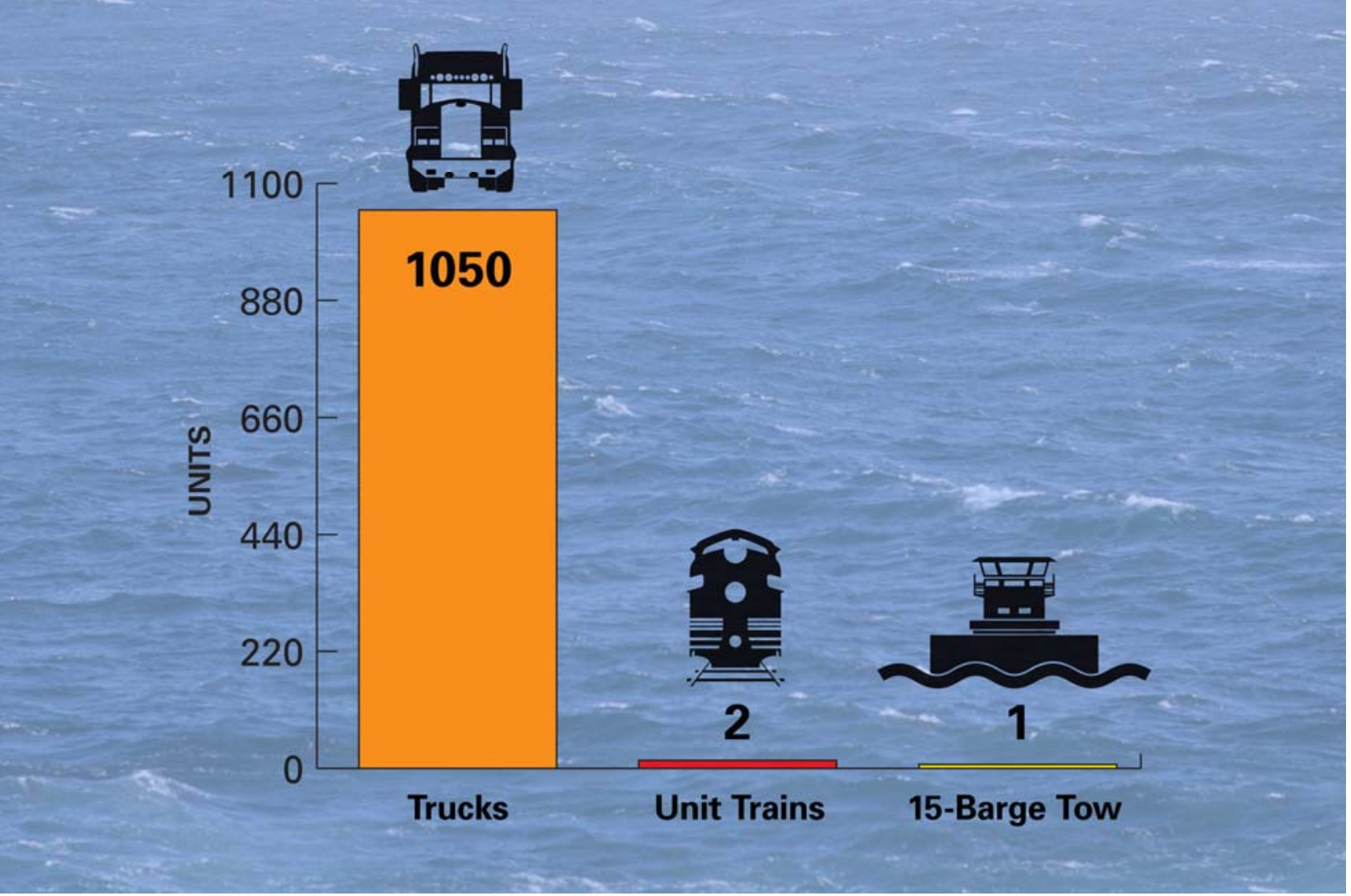

Figure 8. Capacity of 15-Barge Tow.

If the total domestic inland waterway tonnage (624 million tons) were loaded into the modal configurations indicated above at their maximum carrying capacity, and then the units were lined up end-to-end, the line of barges would extend more than 4,800 miles, the line of trains would extend 60,000 miles (2.4 times around the equator), and the line of trucks would extend 331,000 miles (13.3 times around the equator). 



\section{CHAPTER 3: CONGESTION ISSUES}

\section{BACKGROUND}

In the event of a major waterway closure, cargo will have to be diverted to either the rail or highway (truck) mode. The location of the closure and the alternative rail and highway routes available for bypass will determine any predominance in modal share. The geographical extent of the waterway system network does not allow for any realistic predictions to be made in regards to a closure location, the alternate modal routes available for bypass, or the modal split. As a result, this analysis adopts the all-or-nothing modal assignment principle. The evaluation considered the possible impacts resulting from either a theoretical diversion of $100 \%$ of the current waterborne cargo to the highway mode OR a theoretical diversion of $100 \%$ of the current waterborne cargo to the rail mode.

As mentioned earlier, cargoes moved on the inland waterways are typically bulk commodities with low unit values. This characteristic has a strong influence on the types of railcars and trucks that would be chosen to transport freight diverted from the waterways. The distribution by commodity groups in 2005 as shown in Figure 3 is reproduced below.

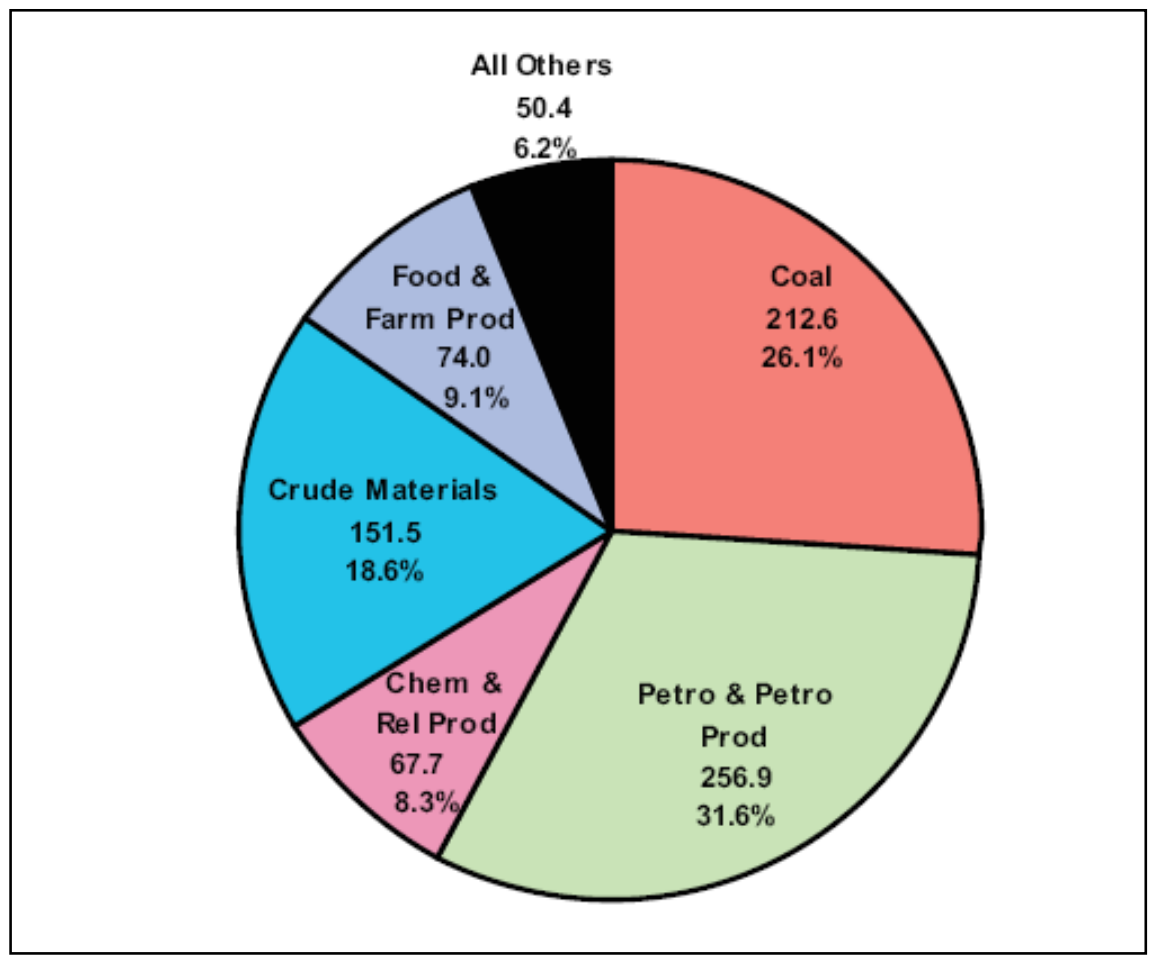

Figure 9. 2005 Barge Traffic by Commodity Group (in millions of tons). Source: Waterborne Commerce of the United States, Calendar Year 2005, Part 5-National Summaries, U.S. Army Corps of Engineers 


\section{HIGHWAY}

The latest national waterborne commerce ${ }^{15}$ data published by the U.S. Army Corps of Engineers Navigation Data Center were obtained for calendar year 2005. The tonnage and ton-mile data for the following major rivers were extracted:

- Mississippi River - Minneapolis to Mouth of Passes

- Ohio River

- Gulf Intracoastal Waterway (GIWW)

- Tennessee River

- Cumberland River

- Columbia River system - Columbia and Snake rivers

The tonnage and ton-mile data were then used to develop estimates of the equivalent truckloads, truck trips, and vehicle miles traveled that would be required if all waterway freight transported on these major rivers were to be transported by truck. All waterway data and estimated truck equivalent values are shown in Table 4. (The table assumes a cargo weight of 25 tons per truckload.) Vehicle miles traveled (vmt) is the typical unit of measure for highway travel and is simply the number of vehicles passing a point on the highway multiplied by the length of that segment of highway, measured in miles and usually on the order of one mile.

Table 4. Waterway and Truck Equivalents - 2005 Tonnage and Ton-miles.

\begin{tabular}{|c|r|r|r|r|r|r|r|}
\hline Waterway & $\begin{array}{c}\text { Tonnage } \\
\text { (x 000) }\end{array}$ & $\begin{array}{c}\text { Ton-miles } \\
\text { (x 000) }\end{array}$ & $\begin{array}{c}\text { Trip } \\
\text { Length } \\
\text { (miles) }\end{array}$ & $\begin{array}{c}\text { Annual } \\
\text { Truckloads }\end{array}$ & $\begin{array}{c}\text { Annual } \\
\text { Truck } \\
\text { Trips }\end{array}$ & $\begin{array}{c}\text { Annual } \\
\text { Loaded } \\
\text { Truck vmt }\end{array}$ & $\begin{array}{c}\text { Total Annual } \\
\text { Truck vmt }\end{array}$ \\
\hline Mississippi & 270,270 & $153,815,506$ & 569 & $10,810,800$ & $21,621,600$ & $6,152,620,240$ & $12,305,240,480$ \\
\hline Ohio & 249,213 & $59,895,324$ & 240 & $9,968,520$ & $19,937,040$ & $2,395,812,960$ & $4,791,625,920$ \\
\hline GIWW & 115,768 & $18,523,919$ & 160 & $4,630,720$ & $9,261,440$ & $740,956,760$ & $1,481,913,520$ \\
\hline Tennessee & 53,225 & $5,806,012$ & 109 & $2,129,000$ & $4,258,000$ & $232,240,480$ & $464,480,960$ \\
\hline Cumberland & 23,418 & $2,520,436$ & 108 & 936,720 & $1,873,440$ & $100,817,440$ & $201,634,880$ \\
\hline Columbia/Snake & 13,129 & 546,925 & 42 & 525,160 & $1,050,320$ & $21,877,000$ & $43,754,000$ \\
\hline Total & $\mathbf{7 2 5 , 0 2 3}$ & $\mathbf{2 4 1 , 1 0 8 , 1 2 2}$ & -- & $\mathbf{2 9 , 0 0 0 , 9 2 0}$ & $\mathbf{5 8 , 0 0 1 , 8 4 0}$ & $\mathbf{9 , 6 4 4 , 3 2 4 , 8 8 0}$ & $\mathbf{1 9 , 2 8 8 , 6 4 9 , 7 6 0}$ \\
\hline
\end{tabular}

Waterway tonnage and ton-mile data were taken from NDC. Average trip length in miles on each waterway was then calculated by division of ton-miles by miles. In reality, though, the number would denote both the average barge and truck trip length, since highway miles have been assumed to be on a 1:1 basis with river miles. Annual truckloads were calculated by dividing the tonnage for each waterway by 25 tons/truck. They were then doubled to account for an equal number of empty return trips. The truck vehicle miles traveled can be calculated in either of two ways that result in the same figure. Ton-miles can be divided by 25 tons/truck and the result doubled - to account for the empty backhaul - or the trip length can be multiplied by the annual truck trips, which has already incorporated the loaded as well as the empty return trips.

\footnotetext{
${ }^{15}$ U.S. Army Corps of Engineers. Navigation Data Center. Waterborne Commerce of the United States 2005.
} 
Trucks that carry bulk commodities are fairly limited in the backhauls they can attract. For example, a grain truck will not return with steel or any liquid product. Therefore, this theoretical diversion scenario assumes that all trucks would return empty - a 100\% empty backhaul. The exact percentage of empty backhaul for existing truck operations has rarely been precisely determined, but it is thought to be around 30-35\%. Currently, however, trucks primarily haul break bulk cargo which would make a non-empty return trip possible. On the other hand, tank trucks and certain commodity carriers tend to return empty. For example, a tank truck that had previously hauled nitrogen gas is unlikely to haul anhydrous ammonia on its return trip.

Therefore, for this study, the annual truck trips are estimated at two times the annual truckloads.

Historical data for roadway congestion trends (rural interstate traffic) and intercity truck tonmiles were obtained in order to enable estimation and prediction of the possible roadway congestion effects due to a hypothetical diversion of river ton-miles to truck ton-miles. The rationale behind examining this particular relationship is that waterway movements are long distance ones, and the equivalent long distance truck movements would occur primarily on interstate highways that pass through rural settings located between urban areas.

The data range used in this analysis is from 1996 through 2003. This is the only period for which all sources provide data. Annual national historic data for intercity freight truck ton-miles over this period were obtained from the Bureau of Transportation Statistics (BTS) ${ }^{16}$. National historic data for Weighted Average Daily Vehicles per lane on rural interstates were obtained from Highway Statistics $2005^{17}$ for respective years. The published vehicle traffic data include all vehicle types and are already weighted by the length of the segment over which the traffic was measured, as length varies among road segments. Table 5 tabulates the data extracted for this analysis.

Table 5. Intercity Truck Ton-Miles vs. Rural Interstate Vehicle Traffic.

\begin{tabular}{|c|c|c|}
\hline Year & $\begin{array}{c}\text { Intercity Truck } \\
\text { (Billion Ton-miles) }\end{array}$ & $\begin{array}{c}\text { Weighted Average Daily Vehicles per Lane } \\
\text { Rural Interstate }\end{array}$ \\
\hline 1996 & $1,071,000$ & 4,630 \\
\hline 1997 & $1,119,000$ & 4,788 \\
\hline 1998 & $1,149,000$ & 5,010 \\
\hline 1999 & $1,186,000$ & 5,147 \\
\hline 2000 & $1,203,000$ & 5,272 \\
\hline 2001 & $1,224,000$ & 5,381 \\
\hline 2002 & $1,255,000$ & 5,511 \\
\hline 2003 & $1,264,000$ & 5,465 \\
\hline
\end{tabular}

${ }^{16}$ Bureau of Transportation Statistics. National Transportation Statistics 2006. Appendix A, Truck Profile, Performance, Revised April 2006. December 2006.

${ }^{17}$ Federal Highway Administration. Highway Statistics 2005. Section V: Roadway Extent, Characteristics, and Performance. System Congestion Trends (Chart). 
Linear regression techniques were then applied to the historical data to develop an equation describing the relationship between these two variables. Figure 10 shows the line fitted, the equation developed, and the $\mathrm{R}^{2}$. (R-squared, the coefficient of determination, is the proportion of variability in a data set that is accounted for by a statistical model.). The $\mathrm{R}^{2}$ is very close to 1 , which indicates that the line is a very good fit to the data. In other words, there is a very strong relationship between values of Average Daily Vehicles per Lane on rural interstates and Intercity Truck Ton-miles, with the former historically dependent on the latter.

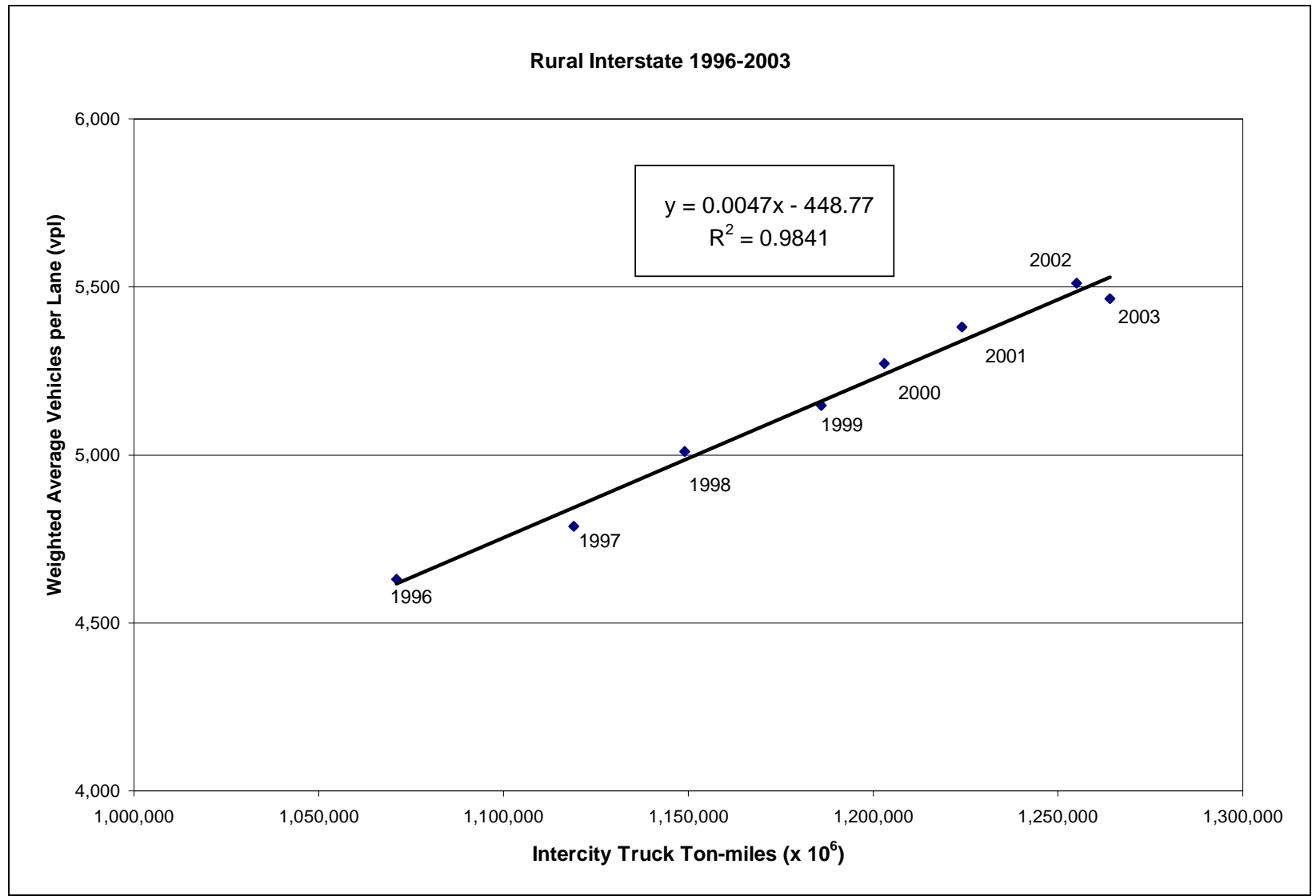

Figure 10. Average Daily Vehicles per Lane of Rural Interstate vs. Intercity Truck Tonmiles.

In 2003 there were 5,465 Average Daily Vehicles per Lane on Rural Interstates, as shown in Table 5 above. Highway Statistics ${ }^{18}$ reports that on rural interstates, in the same year, $84 \%$ of daily traffic (or 4,591 vehicles) was composed of passenger cars, buses, and light and heavy single unit trucks. The remaining $16 \%$ of the traffic (or 874 vehicles) were combination trucks, the types of trucks that would carry diverted waterborne freight.

The total ton-miles transported on the chosen waterways in 2005 were 241,108,122 thousand or 241,108.122 million. The total ton-miles transported by intercity trucks in 2003 (latest available data) were $1,264,000$ million. If the waterway ton-miles are diverted to trucks, the new total ton-miles attributed to intercity trucks adds up to $1,505,108.122$ million. When this number

\footnotetext{
${ }^{18}$ Federal Highway Administration. Highway Statistics 2005. Section V: Roadway Extent, Characteristics, and Performance. Percentage Distribution of Traffic Volumes and Loadings on the Interstate System, Table TC-3.
} 
is input to the developed regression equation, the Weighted Average Daily Vehicles per Lane on Rural Interstates increases to 6,625. Since the number of passenger cars, buses, light trucks, and heavy single unit trucks are constant at 4,591 vehicles per lane, the remaining 2,034 vehicles would be combination trucks. Thus, the percentage of daily

Diversion of waterborne freight to highways could more than double the number of heavy trucks on the average rural interstate. traffic that is combination trucks rises from $16 \%$ to $30.7 \%$. In other words, the hypothetical diversion of current waterway freight traffic would add 1,160 combination trucks (to the current 874) per day per lane on a typical rural interstate.

In summary, the amount of cargo currently transported by the Mississippi main stem, Ohio main stem, Gulf Intracoastal Waterway, Tennessee River, Cumberland River, \& Columbia River, is the equivalent of 58,000,000 truck trips annually that would have to travel on the nation's roadways in lieu of water transportation. This increase in truck trips would cause the Weighted Average Daily Combination Trucks per Lane on segments of interstate between urban areas to rise by $133 \%$ on a nationwide basis.

This increase was derived from national level data and reflects an average nationwide increase. The absolute number and percent combination trucks per lane of rural interstate located in the vicinity of the waterways under study would likely be higher than average. Truck traffic due to the diverted waterborne freight would undoubtedly be concentrated in the corridors that are parallel to the major rivers, especially the outer lane, which tends to be used by trucks more heavily. Thus, the impact in the vicinity of the waterways considered in this study would logically be more severe than the national average, especially during the heavier truck travel periods of the year, month, week, or day.

Figure 11 shows truck traffic levels on the nation's major highways, while Figure 12 shows the locations of the major bottlenecks.

Major waterways help avoid the addition of 58 million truck trips to our highway system annually. 


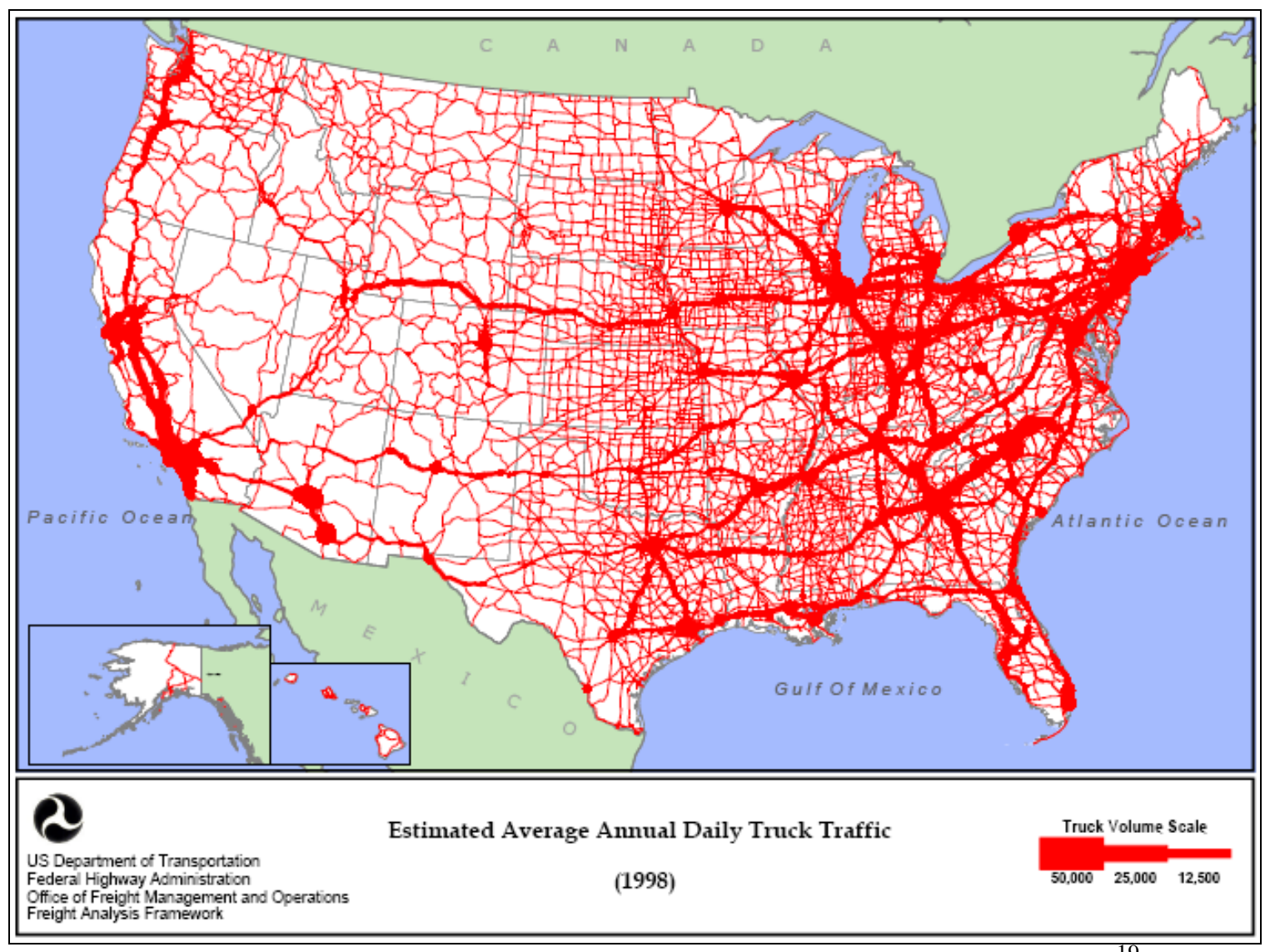

Figure 11. Estimated Average Annual Daily Truck Traffic (1998).

Source: Federal Highway Administration, Office of Freight Management and Operations, Freight Analysis Framework

${ }^{19}$ Source: Federal Highway Administration, Office of Freight Management and Operations, Freight Analysis Framework, accessible at http://ops.fhwa.dot.gov/freight/freight_analysis/nat_freight_stats/nat_stat.htm as of August 2007. 


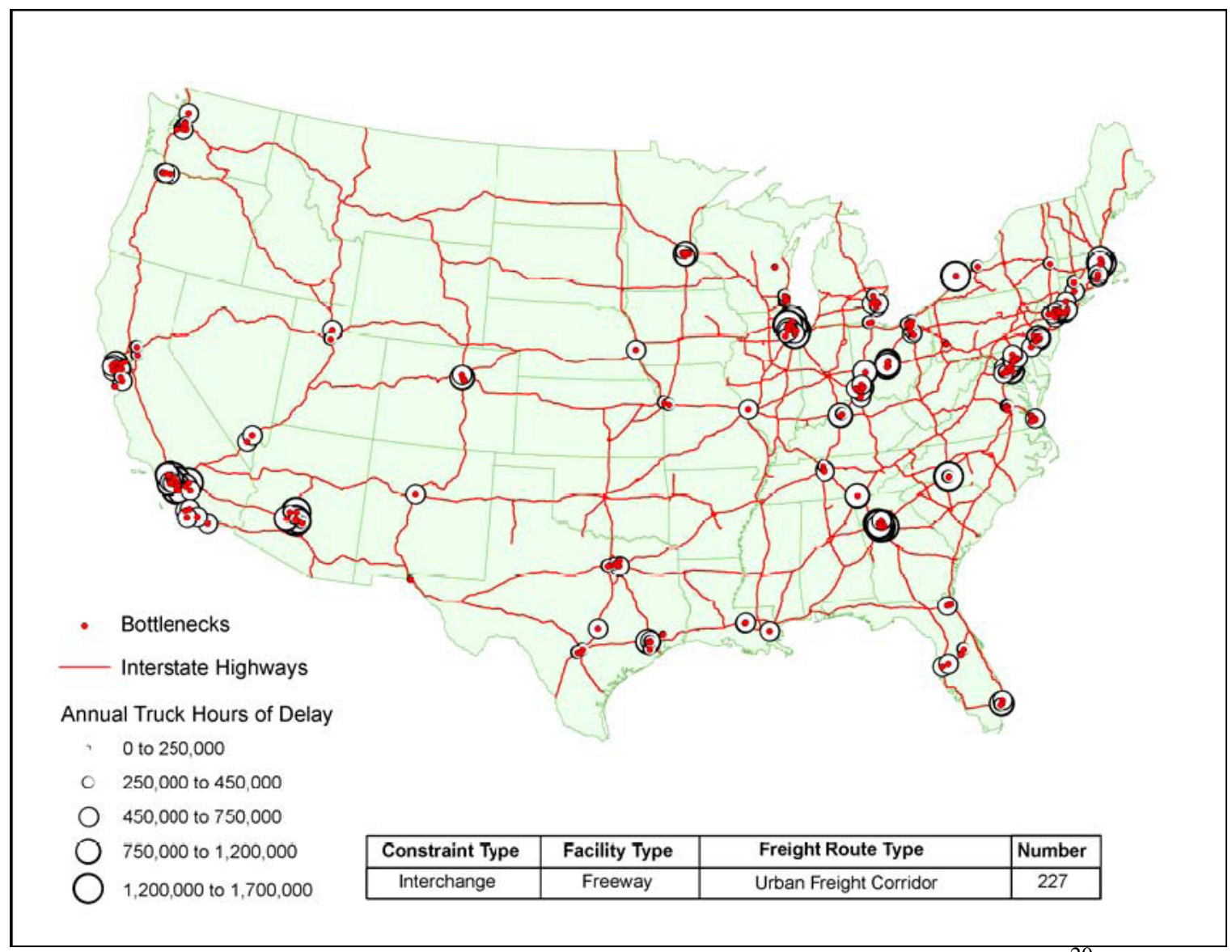

Figure 12. Major Highway Interchange Bottlenecks for Trucks. ${ }^{20}$

Source: An Initial Assessment of Freight Bottlenecks on Highways. Federal Highway Administration, Office of Transportation Policy Studies.

\section{Data Limitations and Necessary Assumptions}

The hypothetical and non-traditional nature of this study requires the adoption of several important assumptions in order to permit usage of existing data that could support a sound analysis.

First, the expanse of the roadway network in relation to the waterway or rail networks could not rationalize link assignment of the new truck traffic to a road class other than the interstate system. In addition, regional or corridor data are not available and analysis at an inter- or multistate geographical level could not be supported. The use of national data is considered to be the only appropriate basis given the scope of this study.

Second, it is necessary to assume that traffic delay is uniform along interstate segments regardless of whether they are classified as urban or rural. The rationale is that these long-haul combination trucks are likely to avoid urban cores that would lead to additional trip delay and

\footnotetext{
${ }^{20}$ Cambridge Systematics Inc. and Battelle Memorial Institute. An Initial Assessment of Freight Bottlenecks on Highways. Federal Highway Administration, Office of Transportation Policy Studies. October 2005.
} 
travel on urban bypasses, which carry less passenger car traffic. The higher traffic volumes in urban areas and subsequent congestion are primarily attributed to a higher number and percentage of passenger cars in the traffic stream. The absolute number of trucks may be equal to the rural interstate segment downstream; however, their percentage of the traffic volume drops around urban areas due to the domination of passenger cars in the traffic stream.

Third, it is assumed that the shorter hauls to/from interstate truck routes are of similar length and other characteristics to the existing shorter hauls to/from river segments and take place on the same road classes, which are primarily major arterials other than the interstate system.

Therefore, compensation due to this issue is considered unnecessary.

Finally, it is assumed that sufficient tractors, trailers, drivers, and other equipment will be available to move diverted cargo by truck. Trade journals such as the Journal of Commerce are reporting that there may be a serious shortage of truck drivers and of equipment for both truck and rail movements in the near term. Realistically, demand levels would most likely soar and, when chain reaction effects are factored in, a serious disruption to the entire supply chain could occur. However, an analysis of this type and complexity is outside the scope of this study.

\section{RAIL SYSTEM CONGESTION IMPACTS}

The intent of this rail system congestion analysis is to provide an estimate of the impact that a closure of the inland river transportation system would have on the railroad industry and the potential impact to the transportation of commodities in particular.

According to the Energy Information Administration, “In 2001, railroads delivered 68.5\% of coal shipments to their final electric utility destinations, followed by water (13.1\%); conveyor belts, slurry pipeline, and tramways (9.3\%); and truck (9.2 \%)."21 The market growth in coal transportation for the railroad industry has grown rapidly in recent years. In 2006 railroads transported a record 852 million tons of coal, which is 6\% greater than the previous record established in 2005. Because the demand for electricity has also continued to grow in recent years, this analysis assumes that the market share for each transportation sector has remained relatively stable since the 2001 study.

Data on unit and grain train velocities as well as available cars on-line were extracted from the published operating statistics for the current 53-week period on the Association of American Railroads (AAR) website ${ }^{22}$. The history data for cars on-line and train velocities were obtained from both U.S. Securities and Exchange Commission (SEC) Annual 10-K Forms and Surface Transportation Board (STB) R-1 Report filings. Railroad train velocity by commodity for the Class I railroads is available on a 53-week history from the AAR. The system velocity for all trains is reported by individual railroads in their annual reports on an inconsistent basis. In order to establish a general train speed for commodity trains east of the Mississippi River and another

\footnotetext{
${ }^{21}$ Source: Energy Information Administration, http://www.careenergy.com/technology/transportation.asp, August 2007

${ }^{22}$ Source: AAR website, individual railroads performance measure, 53 week tab, 07/07/06-07/06/07, http://www.railroadpm.org/ as of August 2007
} 
for those west of the river, the current 53-week (2007) individual railroad performance measures are used.

The railroads were divided into entities operating principally east (Eastern) or west (Western) of the Mississippi river for the principal fact that their unit and grain train markets are located east or west of the river. Railroads operating east of the Mississippi typically have a shorter unit train trip length and slower train velocities than the Western roads. Both the Eastern and Western railroads have operations on both sides of the river, and it is not the intent of this research to imply any limited operating area for the railroads because of the location of the Mississippi river.

For Eastern Class I railroads (Canadian National Railway--CN, CSX Transportation Inc.--CSX, and Norfolk Southern Corp.--NS), the weighted average coal train velocity is currently 17.04 miles per hour. The weighting factor is based on the individual railroad's share of reported gondola cars on-line in the current 53-week tracking data. The R-1 reported train velocities for the years 2003, 2004, and 2005 indicate a continuing decrease in unit train velocities as unit train business increases year by year. ${ }^{23}$

For the Western Class I railroads (Burlington Northern Santa Fe Railway--BNSF, Canadian Pacific Railway--CPR, Kansas City Southern Railway Company--KCS, and Union Pacific Railroad Company--UP) the weighted average coal train velocity is currently 19.78 miles per hour. The 2003, 2004, and 2005 R-1 reports for unit train velocities for the Western railroads also indicate a continuing decrease in unit train velocities as unit train business increases year by year.

The tonnage moved on the inland river system would amount to an addition of nearly $25 \%$ more tonnage on the railroad system. This new burden would not be evenly distributed. The primary burden would be placed on the Eastern U.S. railroads with little real opportunity to take advantage of excess capacity that may exist on the Western U.S. railroads.

The coal traffic on the Ohio River provides a clear example of what the effect of a major diversion of traffic would be.

Diverting river traffic would add $25 \%$ more tonnage to the national rail system. Referring to Figure 9 above, the total waterborne barge coal commodity tonnage in 2005 was 212.6 million tons, which was $26.1 \%$ of all barge tonnage. The Ohio River coal traffic was reported to be 133.1 million tons for the year 2005. The Ohio River coal traffic represents only $16.3 \%$ of the total inland waterway barge tonnage, but it is $62.6 \%$ of the barge coal tonnage for the year. The majority of the Ohio River coal traffic would have to be handled by the CSX railroad if the Ohio River transportation system ceased operations. The CSX lines essentially parallel the Ohio River while the NS Railway lines are principally perpendicular to the river.

If the 133.1 million tons of Ohio River coal traffic were to be shifted to the CSX rail lines, the railroad would be faced with an additional 1,010,250 car loadings of coal annually with 112 tons of coal in each car. If the trains were made up of 108 cars per train there would be an annual addition of 9,354 train movements or 25.6 added train movements per day on the lines

\footnotetext{
${ }^{23}$ STB website, http://www.stb.dot.gov/econdata.nsf/f039526076cc0f8e8525660b006870c9?OpenView as of August 2007
} 
paralleling the Ohio River. Given the average round trip time of a unit coal train of three days, the railroad would be faced with an additional burden of at least 8,300 additional coal cars to meet this new traffic. There would be an additional 76 unit trains of 108 cars each on the Ohio River region of the CSX Railroad to meet the new traffic demand of the Ohio River coal tonnage.

The CSX Railroad Annual Reports provide statistical data for average train velocity, average system dwell time, and total number of cars-on-line for the period between 2001 and 2005. The data are shown in Table $6 .{ }^{24}$ (The dwell time is the average amount of time between when a car arrives in a rail yard and when it departs the rail yard. ${ }^{25}$ )

Table 6. CSX Railroad Performance Measures.

\begin{tabular}{|c|c|c|c|c|c|c|}
\hline \multicolumn{7}{|c|}{ CSX Transportation } \\
\hline & 2001 & 2002 & 2003 & 2004 & 2005 & $\begin{array}{c}\text { With } \\
\text { Diversion }\end{array}$ \\
\hline Velocity & 21.7 & 22.5 & 21.1 & 20.3 & 19.2 & 12.88 \\
\hline Dwell time & 24.5 & 23.2 & 25.3 & 28.7 & 29.7 & NA \\
\hline Coal car loadings & $1,722,000$ & $1,574,000$ & $1,570,000$ & $1,659,000$ & $1,726,000$ & $2,736,000$ \\
\hline
\end{tabular}

An exponential regression analysis indicates the addition of 1,010,250 coal car loadings shifted from the Ohio River to the CSX Railroad would reduce the system average train velocity from $19.2 \mathrm{mph}$ downward to $12.88 \mathrm{mph}$ at a coal car loading requirement of 2,736,000 units that would maintain the 2005 railroad traffic volume with the additional river tonnage. (See Figure 13.)

\footnotetext{
${ }^{24}$ All data, except With Diversion column excerpted from http://investors.csx.com/phoenix.zhtml?c=92932\&p=irolreportsannual .

${ }^{25}$ CSX Annual Report, 2003, p 10, http://media.corporate-ir.net/media_files/irol/92/92932/annual_reports/2003AR.pdf .
} 


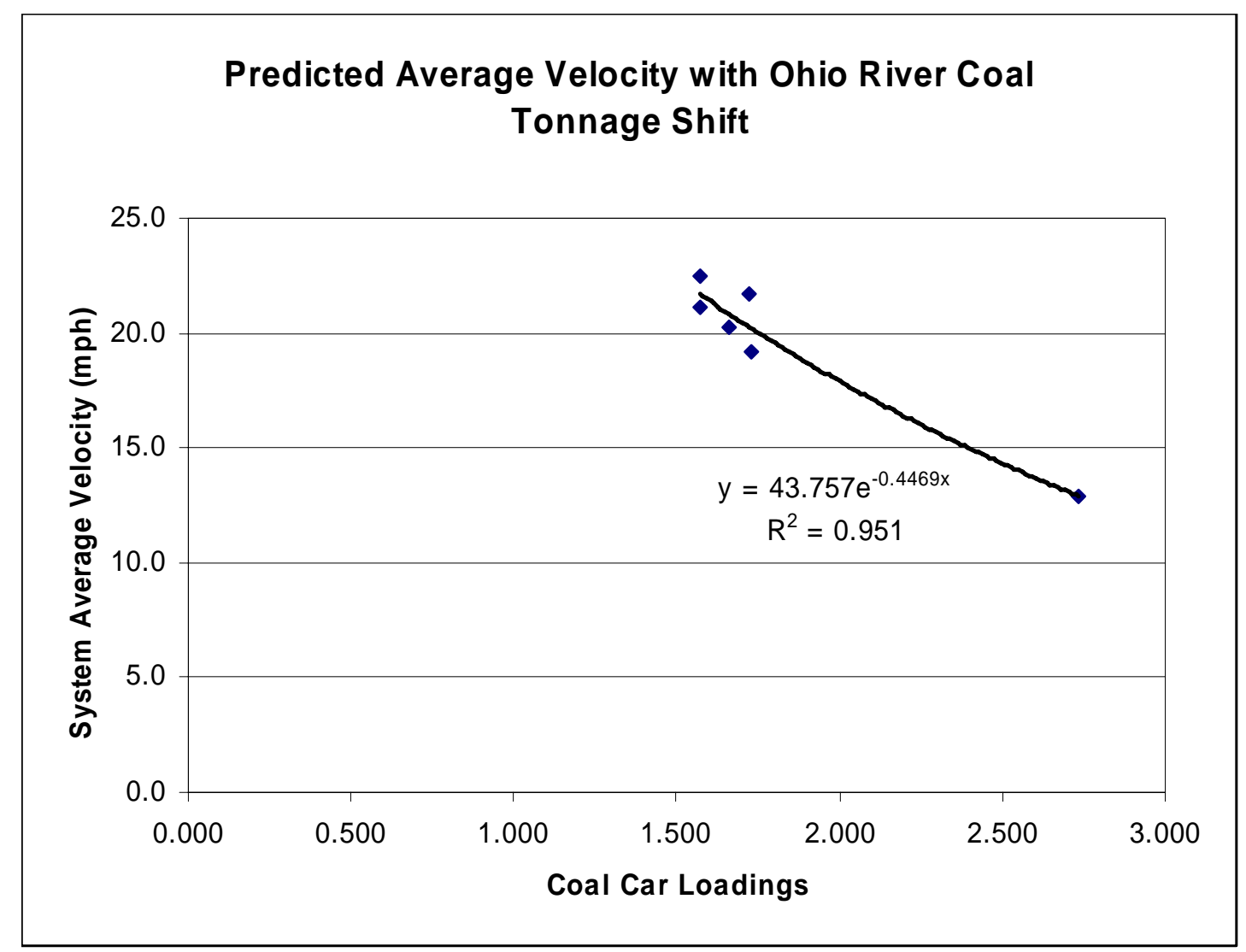

Figure 13. Predicted CSX train velocity with addition of Ohio River coal tonnage.

The exponential curve fit analysis indicates an $\mathrm{R}^{2}$ correlation coefficient of 0.951 , which implies a likely outcome given the assumptions applied to the regression. Other regression analyses were carried out but resulted in low correlation coefficients, below 0.400 . It should be noted that the annual coal loading data and train velocities from the years 2001 to 2005 are for the entire CSX Railroad system. The actual CSX coal traffic train routes and route densities for the period between 2001 and 2005 is unknown.

For the projected increased coal loadings from closing the Ohio River barge traffic, it can reasonably be assumed that the $58 \%$ increase in railroad coal loadings will originate and terminate up or downstream in the vicinity of the Ohio River. Given that the added traffic would use only rail lines along the Ohio River, using the CSX System average train velocity is the best available metric to evaluate the impact on rail traffic. The potential for increased coal rail traffic due to closing the Ohio River transportation system would impact the local rail lines much more severely than the rest of the system. The real possibility exists that the railroad system as currently developed could not respond by accommodating the shift of coal traffic and it would either end up in grid-lock or very little additional coal traffic could be accommodated. 


\section{CHAPTER 4: EMISSIONS ISSUES}

\section{HIGHWAY}

The Environmental Protection Agency's (EPA) MOBILE6 model ${ }^{26}$ estimates mobile source emission factors for several hazardous air pollutants, in grams per vehicle mile traveled. These air pollutants include hydrocarbons ( $\mathrm{HC})$, carbon monoxide (CO), nitrogen oxides $\left(\mathrm{NO}_{\mathrm{x}}\right)$, particulate matter (PM), and carbon dioxide $\left(\mathrm{CO}_{2}\right)$. Mobile sources are simply gasoline fueled and diesel fueled highway motor vehicles.

Basic emission rates developed from national vehicle fleet data are updated with each version of MOBILE to reflect changes in vehicle, engine, and emission control system technologies; changes in applicable regulations, emission standards, and test procedures; and improved understanding of in-use emission levels and the factors that influence them. The model allows modeling of specific, tailored situations via user-defined inputs that complement the basic emission factors (for example, a specific roadway type, time of day, vehicle category, etc.).

Emission factor estimates depend on various conditions, such as ambient temperatures, altitude, travel speeds, operating modes, fuel volatility, and mileage accrual rates. Many of the variables affecting vehicle emissions can be specified by the user. MOBILE6 estimates emission factors for any calendar year between 1952 and 2050, inclusive. Vehicles from the 25 most recent model years are considered to be in operation in each calendar year. On-road vehicles are classified into 28 vehicle classes that include passenger cars, light and heavy duty trucks, buses, and motorcycles.

MOBILE models have been used by the EPA to evaluate highway mobile source control strategies; by states and local and regional planning agencies to develop emission inventories and control strategies for State Implementation Plans under the Clean Air Act; by metropolitan planning organizations and state transportation departments for transportation planning and conformity analysis; by academic and industry investigators conducting research; and in developing environmental impact statements.

The emissions analysis for this project utilizes MOBILE6.2, which was run twice to model two situations - the existing scenario and the hypothetical scenario that assumes diversion of barge traffic onto roadways, on an average summer day in 2005, the waterborne data year.

Identical values for the minimum required inputs were used for both runs in order to ensure consistency. They are the following:

- Calendar year: 2005

- Month: July

- Minimum/maximum temperature: $60.0^{\circ} \mathrm{F} / 90.0^{\circ} \mathrm{F}$

- Altitude: low

- Fuel Reid Vapor Pressure: 9.0 psi (pounds per square inch) (average value across the study area in summer months)

- Diesel Fuel Sulfur Content: 500 ppm (parts per million)

${ }^{26}$ U.S. Environmental Protection Agency. Office of Transportation and Air Quality. User’s Guide to MOBILE6.1 and MOBILE6.2. EPA420-R-03-010. August 2003. 
In both runs, emission factors were estimated in grams per vmt by vehicle class and for the following pollutants:

- Hydrocarbons (HC - expressed as Volatile Organic Compounds, VOC)

- Carbon Monoxide (CO)

- Nitrogen Oxides $\left(\mathrm{NO}_{\mathrm{x}}\right)$

- Carbon Dioxide $\left(\mathrm{CO}_{2}\right)$

- Particulate Matter of diameter 10 micrometers or less (PM-10)

The first run was the baseline or default run. All other inputs that can be user defined, such as vmt distribution by vehicle class, roadway type and hour of day, were left intact, i.e., the model's built-in default values derived from national fleet and vehicle activity data were used.

The second run modeled only the fleet of the additional trucks that would be required in the event of a diversion. The emission factors of these vehicles operating under diversion conditions differ from the values obtained from the default run, which are based on national average activity patterns - or existing conditions. Under diversion the additional fleet's travel activity is assumed to occur almost exclusively on interstate freeways, as well as equally over all 24 hours of the day.

The first default input file that was modified to reflect the characteristics of the truck fleet resulting from the theoretical freight diversion was the distribution of vmt by vehicle class, which allocates the total vmt to each of 16 vehicle classes. The standard vehicle for this study, the diesel fueled combination tractor trailer truck with Gross Vehicle Weight Rating of 80,000 lbs, belongs to the heaviest MOBILE6 vehicle class, HDDV8B (Heavy Duty Diesel Vehicles with GVWR over 60,000 lbs). The vmt distribution groups diesel and gasoline vehicles together into the same weight class. Therefore $100 \%$ of the total vmt of the study's HDDV8B diversion trucks was allocated to HDV8B (Heavy Duty Vehicles with GVWR over 60,000 lbs). By comparison, the HDV8B is responsible for $4 \%$ of the total vmt in the default file used in run 1.

The second default input file that was modified to reflect the characteristics of the truck fleet resulting from the freight diversion was the distribution of vmt by facility. This distribution does distinguish between vehicles of the same weight class by fuel type. It distributes the vmt of each of the 28 vehicle classes, over each of the 24 hours of the day, as a percent vmt on each of four road types: freeways, arterials, local roads, and freeway ramps. The total percent vmt for each hour, for each vehicle class sums up to $100 \%$. In general, the percent vmt allocated to each road type for a given class varies from hour to hour. However, an average percent vmt allocation over all 24 hours for HDDV8B in the default input file is 37\% freeways, 48\% arterials, 13\% local roads, and 3\% freeway ramps. In this study, long haul trucks carrying the diverted freight are assumed to travel primarily on interstates (freeway class), not on arterials, or local roads. Therefore, the vmt by facility for HDDV8B was modified to allocate 95\% to freeways and 5\% on freeway ramps. This allocation scheme was kept constant for each of the 24 hours because long distance hauls have been shown to take place fairly evenly throughout the day and night. The default facility vmt distribution file reflects this fact based on national trends and data and shows that the percent of the hourly vmt over each type of facility for HDDV8B is fairly constant for each of the 24 hours of the day. 
Table 7 shows the emission factors of the above pollutants, in grams per vmt, for HDDV8B resulting from both runs of MOBILE6. The diversion truck fleet, which is assumed to primarily operate on freeways (thus, at higher speeds), has a higher $\mathrm{NO}_{\mathrm{x}}$ emission factor. EPA analyses ${ }^{27}$ show that $\mathrm{NO}_{\mathrm{x}}$ emissions of heavy diesel trucks increase exponentially with respect to speeds above $45 \mathrm{mph}$ (usually occurring on freeways) or below $25 \mathrm{mph}$, approximately.

The output rates in grams per vmt, the vmt of the loaded trucks, and the diverted waterborne tonmiles led to the calculated emission rates in grams per ton-mile, also shown in the table. Every truck was assumed to return empty--or haul zero tons--so its return trip would have zero tonmiles. The conversion of vehicle-mile rates to ton-mile rates was necessary in order to enable a comparison with the water and rail modes on an equal basis. The reason is that the water and rail modes typically report and publish data using ton-miles, whereas highway data conventionally use vehicle-miles.

Also of note is that MOBILE6 outputs the fuel economy in miles per gallon (mpg) of each class of vehicles. For information purposes it is shown in the output table as well but it will be discussed in the next chapter, under energy efficiency.

Table 7. Emission Factors HDDV8B.

\begin{tabular}{|c|c|c|c|c|c|c|c|}
\hline Run & Scenario & VOC & CO & $\mathbf{N O}_{\mathrm{x}}$ & $\mathrm{CO}_{2}$ & PM-10 & MPG \\
\hline 1 & Default/Existing Trucks (g/vmt) & 0.651 & 4.137 & 14.764 & $1,645.3$ & 0.4523 & 6.2 \\
\hline \multirow[t]{2}{*}{2} & Diversion Trucks (g/vmt) & 0.504 & 3.408 & 18.301 & $1,645.1$ & 0.4522 & 6.2 \\
\hline & Diversion Trucks (g/ton-mi) & 0.020 & 0.136 & 0.732 & 65.8 & 0.018 & -- \\
\hline & $\mathrm{k}$ vmt $=9,644$ million & $T$ & $=-2$ & 08 mill & & & \\
\hline
\end{tabular}

It is important to mention at this point that the HDDV8B emission factors resulting from the default run were somewhat higher than those for all classes of HDDV, since HDDV8B is the heaviest subclass and their emission factors are higher than the overall class average. The overall HDDV factors were compared with values seen in other federal sources, for example FHWA's Freight Facts and Figures ${ }^{28}$, and found to be in agreement. This is not surprising since all federally published data are based on the same official sources of national estimates. For comparison purposes, these HDDV emission factors in grams per vmt are 0.54 for VOC, 3.05 for $\mathrm{CO}$, and 11.45 for $\mathrm{NO}_{\mathrm{x}}$.

Although the range of increases in all pollutants is relatively modest, it must be borne in mind that this additional truck fleet will operate primarily in the vicinity of the waterways under study. The impacts will be more severe in this geographical area than locations far away from these river bodies. The middle part of the U.S. already includes several areas designated by the EPA as Non-Attainment Areas, most commonly for ozone. The only Non-Attainment Area (for CO only) along the path of the Columbia/Snake Rivers is the area encompassing Portland, Oregon and Vancouver, Washington. Any emissions increase would only worsen existing problems.

\footnotetext{
${ }^{27}$ U.S. Environmental Protection Agency. Office of Transportation and Air Quality. Sensitivity Analysis of MOBILE6.0. EPA420-R-02-035. December 2002.

${ }^{28}$ Federal Highway Administration. Freight Management and Operations. Freight Facts and Figures 2006. Table 5-11: Estimated National Average Vehicle Emissions Rates of Heavy- and Light- Duty Vehicles (grams per mile).
} 
Figure 14 shows these non-attainment areas for Ozone and Carbon Monoxide along the inland waterways considered in this study.

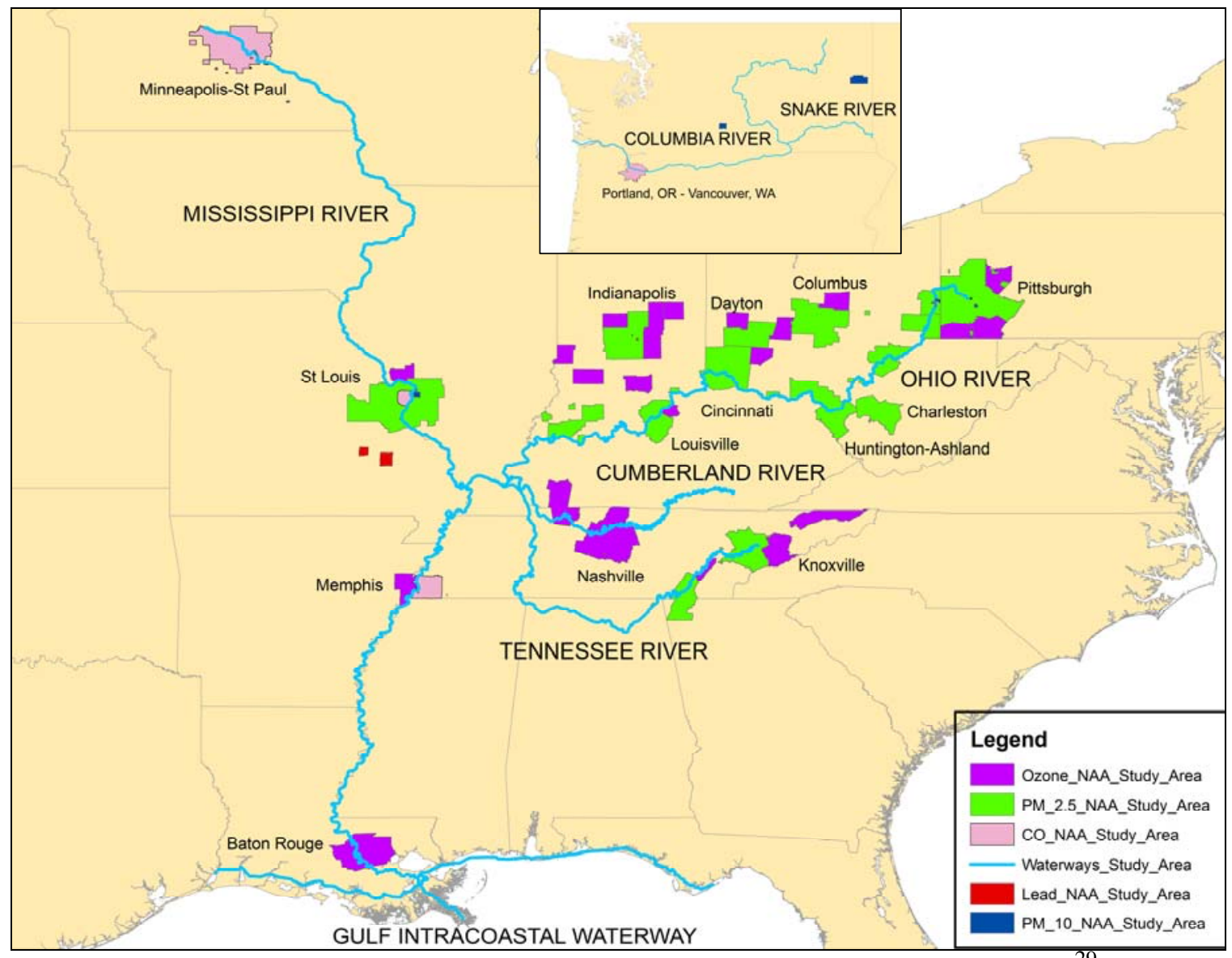

Figure 14. Nonattainment/Maintenance Counties in Study Area.

Source: U.S. Department of Transportation, Research and Innovative Technology Administration, Bureau of Transportation Statistics. National Transportation Atlas Databases

A theoretical waterborne freight diversion would have devastating effects on the entire spectrum of the trucking and fuel industries when new regulations and their implications are also considered. The demand for new trucks, drivers, and additional fuel supplies will increase dramatically. However, the potential air quality impact in future years is not quite as clear.

\section{Future Federal Regulations - On-Road Vehicles}

The EPA is establishing a comprehensive national control program that will regulate the heavyduty vehicle and its fuel as a single system. As part of this program, new emission standards begin taking effect in model year 2007 and apply to heavy-duty highway engines and vehicles. These standards are based on the use of high-efficiency catalytic exhaust emission control devices or comparably effective advanced technologies. Because these devices are damaged by sulfur, the EPA also reduced the level of sulfur in highway diesel fuel by $97 \%$ in mid-2006.

\footnotetext{
${ }^{29}$ U.S. Department of Transportation, Research and Innovative Technology Administration, Bureau of Transportation Statistics. National Transportation Atlas Databases 2007.
} 
The EPA's PM emissions standard for new heavy-duty engines is set at 0.01 grams per brakehorsepower-hour (g/bhp-hr), and will take full effect for diesels in the 2007 model year. The standards for $\mathrm{NO}_{\mathrm{x}}$ and non-methane hydrocarbons (NMHC) are $0.20 \mathrm{~g} / \mathrm{bhp}-\mathrm{hr}$ and $0.14 \mathrm{~g} / \mathrm{bhp}-\mathrm{hr}$, respectively. These $\mathrm{NO}_{\mathrm{x}}$ and NMHC standards will be phased in together between 2007 and 2010, for diesel engines. The phase-in will be on a percent-of-sales basis: $50 \%$ from 2007 to 2009 and 100\% in 2010. Refiners were required to start producing diesel fuel for use in highway vehicles with a sulfur content of no more than 15 parts per million (ppm), beginning June 1, 2006. This study used 2005 data; hence MOBILE6 was run for calendar year 2005; therefore, the 2005 sulfur content of 500 ppm was input in the model.

The EPA estimates that the new standards will result in substantial benefits to the public health and welfare through significant annual reductions in emissions of $\mathrm{NO}_{\mathrm{x}}, \mathrm{PM}, \mathrm{NMHC}$, carbon monoxide, sulfur dioxide, and air toxics. According to the EPA, each new truck will be $90 \%$ cleaner than current models. EPA projects that the average price of $\$ 150,000$ for a new heavy duty truck will increase by an average of $\$ 1,900$. The cost of producing and distributing diesel fuel that is compliant with the new sulfur reduction requirement is estimated to increase by approximately five cents per gallon. ${ }^{30}$ These estimates do not take into account the effect of the dramatic increase in demand for trucks and fuel that would occur if the traffic on the waterways were diverted to trucks.

\section{RAILROAD LOCOMOTIVE AND MARINE EMISSIONS}

The emissions from railroad locomotives have been regulated by the EPA since January 1, $2001 .^{31}$ During the period of this study's “snap shot in time” of 2005, the railroads were subject to two regulated levels of emissions. The locomotive emission levels are designated as Tier 0 and Tier 1 emissions. ${ }^{32}$ The regulations establish emission standards as well as methods and procedures to calculate duty-cycle emissions from locomotives. ${ }^{33}$ The EPA provides a conversion factor for the amount of pollutants locomotives would produce from each gallon of fuel used. The EPA also provides an estimated amount of emissions for each gallon of fuel consumed--270 grams of $\mathrm{NO}_{\mathrm{x}}$ per gallon for line haul duty cycle locomotives. ${ }^{34}$

\section{Conversion of Emission Factors to Grams per Gallon}

It is often useful to express emission rates as grams of pollutant emitted per gallon of fuel consumed (g/gal). The EPA has developed a conversion factor to convert grams per brakehorsepower-hour (g/bhp-hr) to g/gal, and provides Table 8 for use in estimating emissions when fuel gallons are known. The railroad switch emission values are included in the table for completeness, but are not used in reference to emissions from the railroads. The ton-miles due to rail yard switching are not included in EPA calculations or estimates. The railroads are required to provide kilowatt power production or fuel use in switchers for the estimate of emissions.

\footnotetext{
${ }^{30}$ Environmental Protection Agency. Office of Transportation and Air Quality. Regulatory Announcement: HeavyDuty Engine and Vehicle Standards and Highway Diesel Fuel Sulfur Control Requirements. EPA420-F-00-057. December 2000. http://www.epa.gov/otaq/highway-diesel/regs/f00057.pdf.

${ }^{31}$ Title 40 CFR, 92, Subpart A, § 012.a, Tier 0 Standards.

${ }^{32}$ Federal Register / Vol. 63, No. 73 / Thursday, April 16, 1998 / Rules and Regulations, p. 18978, Summary.

33 Title 40 CFR, 92, Subpart B, § 132, Calculations.

${ }^{34}$ EPA420-F-97-051, December 1997, Technical Highlights, Emission Factors for Locomotives, p. 2, accessible at http://www.epa.gov/otaq/regs/nonroad/locomotv/frm/42097051.pdf as of August 2007.
} 
Table 8. Conversion Factors for Emissions in g/gal of Fuel Use.

\begin{tabular}{|c|c|c|c|c|}
\hline \multicolumn{6}{|c|}{ Grams per Gallon Emission Factors (g/gal) } \\
\hline & HC & CO & NO $_{\mathbf{x}}$ & PM \\
\hline RR Line Haul & 10 & 26.6 & 270 & 6.7 \\
\hline RR Switch & 21 & 38.1 & 362 & 9.2 \\
\hline
\end{tabular}

The EPA also promulgated Emission Standards for marine vessel engines. Before this regulation the commercial river boat marine engine emission was unregulated (prior to 2007). In 2005, the emission allowance was focused on $\mathrm{NO}_{\mathrm{x}}$ emissions only. The amount of allowable emissions in 2005 was determined separately for idle conditions and running conditions. Essentially, the amount of emissions for 2005 is equivalent to uncontrolled locomotives. The idle emissions for marine vessels are difficult to evaluate since every engine will idle at a different speed. Since the amount of fuel used per ton mile of revenue is estimated based on reported fuel tax collected by the Internal Revenue Service (IRS) and the tonnage reported to the U.S. Army Corps of Engineers, the idle and running emissions are not at issue in this analysis. The same issue is present for railroad emissions with a comparable solution. Because this analysis does not attempt to develop a route specific emission profile, the idle and running emission profiles are not necessary for this study.

\section{SUMMARY MODAL COMPARISON}

The emission comparison between the three modes is shown in Table 9. The emissions for railroads are divided into East and West for the railroads but a single value supplied by the Tennessee Valley Authority (TVA) is used for marine emissions. The 2005 TVA value from Table 11 in the next chapter is used, 575.6 ton-miles per gallon of fuel. The average Eastern Railroad and average Western Railroad values from Table 10 (also in the next chapter) are used for the railroad emissions values.

Table 9. Summary of Emissions - Grams per Ton-Mile.

\begin{tabular}{|c|c|c|c|c|}
\hline \multicolumn{5}{|c|}{ Emissions (grams/ton-mile) } \\
\hline & HC & CO & NO $_{\mathbf{x}}$ & PM \\
\hline Inland Towing & 0.01737 & 0.04621 & 0.46907 & 0.01164 \\
\hline Eastern Railroad & 0.02419 & 0.06434 & 0.65312 & 0.01624 \\
\hline Western Railroad & 0.02423 & 0.06445 & 0.65423 & 0.01621 \\
\hline Truck & 0.020 & 0.136 & 0.732 & 0.018 \\
\hline
\end{tabular}




\section{CHAPTER 5: ENERGY EFFICIENCY}

In the comparisons for the energy intensities of the freight modes evaluated in this study, energy used for moving the empty transportation equipment on return trips has been taken into account. The data for each freight transportation mode were examined to ensure that the empty movement portion was accounted for in the energy per revenue ton-mile calculations.

The MOBILE6 outputs include the fuel economy rate for HDDV8B in miles per gallon as estimated by the EPA, shown in the emissions impacts section to be $6.2 \mathrm{mpg}$, for both the existing truck fleet and the additional truck fleet that would be transporting the waterborne freight under a diversion scenario. This figure fares well in comparison with FHWA's published average fuel consumption of combination trucks of $5.9 \mathrm{mpg}$ in 2004, which is the latest data year in the respective table in Freight Facts and Figures $2006^{35}$. Conventionally, vehicle-miles traveled are used in reporting and publishing data for the highway mode, whereas ton-miles are used for the water and rail modes. For this reason, comparison of the highway mode to the other two modes in this study, warranted conversion of vehicle-mile rates to ton-mile rates.

When the truck fuel efficiency rate of 6.2 miles per gallon is multiplied by the assumed truckload of 25 tons of cargo, a truck fuel efficiency of 155 ton-miles per gallon is generated. Each return trip is assumed to be empty - or haul zero cargo tons. The fuel efficiency of the return trip in ton-miles per gallon mathematically would equal zero, but the fuel efficiency in vehicle-miles per gallon would still equal 6.2. Since an across the board comparison of the three modes requires the use of a ton-miles per gallon rate, 155 ton-miles per gallon is the proper figure to use, which describes the fuel efficiency of a loaded truck.

A comparison of energy consumption for freight movement by the various surface transportation modes has previously been attempted. The researchers investigated the possible use of such a comparison contained in the U.S. Transportation Energy Data Book ${ }^{36}$, but determined that the methodology used was not appropriate. For this report, the researchers calculated energy efficiencies using detailed data supplied by each transportation industry sector to government regulatory entities.

For freight modes, a significant portion of the energy expended is attributed to non-haul purposes. For example, almost half of the energy consumed by freight rail is not used to move freight:

- $\quad$ More than $30 \%$ is used for empty backhaul.

- About $4 \%$ is reported lost or spilled each year.

- About $4 \%$ is consumed in idling.

- $10 \%$ is used by yard locomotives assembling and switching cars. ${ }^{37}$

\footnotetext{
${ }^{35}$ Federal Highway Administration. Freight Management and Operations. Freight Facts and Figures 2006. Table 5-9: Combination Truck Fuel Consumption and Travel.

${ }^{36}$ U.S. Department of Energy. Oak Ridge National Laboratory. Davis, S.C. and Diegel, S.W. Transportation Energy Data Book: Edition 26. ORNL-6978. 2007.

${ }^{37}$ A.B. Rose, Energy Intensity and Related Parameters of Selected Transportation Modes: Freight Movements, ORNL-5554 (Oak Ridge, TN: Oak Ridge National Laboratory, June 1979), pp. S-10 and 5-4.
} 
The energy consumption in the railroad industry was carefully evaluated in order to ensure that the full energy as well as the total equipment and freight mileage movements were included.

The data for the railroads were spread among four primary sources: the Association of American Railroads (AAR), the Surface Transportation Board (STB), Security and Exchange Commission (SEC), and the railroads' own annual reports to stockholders.

The AAR data were found on the AAR website in the RR Industry Info, Statistics, and Performance Measures sections. Both the SEC and the STB websites provide each railroad's required federal filings. The SEC data source is the $10-\mathrm{K}$ annual report of financial status and operating data. The STB provides each railroad's R-1 report that includes operating data, particularly the railroad's locomotive fuel dollars on Schedule 410, line 409, and the gross tonmiles of traffic reported on Schedule 755, line 104. The individual railroad's average annual cost per gallon of fuel is discretionarily available in their individual annual report. Additionally, individual railroads may include the actual gallons of locomotive fuel consumed in their annual report; however this value is not consistently reported by any of the railroads.

Table 10 lists the fuel efficiency calculated by the researchers using the available data from sources described above and the AAR reported value for gross ton miles per gallon of fuel for the year 2005 as provided in the RR Statistics document on their website.

Table 10. Calculated Railroad Fuel Efficiency.

\begin{tabular}{|c|c|c|c|}
\hline & $\begin{array}{c}\text { Gross Revenue } \\
\text { Ton-Miles } \\
\left(\mathbf{( x 1 0}^{\mathbf{3}} \mathbf{3}^{-}\right.\end{array}$ & $\begin{array}{c}\text { Fuel Consumed } \\
\mathbf{( x 1 0}^{\mathbf{3}} \mathbf{3}^{3}\end{array}$ & Ton-Miles/Gallon ${ }^{\mathbf{4 0}}$ \\
\hline AAR & 594,676 & $1,402.3$ & 414 \\
\hline BNSF & 54,064 & 110.7 & 424 \\
\hline CN & 23,595 & 49.3 & 478 \\
\hline CPR & 247,411 & 595.5 & 415 \\
\hline CSX & 25,167 & 74.0 & 340 \\
\hline KCS & 202,751 & 513.4 & 395 \\
\hline NS & 548.761 & $1,362.9$ & 403 \\
\hline UP & $1,696,425$ & $4,108.1$ & 412.9 \\
\hline Average All Roads & $1,192,199$ & $2,888.5$ & 413.4 \\
\hline Average West Roads & 504,226 & $1,219.6$ & \\
\hline Average East Roads & & & \\
\hline
\end{tabular}

It is more difficult to develop energy consumption data for the inland waterways (river and Gulf Intracoastal Waterways) operators than for the railroad industry. The marine industry only

\footnotetext{
${ }^{38}$ STB R-1 Annual Report, Schedule 755, Line 110: Total Gross revenue ton-miles all trains.

${ }^{39}$ STB R-1 Annual Report, Schedule 750, Line 4: Total Fuel Consumed all trains except passenger.

${ }^{40}$ Calculated value, Gross Revenue Ton-Miles divided by Fuel Consumed.
} 
reports tax information on fuel purchases to the federal government. Access to detailed information on individual moves is restricted and is generally available only to the Corps. The Corps has contracted with the Tennessee Valley Authority (TVA) to develop software to model the fuel consumption, reported tonnages, and traffic mileage of marine freight transportation for the waterways for which the Corps has jurisdictional responsibility.

TVA provided the modeled data for the marine ton-miles per gallon of fuel for the years 2003, 2004, and 2005. The model has been repeatedly tested by the TVA against the U.S. IRS tax data for fuel tax collected on various sections of the U.S. river system in order to verify its validity. The model has been verified to be consistently accurate within $0.3 \%$ of the actual reported tonnage and fuel tax collected in the validation tests. Table 11 lists the TVA modeled fuel efficiency for the marine industry for the river navigation system. ${ }^{41}$

Table 11. Marine Fuel Efficiency.

\begin{tabular}{|c|c|}
\hline \multicolumn{2}{|c|}{ TVA Fuel Efficiency Model - Ton-Mile Values } \\
\hline Year & Ton-Miles/Gallon \\
\hline 2003 & 574.1 \\
\hline 2004 & 575.7 \\
\hline 2005 & 575.6 \\
\hline
\end{tabular}

Source: Tennessee Valley Authority

The railroads are $28.3 \%$ less fuel efficient than the inland waterway freight transportation system based on revenue ton-miles per gallon. This difference could possibly increase in future years. The increased demand for freight transportation on the rivers has caused a waiting queue to develop at the locks on the rivers. Where shorter locks (less than 1200 feet) are located, more tows must be broken up and moved through in multiple lockages. This causes a significant amount of fuel usage by the towboats to maintain steerage control during the wait period. Improving the locks could make a significant difference in fuel consumption. Additionally, the railroads have been subject to new regulation by the EPA to reduce locomotive emissions. This impetus has forced the manufacturers of locomotives to provide lower emission engines. One way the locomotive engine manufacturers found to lower emissions was to increase engine efficiency by reducing fuel consumption. Reducing locomotive fuel consumption while maintaining power requirements has increased railroad ton-mile efficiency. Marine engine emission regulations have not yet been finalized, although the industry is already moving to more fuel-efficient engines for economic reasons. Once the marine industry is required by regulation to reduce emissions, the towboat fuel consumption will follow the logical path already explored by the railroad industry.

\footnotetext{
${ }^{41}$ Data provided by Chrisman A. Dager, Transportation Economist, Tennessee Valley Authority.
} 
Table 12 and Figure 15 present the results of the fuel efficiency calculations on a national industry-wide basis in summary form.

Table 12. Summary of Fuel Efficiency.

\begin{tabular}{|c|c|}
\hline Mode & Ton-Miles/Gallon \\
\hline Inland Towing & 576 \\
\hline Western Railroads & 413 \\
\hline Eastern Railroads & 413 \\
\hline Truck & 155 \\
\hline
\end{tabular}

\section{Miles per Gallon Carrying One Ton of Cargo}

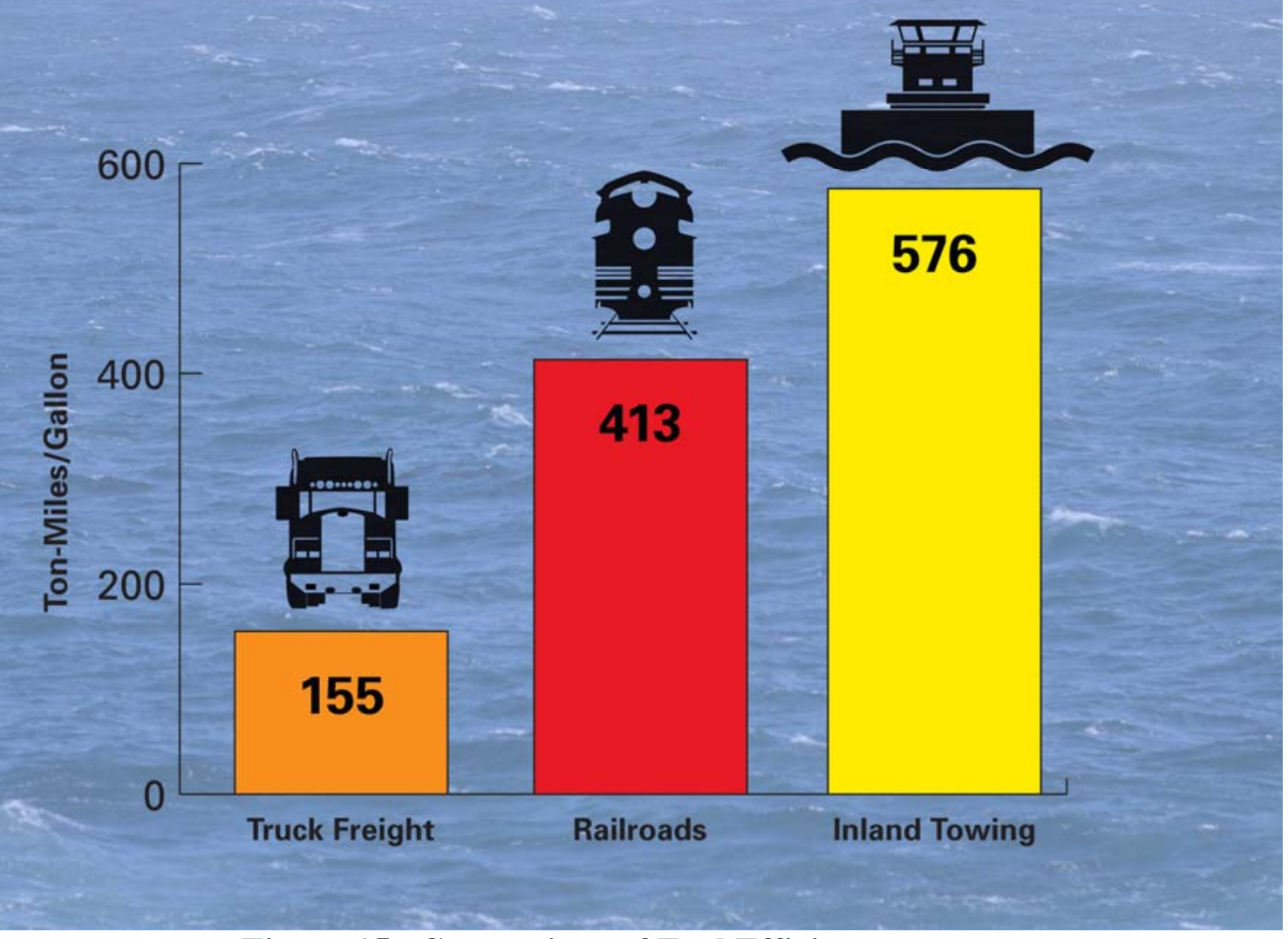

Figure 15. Comparison of Fuel Efficiency. 


\section{CHAPTER 6: SAFETY IMPACTS}

This study evaluates the impacts resulting from diversion of barge freight to the highway or rail mode using three primary types of safety measures: fatalities, injuries, and hazardous materials spills.

\section{FATALITIES AND INJURIES}

The data for rail fatalities and injuries respectively were obtained from Railroad Statistics: National Transportation Statistics - 2006, Table 2-35: Railroad and Grade-Crossing Fatalities by Victim Class and National Transportation Statistics - 2006, Table 2-36: Railroad and GradeCrossing Injured Persons by Victim Class. Data for truck-related incidents were obtained from Large Truck Crash Facts, 2005, a publication of the Federal Motor Carrier Safety Administration. The data for waterborne incidents were taken from the Marine Casualty and Pollution Database, July 2006, a database that is maintained by the U.S. Coast Guard. The marine casualty database includes all incidents that occurred in water, whether deep-sea or inland; therefore, the dataset was reduced to only those incidents involving river barge traffic in order to facilitate further analysis.

Both rail and truck statistics include incidents involving only vehicular crashes or derailments. However, the waterborne database reports incidents resulting from a wide variety of causes. In order to conduct a valid modal comparison for this study, a definition of "incident" analogous to the one used in the surface mode data was adopted. Data pertaining only to waterborne incidents involving collisions, allisions (vessels striking a fixed object), or capsizings were further extracted and used in analysis.

The statistics for each mode were converted to a rate per million or billion ton-miles to facilitate comparison. Four sources were used for ton-mile data: National Transportation Statistics 2006, Table 1-46a: U.S. Ton-Miles of Freight (Millions); National Transportation Statistics 2006, Table 1-46b, Special Tabulation (highway data); Association of American Railroads Website (2005 ton-miles); Waterborne Commerce Statistics, 2005.

The comparison of fatality rates is shown in Table 13 and Figure 16. Figure 16 shows the ratio of rail to water and truck to water; it is simply each mode's rate per billion ton-miles divided by the inland waterway rate per billion ton-miles. 
Table 13. Fatality Statistics by Mode.

\begin{tabular}{|c|c|c|c|c|c|c|c|}
\hline Mode & $\begin{array}{l}\text { 4-yr avg } \\
\text { ton-miles } \\
\text { (millions) }\end{array}$ & $\begin{array}{l}\text { 4-yr avg } \\
\text { fatalities } \\
\text { (operator) }\end{array}$ & $\begin{array}{l}\text { Rate per Billion } \\
\text { ton-miles }\end{array}$ & $\begin{array}{l}4-y r \text { avg } \\
\text { n fatalities } \\
\text { (other) }\end{array}$ & $\begin{array}{l}\text { Rate per Billion } \\
\text { ton-miles }\end{array}$ & $\begin{array}{l}\text { 4-yr avg } \\
\text { total } \\
\text { fatalities }\end{array}$ & $\begin{array}{l}\text { Rate per } \\
\text { Billion ton- } \\
\text { miles }\end{array}$ \\
\hline Highway & $1,259,535$ & 722 & 0.573227 & 4,758 & 3.777585 & 5,480 & 4.351 \\
\hline Railroad & $1,554,130$ & 28 & 0.018017 & 884 & 0.568807 & 1,008 & 0.649 \\
\hline Inland Towing & g 287,680 & & 0.003476 & 7 & 0.024333 & 8 & 0.028 \\
\hline
\end{tabular}

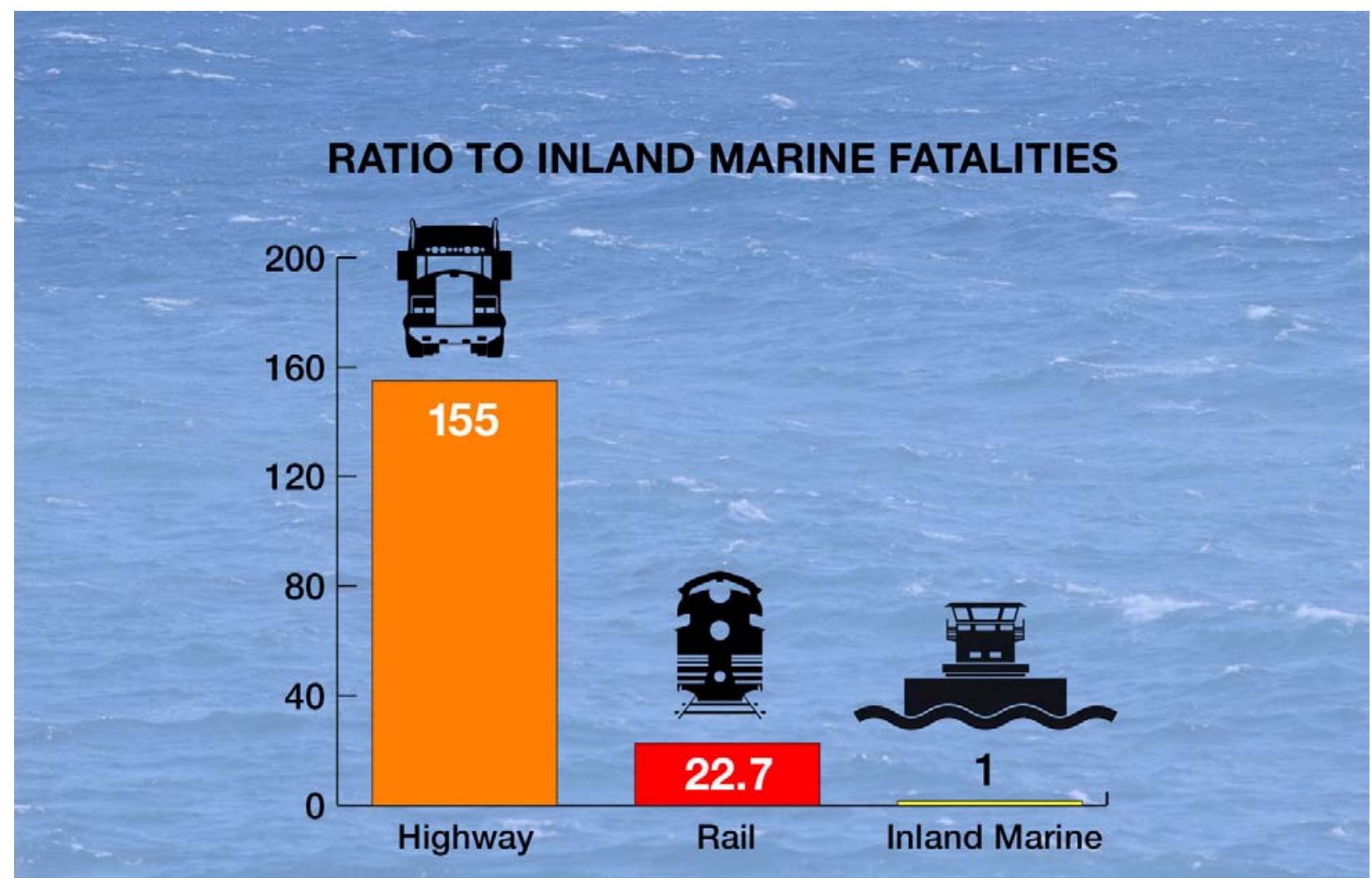

Figure 16. Ratio of Fatalities per Bill Ton-Miles Versus Inland Marine.

In the case of fatalities it is possible to distinguish between injuries to operators of the modal equipment and injuries to other individuals. In the case of injuries, the data are not sufficiently detailed for trucks to allow a comparison; therefore, all injuries are lumped together, as shown in Table 14 and Figure 17. Figure 17 is similar to Figure 16. It shows the ratio of rail to water and truck to water; it is simply each mode's rate per billion ton-miles divided by the inland waterway rate per billion ton-miles. 
Table 14. Comparison of Injuries by Mode.

\begin{tabular}{|c|c|c|c|}
\hline Mode & $\begin{array}{l}4-y r \text { avg } \\
\text { ton-miles } \\
\text { (millions) }\end{array}$ & $\begin{array}{l}4-y r \text { avg } \\
\text { total } \\
\text { injuries }\end{array}$ & $\begin{array}{l}\text { Rate per } \\
\text { Billion ton- } \\
\text { miles }\end{array}$ \\
\hline Highway & $1,259,535$ & 124,750 & 99.044 \\
\hline Railroad & $1,554,130$ & 9,036 & 5.814 \\
\hline Inland Towing & 287,680 & 13 & 0.045 \\
\hline
\end{tabular}

\section{RATIO TO INLAND MARINE INJURIES}

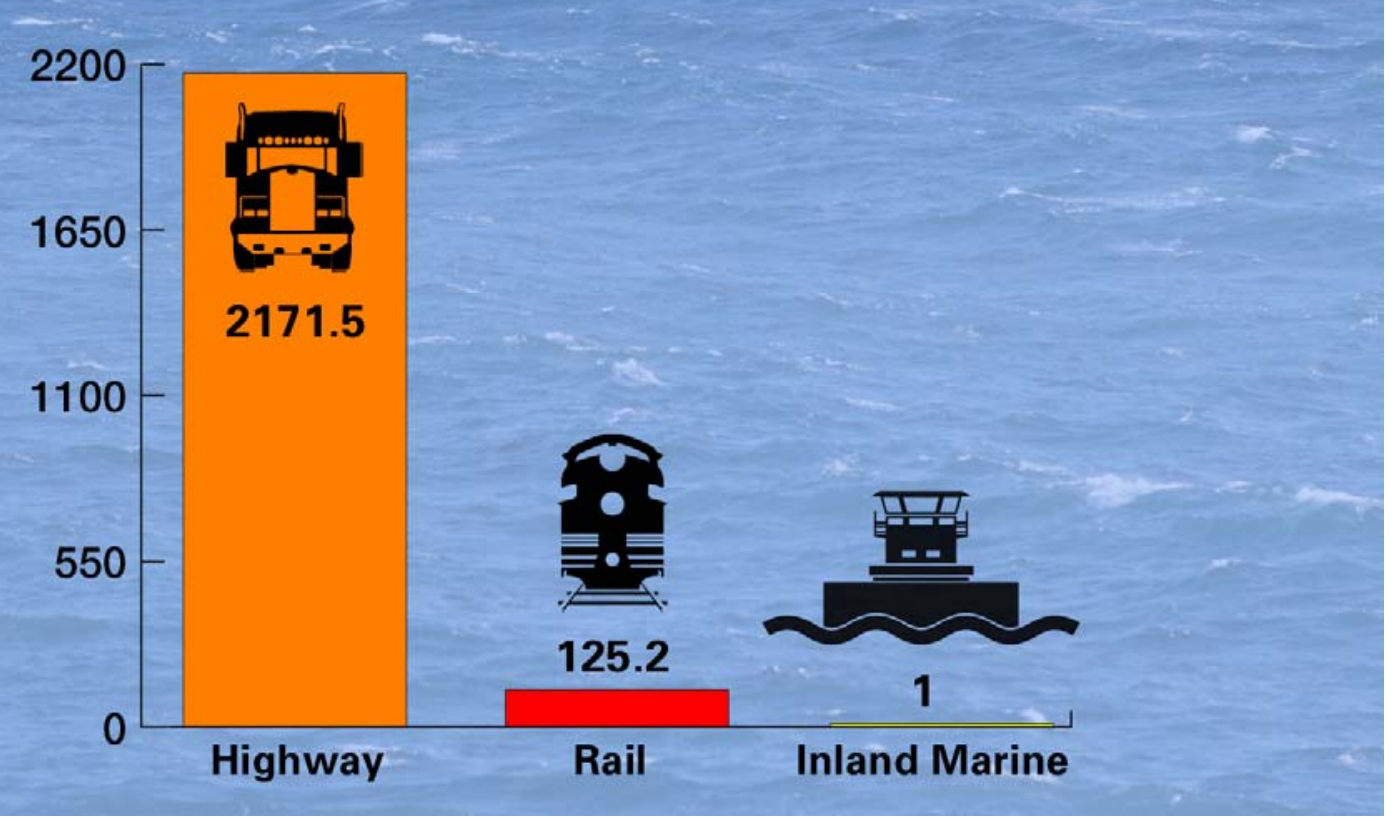

Figure 17. Ratio of Injuries per Bill Ton-Miles Versus Inland Marine.

\section{HAZARDOUS MATERIALS INCIDENTS}

Hazardous materials incidents are reported differently across the modes. Incidents for all three modes are contained in the Pipeline and Hazardous Materials Safety Administration's Hazardous Materials Incident Reporting System, 2001-2005. However, a close examination of the incidents for marine transportation revealed that only deep-sea incidents are being stored in the system; therefore, it was necessary to acquire data from the Coast Guard and from the Corps of Engineers regarding IWWS-related traffic.

The Coast Guard stores information on all incidents involving marine transportation while the Corps of Engineers reports tonnage and ton-mile statistics. The Corps reports the commodities 
according to Standard International Trade Classification (SITC) code, a statistical classification system designed by the United Nations for commodities in international trade to provide the commodity aggregates needed for purposes of economic analysis and to facilitate the international comparison of trade-by-commodity data. The data reported by the Pipeline and Hazardous Materials Safety Administration (PHMSA) use United Nations UN Identification Numbers for tracking commodities. Since the objective of this analysis is to develop an incident rate (as opposed to a comparison of how much of a given product is spilled), the PHMSA spill and ton-mile data are used for truck and rail statistics, while the Coast Guard and Corps data are used for the waterborne activity.

The Coast Guard transitioned to a new marine casualty tracking system in late 2001. Prior reviews have indicated that some of the data from 2001 were not picked up in the newer system. Since this report covers 2001-2004, it was necessary to review the data for both systems for 2001, while the newer system was used exclusively for 2002-2004. The earlier system was known as the Marine Safety Information System (MSIS). The current system is referred to as the Marine Information for Safety and Law Enforcement (MISLE) system. The Coast Guard data do not segregate deep-sea incidents from IWWS incidents, so the research team extracted the spills related to IWWS traffic. Then the team coded the commodities that were spilled according to the SITC scheme. Only SITC codes that coincide with the Corps' statistics on HazMat traffic were retained. This allows a valid calculation of the rate of spills versus the ton-miles of material that were transported.

Due to the fact that all three reporting systems basically rely on self-reporting, and the definitions of materials that require reporting are very complex, much of the spill data are suspect. However, for larger spills, it seems reasonable to assume that the accuracy of the data improves, due to the severity of the incident and public scrutiny; therefore, the research team decided to analyze only large spills as a measure of the overall safety of the modes in the area of spills. The threshold quantity was set at 1,000 gallons.

Table 15 and Figure 18 provide a comparison of spills across the modes:

Table 15. Comparison of Large Spills Across Modes.

\begin{tabular}{|c|c|c|c|c|c|c|c|c|c|}
\hline & \multicolumn{2}{|l|}{ Totals } & \multicolumn{5}{|c|}{ 4-Year Averages (2001-2004) } & \multicolumn{2}{|l|}{ Rates } \\
\hline & $\begin{array}{l}\text { Number } \\
\text { of Spills }\end{array}$ & $\begin{array}{l}\text { Amt in } \\
\text { Gallons }\end{array}$ & $\begin{array}{l}\text { Number } \\
\text { of Spills }\end{array}$ & $\begin{array}{l}\text { Amt in } \\
\text { Gallons }\end{array}$ & $\begin{array}{l}\text { Average } \\
\text { Ton-Miles } \\
\text { (millions) }\end{array}$ & $\begin{array}{l}\text { Percent } \\
\text { Haz- } \\
\text { Mat }\end{array}$ & $\begin{array}{l}\text { Haz-Mat } \\
\text { Ton- } \\
\text { Miles } \\
\text { (millions) }\end{array}$ & $\begin{array}{l}\text { Spills/B } \\
\text { Ton-Mile }\end{array}$ & $\begin{array}{l}\text { Gal/M } \\
\text { Ton- } \\
\text { Mile } \\
\end{array}$ \\
\hline Truck & 643 & $2,698,490$ & 161 & 674,622 & $1,259,535$ & $8.84 \%$ & 111,404 & $1,442,942$ & 6.06 \\
\hline Rail & 115 & $1,147,105$ & 29 & 286,776 & $1,554,130$ & $4.78 \%$ & 74,341 & 386.729 & 3.86 \\
\hline $\begin{array}{l}\text { Inland } \\
\text { Towing }\end{array}$ & 25 & 470,579 & 6 & 117,645 & 287,680 & $11.36 \%$ & 32,668 & 191.319 & 3.60 \\
\hline
\end{tabular}




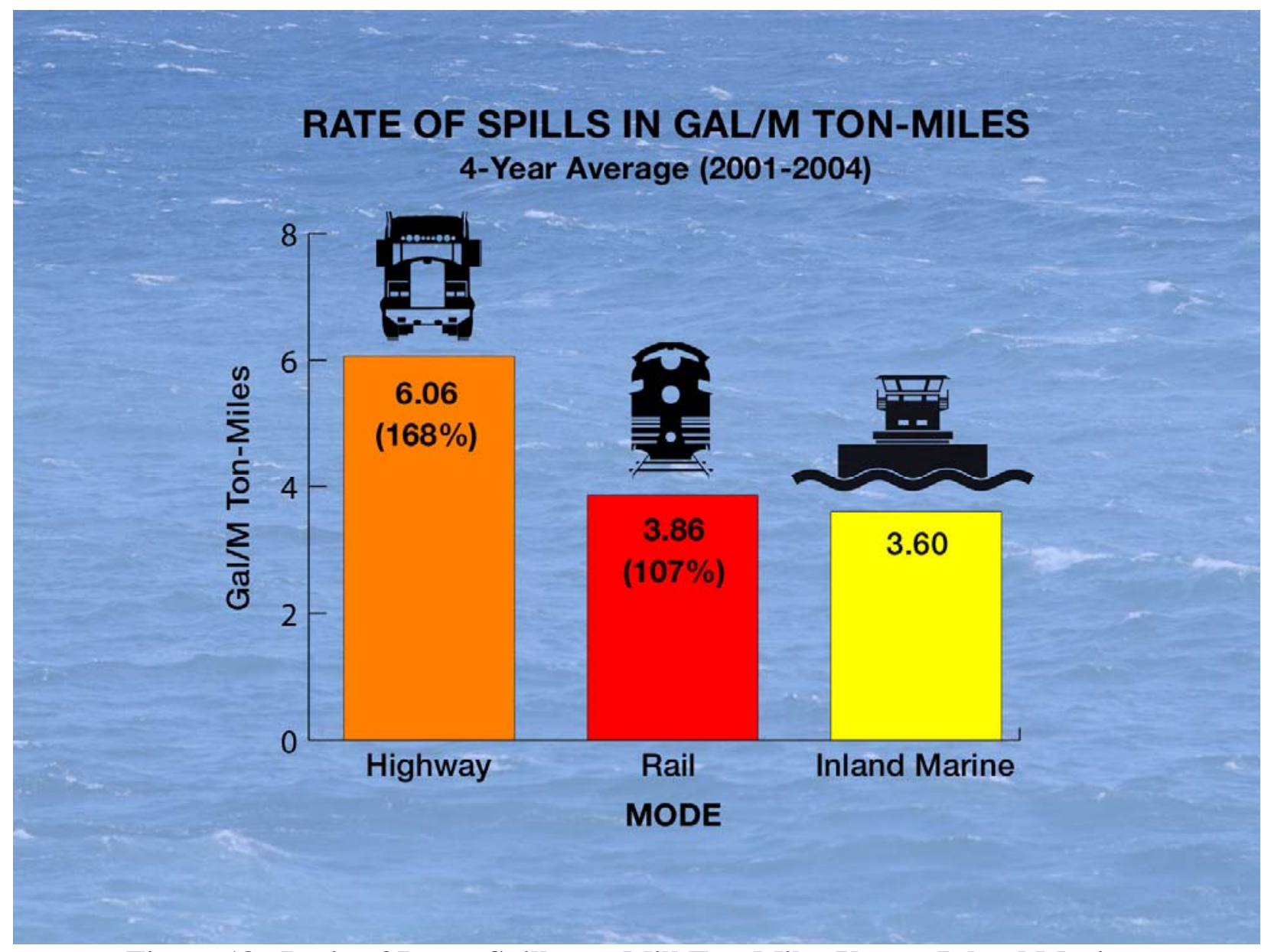

Figure 18. Ratio of Large Spills per Mill Ton-Miles Versus Inland Marine.

Large spills ( $\geq 1,000$ gal) are $97 \%$ of the total volume for waterborne traffic, $96 \%$ for rail, and $85 \%$ for trucks. What the statistics do not show (and this project does not attempt to analyze) is the effect such incidents have on the human population. Because they use infrastructure shared with the general public - infrastructure which has a high utilization rate by the general publicspills from truck and rail incidents almost always pose an immediate threat to the health of human beings. Waterborne transportation, by virtue of the fact that it occurs on a river, rarely poses an immediate threat to human beings, although it may have a detrimental effect on aquatic flora and fauna.

The project team attempted to compare damages from hazardous materials incidents, but the data are extremely unreliable, so this analysis was not performed. 



\section{CHAPTER 7: INFRASTRUCTURE IMPACTS}

The question addressed in this part of the analysis is, "What are the potential impacts to rail and highway infrastructure caused by a hypothetical diversion of waterborne traffic to either mode?"

In order to analyze the advantages of waterborne over surface transportation with respect to infrastructure, the effects of a situation where the waterways are closed and all cargo is forced to move either by rail or truck are evaluated. It is a highly unlikely event, but such an analysis helps emphasize the savings to the nation due to the utilization of waterborne transportation.

\section{PAVEMENT DETERIORATION}

Roadway pavements need to be designed at a level of structural capacity that can withstand the repeated loadings inflicted by heavy trucks. Passenger cars inflict minimal damage to the pavement by comparison. Pavement structural capacity is measured by the Structural Number (SN) and new pavements - which are at "full strength"- have a SN of 4.5-5.0. The useful life of a new pavement is approximately 20 years, at which point the $\mathrm{SN}$ drops to about 2.5 and major rehabilitation is required. The total load expected over the pavement's "lifetime" due to heavy truck traffic is the primary input in calculating the thickness of a new pavement.

Previous chapters have defined the "standard" truck to be used in the event of a waterborne freight diversion as the combination tractor-semitrailer truck with GVWR of 80,000 lbs. Figure 19 shows the axle configuration of this type of truck. There are five axles total, one steering axle, and four remaining axles in pairs, called "tandem axles".

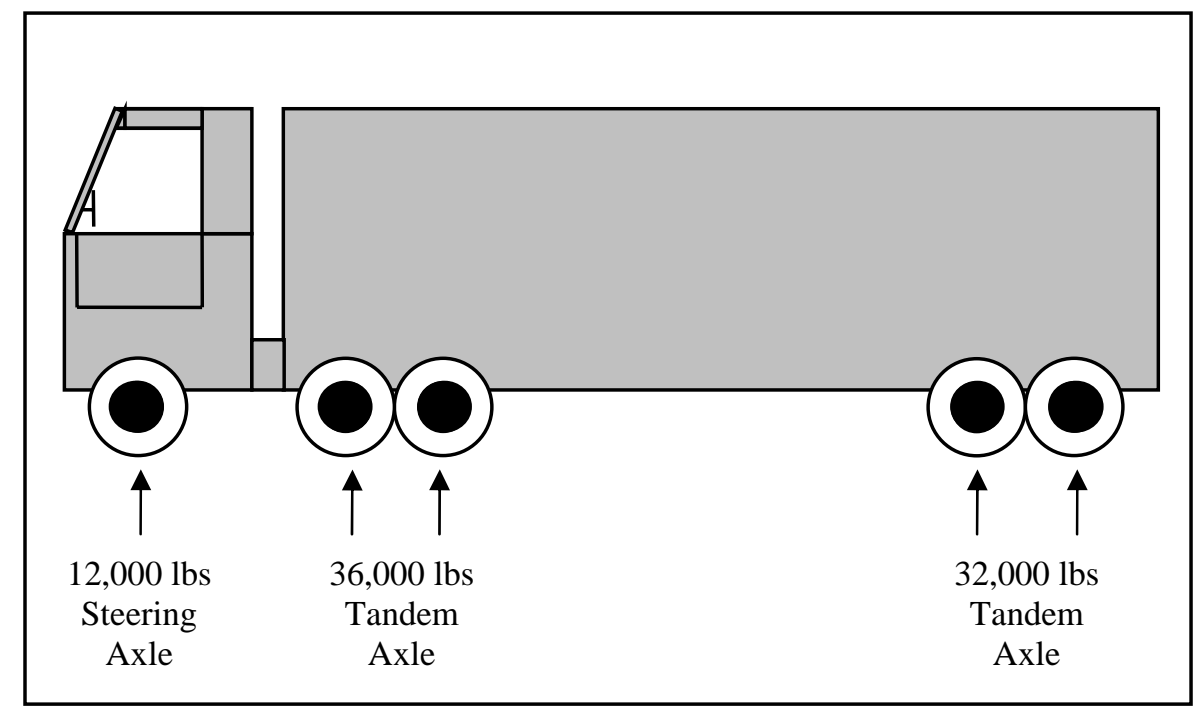

Figure 19. Semitrailer configuration 3-S2: the 18-wheeler.

Tandem axles are closer together and inflict less pavement damage than two single axles further apart. The integrated load a truck exerts on a pavement is estimated by the number of Equivalent 18,000-pound (or 18-kip) Single Axle Loads or ESAL using the Association of State Highway and Transportation Officials (AASHTO) "fourth power" equation. The two equations for 
calculating the ESAL on a flexible (asphalt) pavement due to the weight on a single axle ( $\left.\mathrm{W}_{\text {Single }}\right)$ and due to the weight on a tandem axle ( $\left.\mathrm{W}_{\text {Tandem}}\right)$ respectively are:

$$
E S A L_{\text {Single }}=\left(\frac{W_{\text {Single }}}{18,000 \mathrm{lbs}}\right)^{4} \quad E S A L_{\text {Tandem }}=\left(\frac{W_{\text {Tandem }}}{33,200 \mathrm{lbs}}\right)^{4}
$$

The standard 18-wheeler has one 12,000 lb steering axle, a 36,000 lb tandem axle, and a $32,000 \mathrm{lb}$ tandem axle, so the ESAL it exerts on the asphalt pavement is $2.44 \mathrm{ESAL}$, as shown below:

$$
E S A L_{18-\text { Wheeler }}=\left(\frac{12,000}{18,000}\right)^{4}+\left(\frac{36,000}{33,200}\right)^{4}+\left(\frac{32,000}{33,200}\right)^{4}=2.44
$$

In 2003 there were 5,465 Average Daily Vehicles per Lane on Rural Interstates. Highway Statistics $^{42}$ reports that, in the same year on rural interstates, $16 \%$ of the traffic - or 874 vehicles - were combination trucks, or 18-wheelers. Assuming that no waterborne freight diversion will occur, the annual ESAL would be:

$$
E S A L_{\text {Annual }}=2.44 \times 874 \times 365=0.78 \text { million }
$$

The analysis for congestion impacts estimates that a diversion of waterborne freight to the highway mode would result in a total of 2,034 combination trucks per day per lane of a typical rural interstate, thus the annual ESAL would be:

$$
E S A L_{\text {Annual }}=2.44 \times 2,034 \times 365=1.8 \text { million }
$$

Since the total loadings over the pavement lifetime are to be considered in designing a new pavement, the expected growth in truck traffic over the same period has to be included. At an annual constant percentage growth, $g$, of $2 \%$ and a pavement design lifetime, $N$, of 20 years, the ESAL expected assuming continuation of current conditions would be:

$$
E S A L_{\text {Expected }}=E S A L_{\text {Annual }} \times \frac{(1+g)^{N}-1}{g}=0.78 \text { million } \times \frac{(1+.02)^{20}-1}{0.02}=18.9 \text { million }
$$

Similarly, assuming a waterborne freight diversion occurs, the ESAL expected over a 20-year pavement life would be:

$$
E S A L_{\text {Expected }}=E S A L_{\text {Annual }} \times \frac{(1+g)^{N}-1}{g}=1.8 \text { million } \times \frac{(1+.02)^{20}-1}{0.02}=44.1 \text { million }
$$

\footnotetext{
${ }^{42}$ Federal Highway Administration. Highway Statistics 2005. Section V: Roadway Extent, Characteristics, and Performance. Percentage Distribution of Traffic Volumes and Loadings on the Interstate System, Table TC-3.
} 
A quick comparison of the two calculated values indicates that if a waterborne freight diversion occurs, the ESAL expected over the pavement throughout its 20-year lifetime is more than double (233\%) the ESAL expected under current conditions.

The AASHTO guidelines for pavement design ${ }^{43}$ were then followed to determine the pavement thickness required to accommodate the ESAL expected over the pavement's lifetime, first, assuming continuation of current conditions, and second, that a waterborne freight diversion will occur. Identical values for these remaining required parameters were used to ensure comparison on an equal basis:

- $\quad$ Reliability, R: 90\%

- $\quad$ Standard Deviation $\mathrm{S}_{\mathrm{o}}: 0.35$

- $\quad$ Serviceability Loss, $\Delta$ PSI: 2.0

- $\quad$ Subgrade Strength, $\mathrm{M}_{\mathrm{R}}: 10,000 \mathrm{psi}$

- Asphalt Concrete Elastic Modulus, $\mathrm{E}_{\mathrm{AC}}$ : 380,000 psi

- Asphalt Concrete Surface Course Structural Layer Coefficient, a: 0.41

At the current level of ESAL expected over the pavement throughout the 20 years, the design Structural Number, SN, was found to be 4.6, which is within the range of an SN of 4.5 to 5.0 for a new pavement or a pavement at full strength - one that has undergone major rehabilitation, typically 20 years after construction. In order for clearer comparison to take place, an all-asphalt pavement is assumed, whose required thickness, $d$, in inches, is:

$d=\frac{S N}{a} \quad$ Here, $\quad d=\frac{S N}{a}=\frac{4.6}{0.41}=11.2$ inches

At the level of ESAL assuming freight diversion, the design Structural Number, SN, was found to be 5.3, which is natural since a higher ESAL is expected over the pavement's lifetime. Similarly, in order for clearer comparison to take place, an all-asphalt pavement is assumed, whose required thickness, $d$, in inches, is:

$d=\frac{S N}{a} \quad$ Here, $\quad d=\frac{S N}{a}=\frac{5.3}{0.41}=12.9$ inches

Comparison of the thickness results implies that in the event of a waterborne freight diversion, a flexible pavement on an average rural interstate would require an additional 1.7 inches of asphalt layer in order to adequately withstand the 20-year loadings of combination trucks without requiring premature major rehabilitation (before the 20 years expire). The asphalt thickness addition would occur at the construction stage of a new pavement or as an overlay to an existing pavement so that the pavement strength rises to the required SN of 5.3 and its longevity for the next 20 years is ensured, at which point major rehabilitation will have to be undertaken. Of course if the existing pavement is already worn, the asphalt layer thickness will have to be first brought up to the 11.2 inches, and then up to the 12.9 inches so that it is strong enough to last for the next 20 years.

\footnotetext{
${ }^{43}$ American Association of State Highway Transportation Officials. Guide for Design of Pavement Structures 1993
} and 1998 Supplement. 
In the field, the additional 1.7 inches of asphalt layer calculated above would be rounded to 2 inches, which is also the minimum asphalt overlay thickness typically performed by departments of transportation. Assuming an even truck traffic distribution, a minimum 2 inches thickness of asphalt layer would have to be added to the pavement of 126,000 lane-miles of rural interstate given the higher levels of expected 20-year truck loadings.

\section{Further Highway Infrastructure Impacts}

The system wide impacts to infrastructure

Assuming an even truck traffic distribution, a minimum 2 inch thickness of asphalt layer would have to be added to the pavement of 126,000 lane-miles of rural interstate given the higher levels of expected 20-year truck loadings.

can be put into perspective when it is borne in mind that the rural segments of the interstate system consist of 126,000 lane-miles ${ }^{44}$. In addition, there are 86,000 lane-miles of urban interstate, 350,000 lane-miles of other classes of National Highway System roadways, and 1.8 million lane-miles of other federal-aid highways.

Corridors that are parallel to the major rivers considered would undoubtedly receive a higher concentration of the additional truck traffic, and would be impacted at a higher degree than the national average. This analysis assumed that truck traffic would be equally distributed over all lanes, but in reality this may not be always true. In rural road segments with a low density of entry and exit ramps the outer lane is used by trucks more heavily and the pavement in that lane sustains considerably higher levels of damage than the inner lane.

It is beyond the scope of this analysis to accurately predict, analyze, or associate any monetary cost with other possible infrastructure impacts or improvements that would be required in the event of a waterborne freight diversion to heavy trucks. However, a transportation engineer Higher levels of heavy truck traffic typically require significant capital expenditure on bridges, ramps, highway geometric features such as horizontal and vertical curves and shoulders, truck stops, weigh stations, signage, etc., as well as higher routine maintenance costs. can safely rely on past trends and experience to argue that these would include improvements in the form of capital expenditures on new construction of infrastructure and facilities such as bridges, ramps, highway geometric features such as horizontal and vertical curves and shoulders, truck stops, service stations, rest areas, weigh stations, and signage. In addition, routine maintenance costs associated with the new infrastructure as well as with the existing, which would be used more heavily, would likely be significantly higher.

\section{RAILROAD INFRASTRUCTURE IMPACTS}

The shift of the inland waterways freight to the existing railroads would impact the individual railroads at substantially different levels. Although a detailed economic analysis of costs to the railroads of the modal shift of all the inland waterway freight is beyond the scope of this analysis, a closer look at the previous rail impact example discussed in Chapter 3 can provide

\footnotetext{
44 Federal Highway Administration. Highway Statistics 2005. Section V: Roadway Extent, Characteristics, and Performance. Federal Aid Highway Lane Length, Lane-Miles by System. Table HM-48. October 2006.
} 
further indication of what the railroads could be expected to encounter with the possible closure of individual water transportation segments or entire routes.

CSX currently delivers coal to electric generating plants located along or in the near vicinity of the Ohio River. Consequently, the CSX Ohio River route track has some amount of dedicated coal train traffic. (See Figure 20.) If, in the example of the Ohio River closure, the CSX railroad were tasked with the transportation of the entire coal tonnage of the river, the probable initial outcome would be electric brownouts and interrupted manufacturing output.

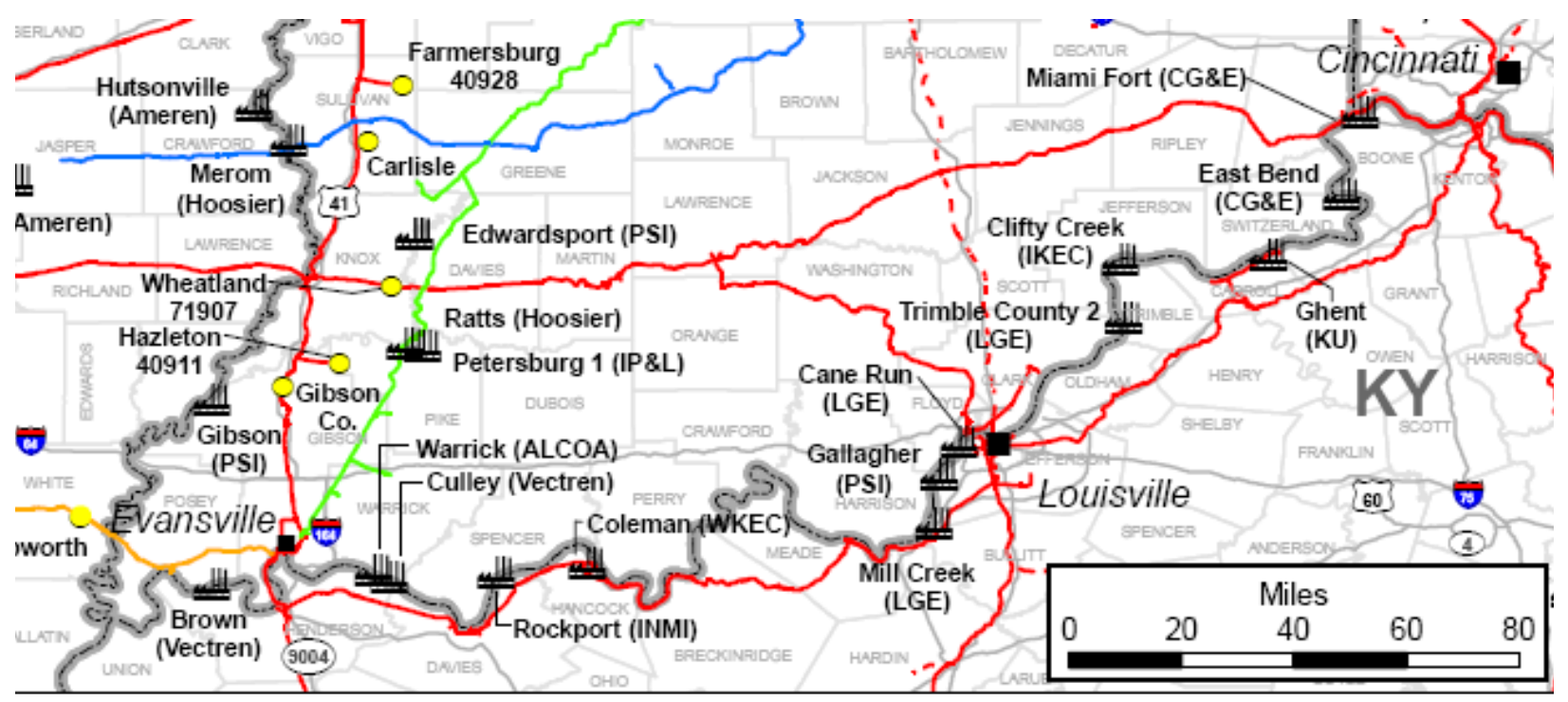

Figure 20. CSX map section for Indiana and Illinois along the Ohio River illustrating the CSX railroad tracks and coal powered electric generating plants. ${ }^{45}$

The Ohio River coal that is transported by barge is principally destined for the electric generation market along the river. The capacity requirements, in excess of one million railroad car loadings per year, could not be immediately met because there are not enough coal cars available to meet the initial demand for the increased transportation. The first impact therefore would be the need to provide rail cars for the coal. Since there is little if any excess coal car capacity, large car orders would need to be negotiated. Potentially all the rail car manufacturing capacity would be required to meet the initial car demand requirement. An estimation of a typical unit coal car cost is approximately $\$ 48,000$ each.

Additional dedicated locomotives would also be required to be added to operate the new coal trains as coal cars are delivered to the system. Typical locomotive costs are estimated to be $\$ 2,000,000$ each.

The number of rail cars needed can be estimated by making a few assumptions. First, the cycle time for the typical river diverted traffic to a coal train might only be two days from the coal mine to the utility and returning to the mine. However, since all train traffic may be assumed to

\footnotetext{
${ }^{45}$ CSX Railroad Coal Rate District map, Illinois and Indiana coal rate district. http://www.csx.com/share/customers/co_locations/docs/Illinois_and_Indiana-REF22631.pdf
} 
be much slower because of the large amount of new traffic, existing coal trains sharing the affected routes would also have their cycle times increased, or, in other words, the existing coal trains using the route would be slowed down. A requirement of 1,010,250 coal loadings using 108 car unit trains will require 9,354 unit train initiations per year. Considering that each train requires two days per trip and there are only 365 days in the year, each train can only make 182.5 trips per year. Dividing the number of train initiations by the number of train trips per year for each additional train set, the minimum number of new train sets to meet the demand is 51.25 train sets. It is assumed any partial train set must be added as a whole train set and so there will need to be 52 train sets.

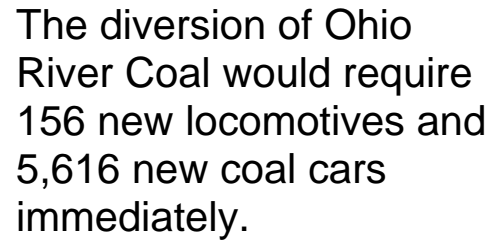

Typical coal trains of 100 or more loaded coal cars require three locomotives to operate safely and efficiently. A conservative estimate of 156 new locomotives would be needed to provide power for the new trains. The total number of new cars needed to meet the requirements for 52 new train sets is 5,616. The price tag for 156 new locomotives at a unit cost of \$2,000,000 each is $\$ 312,000,000$. At a unit cost of $\$ 48,000$ each, the 5,616 new coal cars will cost $\$ 269,568,000$. Together, the minimum equipment cost would be $\$ 581,568,000$.

Many regulatory issues, operating concerns, and constraints are excluded from this example; for instance, the fact that every locomotive is required by regulation to have a substantial inspection four times each year is not considered in this example. The typical downtime for a scheduled 92day locomotive inspection would be one day, where one day is the equivalent of one work shift. The inspection could easily take less time; however, if there were any unexpected events requiring extra shop time for minor repairs, the inspection event could exceed a 24-hour time period.

Referring to the example in Chapter 3, the system average train speed for the CSX system could go from approximately $19 \mathrm{mph}$ down to less than $13 \mathrm{mph}$, or a decrease in system velocity of close to $45 \%$. While it would be unreasonable to assume that all coal traffic on the CSX system would be impacted with a decrease in cycle times equal to the estimated system velocity reduction of $45 \%$, it is not unreasonable to assume that if an increase in cycle time of $20 \%$ were to occur for existing traffic, the existing coal delivery traffic would require additional train sets to meet their current demand. Additional train sets would need to be added in order to recover the reduced train trip Diversion of river traffic could be expected to cause:

- Increased demand for rail cars and locomotives

- Higher freight rates

- Need to expand infrastructure (rail lines)

- Slower and less reliable delivery times efficiency from adding so many new train sets to this single route.

Because the current track capacity and train density along the CSX Ohio River route are unknown, it cannot be assumed that the addition of 52 additional train sets would introduce gridlock on the route. However, it can be assumed that the addition of 52 train sets would severely limit the operational efficiency of all trains on the route. 
This is only one example of what might happen if any of the waterways were to be shut down. Regions outside the area discussed above might experience a more severe or less severe impact on rail operations, but the above illustration points out several effects that could be expected in almost every case:

- Increased demand for rail cars and locomotives

- Higher freight rates

- $\quad$ Need to expand infrastructure (rail lines)

- $\quad$ Potentially slower and less reliable delivery times

- Increased motor vehicle congestion at rail crossings

- Increased noise abatement issues 



\section{CHAPTER 8: A CASE STUDY - ST. LOUIS, MO}

\section{INTRODUCTION}

This chapter uses a model developed by the Federal Highway Administration to estimate the impacts on highway traffic that would accrue in the event of a closure of the Illinois and Mississippi Rivers in the vicinity of St. Louis, Missouri. This model, known as "HERS-ST" is a very detailed and complicated model, typically used by traffic engineers for planning and budgeting purposes. The inputs and outputs are described - to the degree possible-in lay terms in this chapter.

Table 26 at the end of this chapter summarizes the impacts of a diversion of all waterborne traffic to the highways that are of most concern to the general public. The impacts are calculated as of 10 years after the waterway closure. The average speed on I-55 and I-255 will decrease by 6-11\% during peak hours and up to 7\% in off-peak hours. Hours of delay will be almost five times greater. Crashes, injuries, and fatalities will all rise by 36-45\%. Emissions costs will rise by $37-52 \%$.

\section{HERS-ST OVERVIEW}

The Highway Economic Requirements System-State Version (HERS-ST) ${ }^{46}$ is a highway investment/performance software model that operates on a personal computer. It considers engineering and economic concepts and principles in determining the impact of alternative highway investment levels and program structures on highway condition, performance, and user impacts. HERS-ST offers a range of capabilities and potential uses. For example, HERS-ST can be used in program development, in "needs" analysis, and in establishing performance objectives. HERS-ST was developed by the Federal Highway Administration (FHWA) and is based on the Highway Economic Requirements System (HERS), which was also developed by the FHWA Office of Policy in order to bring economic principles and measures into its analyses of highway investment. The HERS model is used to estimate future investment requirements for pavement preservation and system expansion in the biannual Status of the Nation's Highways, Bridges, and Transit: Conditions and Performance Report to Congress (C\&P Report). (The latest report is the 2006 edition, which is the seventh in the series that combines information on the nation's highway and transit systems.)

HERS-ST estimates the investment required to achieve certain highway system performance levels. With the information produced from the analysis results, reports can then be generated using four different types of document formats - tables, reports, charts, or maps. One of several analytical scenarios provided by HERS-ST can be selected and then tailored by selecting from an array of values and parameters defined by the user. The analytical procedure relies on a database of records in the Highway Performance Monitoring System (HPMS) sample data format. This database supplies information regarding the highway system, particularly its current condition and performance. The analytical procedure involves identifying highway deficiencies and

\footnotetext{
${ }^{46}$ U.S. Department of Transportation. Federal Highway Administration. HERS-ST User’s Guide Software Version 4.X. March 2007.
} 
candidate improvements based on engineering standards. Finally, the analytical procedure selects the most economically worthwhile improvement projects according to economic criteria and scenario specifications provided by the user. The HERS-ST software is primarily intended for use by state or local Department of Transportation (DOT) officials who have a general understanding of the engineering and economic principles underlying highway decision-making activities, as well as access to their State’s HPMS data, the primary data input.

The HERS-ST application allows for the evaluation of three general types of scenarios, which can be used for answering three specific questions:

- What level of spending is required to achieve an economically optimal program structure that implements all economically worthwhile projects?

- What user cost/condition/performance level will result from a given spending level?

- What level of spending is required to achieve a certain user cost level?

The general scenarios may be tailored by providing various input values such as the discount rate and deficiency levels. The default value for the overall length of the analysis period is 20 years, divided into four funding periods of five years each, but can be otherwise defined by the user. HERS-ST offers four primary types of analyses:

- Minimum BCR: Select for implementation all improvements with minimum benefit-tocost ratios (BCR) exceeding a specified threshold

- Constraint by Funds: Maximize benefits as constrained by available funds

- $\quad$ Constraint by Performance: Maximize return on investment as constrained by performance

- Full Engineering Needs Analysis: Identify and correct all deficiencies

This case study analysis utilized the Minimum BCR and the Constraint by Funds types of analyses. The Minimum BCR analysis works on the premise of implementing all improvements with BCRs greater than a defined threshold value. The user must specify the minimum acceptable BCR for any implemented improvement. The Minimum BCR analysis addresses the following questions:

- What improvements exceed a specified minimum BCR?

- What level of investment would meet this BCR threshold?

- What will be the condition and performance of the highway system after investing at this level?

With the minimum BCR set to 1.0, HERS-ST will implement all cost-beneficial improvements. In doing so, it defines the upper limit of highway investment and maximum improvement in conditions and performance that could be economically justified. The FHWA calls this approach the Maximum Economic Investment scenario, which is used to help estimate the Cost to Improve Highways investment scenario in the Conditions and Performance (C\&P) Report.

A minimum BCR analysis can also be used to define the cost of implementing the most economically attractive set of improvements that would meet a particular benchmark or goal, by iteratively changing the BCR threshold until the target is reached. For example, FHWA uses this approach to define the Cost to Maintain Highways scenario in the C\&P Report, adjusting the 
BCR threshold until average highway user costs at the end of the 20-year analysis period match those in the base year.

The Constraint by Funds analysis functions on the premise of maximizing the net present value of the benefits of improvements subject to specified constraints on funds available during each funding period, as specified by the user. The Constraint by Funds analysis addresses the following questions:

- How many improvements can be implemented at the specified level?

- What level of system condition and performance can be obtained when the improvements are implemented?

During each funding period, the model identifies potential improvements, and ranks them by BCR. After examining all sections, the model selects the most economically attractive improvements in order, until the available funds are expended or no economically justifiable candidate improvements remain.

\section{A CASE STUDY: ST. LOUIS, MO}

The HERS-ST software was utilized to evaluate and assess the impacts on roadway infrastructure, capacity, and public investment in the event of a hypothetical diversion of $100 \%$ of waterway freight to combination trucks. This case study is based on the metropolitan area surrounding St. Louis, Missouri for a variety of reasons:

- It is located along the Mississippi main stem at the confluence of the mouths of the Missouri and Illinois rivers.

- It is located at the intersection of several primary East-West and North-South interstate truck routes.

- It is the major truck highway bottleneck location along the Mississippi as seen in the figures in the congestion impacts analysis.

- The counties containing the St. Louis Missouri-Illinois metropolitan area have been designated "Nonattainment" or "Moderate" by the EPA for Clean Air Act's National Ambient Air Quality Standards (NAAQS) primarily for eight-hour Ozone and PM-2.5. Table 16 details the counties, pollutants, and respective classification standards of the most recent designations per the EPA's "Green Book"

\footnotetext{
${ }^{47}$ U.S. Environmental Protection Agency. The Green Book: Nonattainment Areas for Criteria Pollutants. http://www.epa.gov/air/oaqps/greenbk/index.html, accessed September 2007.
} 
Table 16. St. Louis Nonattainment Areas.

\begin{tabular}{|c|c|c|c|c|}
\hline \multirow{2}{*}{ State } & \multirow{2}{*}{ County } & \multicolumn{3}{|c|}{ Pollutant \& Classification Standard } \\
\hline & & 8-Hr Ozone & PM-2.5 & Lead \\
\hline \multirow{4}{*}{ MO } & Franklin & M & $\mathrm{N}$ & \multirow{4}{*}{ (part) } \\
\hline & Jefferson & M & $\mathrm{N}$ & \\
\hline & St Charles & M & $\mathrm{N}$ & \\
\hline & St Louis & M & $\mathrm{N}$ & \\
\hline \multirow{5}{*}{ IL } & Jersey & M & & \\
\hline & Madison & M & $\mathrm{N}$ & \\
\hline & Monroe & M & $\mathrm{N}$ & \\
\hline & Randolph & & $\mathrm{N}$ & \\
\hline & St Clair & M & $\mathrm{N}$ & \\
\hline \multicolumn{5}{|c|}{ M=Moderate (less severe) } \\
\hline
\end{tabular}

Source: U.S. Environmental Protection Agency. The Green Book: Nonattainment Areas for Criteria Pollutants

Figure 21 shows a map of the latest EPA nonattainment county designations in the St. Louis MO-IL area as well as the urban interstate links, focusing on I-55 and I-255. 


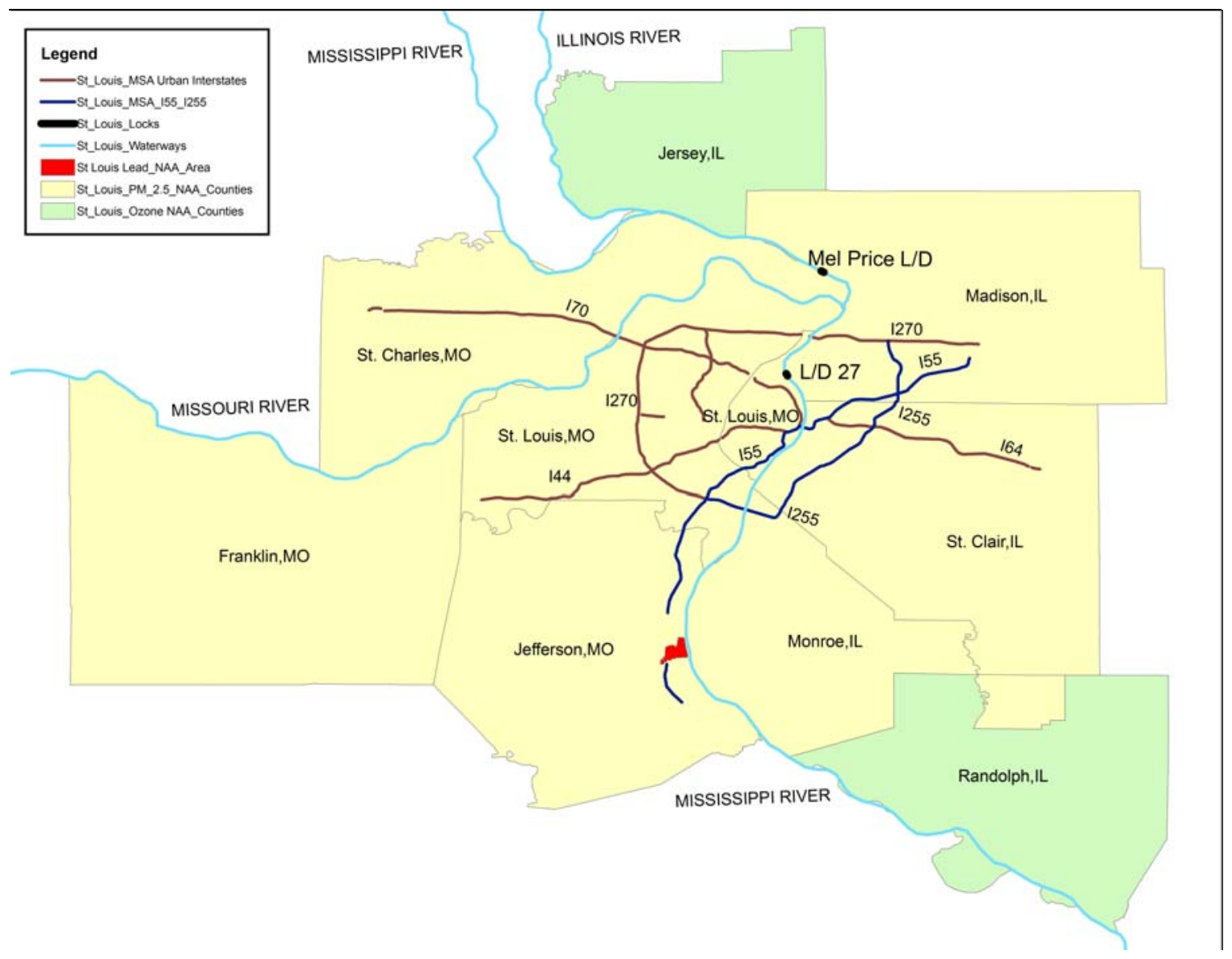

Figure 21. St. Louis Nonattainment/Maintenance Area.

There are two locks on the Mississippi river within the nonattainment area of St. Louis: Melvin Price Lock and Dam, and Lock and Dam 27. Data for the tons locked by each in 2005 were obtained from the U.S. Army Corps of Engineers' Waterborne Commerce of the U.S., also used previously in this study. The equivalent daily truck traffic that would have to traverse the area in the event of a theoretical freight diversion from barges to trucks was calculated in a manner similar to the analysis for the congestion impacts. The data and calculation results are shown in Table 17. Diversion of barge tonnage would add 14,780 combination trucks to the Average Annual Daily Traffic (AADT) through the St. Louis nonattainment area. 
Table 17. St. Louis Lock Tonnage and Truck Traffic Equivalent.

\begin{tabular}{|c|c|c|c|c|}
\hline \multirow{2}{*}{$\begin{array}{c}\text { St.Louis MSA } \\
\text { Locks }\end{array}$} & Downstream & Upstream & Total Annual & Total Daily** \\
\cline { 2 - 5 } & $37,519,226$ & $28,993,864$ & $66,513,090$ & 182,228 \\
Melvin Price & Tons Locked 2005* & 187,262 \\
\hline L/D 27 & $39,682,706$ & $28,668,091$ & $68,350,797$ & 184,745 \\
\hline \multicolumn{4}{|c|}{ Average Daily Tons } & 7,390 \\
Average Daily 25-ton Combination Trucks & 7,390 \\
\hline Average Daily Empty Backhaul Trucks \\
Additional Average Daily Combination Trucks & 14,780 \\
*U.S. Army Corps of Engineers. Navigation Data Center. Waterborne \\
Commerce of the United States 2005 \\
** Assumes 365 days/year
\end{tabular}

The Mississippi river runs in a North-South direction, so it is logical to assume that any freight diversion from barges to trucks would also occur in the same direction. Therefore the AADT along I-55 and I-255, as seen in the map, would increase by an average of 14,780 vehicles per day, all of which would be combination trucks.

The reader should keep in mind that the assumptions and constraints detailed earlier in this report also pertain to this case study. These assumptions are imperative due to the "what if" nature of this analysis.

Data for 24 urban sections of I-55 and I-255 located within the St. Louis MO-IL nonattainment area were filtered from the 2005 Highway Performance Monitoring System sample section data into a Microsoft Excel file named "Current". The original dataset included current highway conditions as well as future forecasts of the AADT in year 2025. In other words this file served as the "as-is" or "control" case by assuming that no waterborne freight diversion will occur and current conditions will continue.

A second highway data file, named "Diversion" was created, which reflected the additional 14,780 combination trucks to the AADT of the 24 sections, and subsequent data modifications to the pertinent fields. The highway data in this file assume that diversion has occurred, and the 2025 AADT projections were adjusted accordingly.

Table 18 shows selected highway data fields of the HPMS, denoted by an asterisk, and their values in the Current file. The table also shows the results of subsequent calculations based on the reported values of the respective field(s). These calculations were conducted in order to determine the new values for these same fields that were input to the Diversion highway data file, shown in Table 19. Any discrepancies are attributable to rounding. 
Table 18. Current Highway Data.

\begin{tabular}{|c|c|c|c|c|c|c|c|c|c|c|c|c|c|c|c|}
\hline \multirow{2}{*}{ Section } & \multirow{2}{*}{ Interstate } & \multirow{2}{*}{ AADT* } & \multirow{2}{*}{ K-Factor* } & \multirow{2}{*}{ PHV } & \multicolumn{2}{|c|}{\begin{tabular}{|c|} 
Average Daily Single \\
Unit Trucks \\
\end{tabular}} & \multicolumn{2}{|c|}{$\begin{array}{l}\text { Average Peak Hour } \\
\text { Single Unit Trucks }\end{array}$} & \multicolumn{2}{|c|}{$\begin{array}{c}\text { Average Daily } \\
\text { Combination Trucks } \\
\end{array}$} & \multicolumn{2}{|c|}{$\begin{array}{l}\text { Average Peak Hour } \\
\text { Combination Trucks }\end{array}$} & \multirow{2}{*}{$\begin{array}{c}\text { \% Daily CTs } \\
\text { in Peak Hour } \\
\text { (Constant) }\end{array}$} & \multirow[t]{2}{*}{ V/SF* } & \multirow{2}{*}{$\begin{array}{c}\text { Future } \\
\text { AADT } \\
(2025)^{*}\end{array}$} \\
\hline & & & & & \% AADT* & Number & \% PHV* & Number & $\%$ AADT* & Number & \% PHV* & Number & & & \\
\hline 1 & 55 & 49,400 & 10 & 4,940 & 4 & 1,976 & 2 & 99 & 18 & 8,892 & 5 & 247 & 3 & 0.57 & 70,000 \\
\hline 2 & 55 & 49,400 & 10 & 4,940 & 4 & 1,976 & 2 & 99 & 18 & 8,892 & 5 & 247 & 3 & 0.57 & 70,000 \\
\hline 3 & 55 & 39,400 & 10 & 3,940 & 4 & 1,576 & 3 & 118 & 22 & 8,668 & 9 & 355 & 4 & 0.70 & 58,000 \\
\hline 4 & 55 & 39,400 & 10 & 3,940 & 4 & 1,576 & 3 & 118 & 22 & 8,668 & 9 & 355 & 4 & 0.70 & 58,000 \\
\hline 5 & 55 & 38,600 & 10 & 3,860 & 4 & 1,544 & 4 & 154 & 22 & 8,492 & 13 & 502 & 6 & 0.70 & 57,000 \\
\hline 6 & 55 & 38,600 & 10 & 3,860 & 4 & 1,544 & 4 & 154 & 22 & 8,492 & 13 & 502 & 6 & 0.60 & 57,000 \\
\hline 7 & 55 & 57,500 & 9 & 5,175 & 4 & 2,300 & 2 & 104 & 10 & 5,750 & 6 & 311 & 5 & 0.84 & 87,500 \\
\hline 8 & 55 & 93,300 & 9 & 8,397 & 4 & 3,732 & 2 & 168 & 14 & 13,062 & 6 & 504 & 4 & 0.96 & 129,500 \\
\hline 9 & 55 & 126,200 & 9 & 11,358 & 4 & 5,048 & 2 & 227 & 12 & 15,144 & 8 & 909 & 6 & 0.73 & 166,500 \\
\hline 10 & 55 & 68,800 & 9 & 6,192 & 4 & 2,752 & 2 & 124 & 13 & 8,944 & 5 & 310 & 3 & 0.66 & 87,200 \\
\hline 11 & 55 & 68,800 & 9 & 6,192 & 4 & 2,752 & 2 & 124 & 13 & 8,944 & 5 & 310 & 3 & 0.66 & 88,800 \\
\hline 12 & 55 & 68,800 & 9 & 6,192 & 4 & 2,752 & 2 & 124 & 13 & 8,944 & 5 & 310 & 3 & 0.53 & 88,800 \\
\hline 13 & 55 & 53,398 & 9 & 4,806 & 4 & 2,136 & 2 & 96 & 15 & 8,010 & 5 & 240 & 3 & 0.55 & 88,800 \\
\hline 14 & 55 & 97,422 & 11 & 10,716 & 6 & 5,845 & 6 & 643 & 12 & 11,691 & 12 & 1,286 & 11 & 0.55 & 118,757 \\
\hline 15 & 55 & 59,570 & 12 & 7,148 & 5 & 2,979 & 5 & 357 & 11 & 6,553 & 11 & 786 & 12 & 0.94 & 72,616 \\
\hline 16 & 55 & 45,388 & 8 & 3,631 & 4 & 1,816 & 4 & 145 & 26 & 11,801 & 26 & 944 & 8 & 0.50 & 55,328 \\
\hline 17 & 55 & 36,660 & 17 & 6,232 & 6 & 2,200 & 6 & 374 & 12 & 4,399 & 12 & 748 & 17 & 0.81 & 44,689 \\
\hline 18 & 55 & 27,506 & 17 & 4,676 & 6 & 1,650 & 6 & 281 & 12 & 3,301 & 12 & 561 & 17 & 0.61 & 33,530 \\
\hline 19 & 55 & 113,002 & 13 & 14,690 & 6 & 6,780 & 6 & 881 & 12 & 13,560 & 12 & 1,763 & 13 & 0.75 & 137,749 \\
\hline 20 & 255 & 42,200 & 9 & 3,798 & 5 & 2,110 & 2 & 76 & 12 & 5,064 & 7 & 266 & 5 & 0.35 & 53,500 \\
\hline 21 & 255 & 31,800 & 9 & 2,862 & 5 & 1,590 & 3 & 86 & 16 & 5,088 & 13 & 372 & 7 & 0.27 & 38,000 \\
\hline 22 & 255 & 43,400 & 9 & 3,906 & 3 & 1,302 & 2 & 78 & 13 & 5,642 & 6 & 234 & 4 & 0.36 & 49,300 \\
\hline 23 & 255 & 76,812 & 12 & 9,217 & 5 & 3,841 & 5 & 461 & 7 & 5,377 & 7 & 645 & 12 & 0.61 & 93,634 \\
\hline 24 & 55 & 92,334 & 13 & 12,003 & 5 & 4,617 & 5 & 600 & 7 & 6,463 & 7 & 840 & 13 & 0.75 & 112,555 \\
\hline \multicolumn{6}{|c|}{$\begin{array}{l}\text { *HPMS Current Data } \\
\text { AADT=Average Annual Daily Traffic, vehicles per day } \\
\text { PHV=AADT*K=Peak Hour Volume, vehicles per hour } \\
\text { VHT=Vehicle Hours of Travel }\end{array}$} & $\begin{array}{l}\text { K-Factor=I } \\
\text { V/SF=Volu } \\
\text { D=Directio } \\
\text { VMT=Veh }\end{array}$ & $\begin{array}{l}\text { esign Houl } \\
\text { me to Servic } \\
\text { nal Distribu } \\
\text { cle Miles of }\end{array}$ & $\begin{array}{l}\text { (taken her } \\
\text { e Flow Rat } \\
\text { ion; \% PH } \\
\text { Travel }\end{array}$ & $\begin{array}{l}\text { e to mean the } \\
\text { io = AADT* } \\
\text { V in peak dir }\end{array}$ & $\begin{array}{l}\text { Peak Hou } \\
\mathrm{K}^{*} \mathrm{D} / \text { Peak } \\
\text { ection }\end{array}$ & $\begin{array}{l}\text { r) Volume a } \\
\text { Capacity }\end{array}$ & a percent & of AADT & & \\
\hline
\end{tabular}


Table 19. Diversion Highway Data.

\begin{tabular}{|c|c|c|c|c|c|c|c|c|c|c|c|c|c|c|c|c|c|c|}
\hline \multirow[t]{2}{*}{ Section } & \multirow{2}{*}{ Interstate } & \multirow{2}{*}{$\begin{array}{c}\text { Added } \\
\text { Daily CTs }\end{array}$} & \multirow[t]{2}{*}{ AADT* } & \multicolumn{2}{|c|}{$\begin{array}{c}\text { Average Daily } \\
\text { Combination Trucks }\end{array}$} & \multirow{2}{*}{\begin{tabular}{|c|} 
Added \\
Peak Hour \\
CTs
\end{tabular}} & \multirow[t]{2}{*}{ PHV } & \multicolumn{2}{|c|}{$\begin{array}{l}\text { Average Peak Hour } \\
\text { Combination Trucks }\end{array}$} & \multicolumn{2}{|c|}{\begin{tabular}{|c|} 
Average Daily Single \\
Unit Trucks
\end{tabular}} & \multicolumn{2}{|c|}{\begin{tabular}{|c|} 
Average Peak \\
Hour Single Unit \\
\end{tabular}} & \multirow{2}{*}{\begin{tabular}{|c} 
K- \\
Factor* \\
$(\%)$ \\
\end{tabular}} & \multirow[t]{2}{*}{ D (\%) } & \multirow{2}{*}{$\begin{array}{c}\text { Capacity } \\
\text { (vph) }\end{array}$} & \multirow[t]{2}{*}{ V/SF* } & \multirow{2}{*}{\begin{tabular}{|c|} 
Future \\
AADT \\
$(2025)^{*}$ \\
\end{tabular}} \\
\hline & & & & Number & $\%$ AADT* & & & Number & \% PHV* & \begin{tabular}{|l|} 
Number \\
\end{tabular} & $\%$ AADT* & \begin{tabular}{|l|} 
Number \\
\end{tabular} & $\%$ PHV* & & & & & \\
\hline 1 & 55 & 14,780 & 64,180 & 23,672 & 37 & 411 & 5,351 & 658 & 12 & 1,976 & 3 & 99 & 2 & 8 & 70 & 6,138 & 0.61 & 84,096 \\
\hline 2 & 55 & 14,780 & 64,180 & 23,672 & 37 & 411 & 5,351 & 658 & 12 & 1,976 & 3 & 99 & 2 & 8 & 70 & 6,099 & 0.61 & 84,096 \\
\hline 3 & 55 & 14,780 & 54,180 & 23,448 & 43 & 605 & 4,545 & 959 & 21 & 1,576 & 3 & 118 & 3 & 8 & 70 & 3,970 & 0.80 & 71,799 \\
\hline 4 & 55 & 14,780 & 54,180 & 23,448 & 43 & 605 & 4,545 & 959 & 21 & 1,576 & 3 & 118 & 3 & 8 & 70 & 3,970 & 0.80 & 71,799 \\
\hline 5 & 55 & 14,780 & 53,380 & 23,272 & 44 & 873 & 4,733 & 1,375 & 29 & 1,544 & 3 & 154 & 3 & 9 & 70 & 3,878 & 0.85 & 70,815 \\
\hline 6 & 55 & 14,780 & 53,380 & 23,272 & 44 & 873 & 4,733 & 1,375 & 29 & 1,544 & 3 & 154 & 3 & 9 & 60 & 3,878 & 0.73 & 70,815 \\
\hline 7 & 55 & 14,780 & 72,280 & 20,530 & 28 & 798 & 5,973 & 1,109 & 19 & 2,300 & 3 & 104 & 2 & 8 & 65 & 4,046 & 0.96 & 94,057 \\
\hline 8 & 55 & 14,780 & 108,080 & 27,842 & 26 & 570 & 8,967 & 1,074 & 12 & 3,732 & 3 & 168 & 2 & 8 & 70 & 6,156 & 1.02 & 138,080 \\
\hline 9 & 55 & 14,780 & 140,980 & 29,924 & 21 & 887 & 12,245 & 1,795 & 15 & 5,048 & 4 & 227 & 2 & 9 & 65 & 10,148 & 0.78 & 178,537 \\
\hline 10 & 55 & 14,780 & 83,580 & 23,724 & 28 & 512 & 6,704 & 821 & 12 & 2,752 & 3 & 124 & 2 & 8 & 65 & 6,138 & 0.71 & 107,952 \\
\hline 11 & 55 & 14,780 & 83,580 & 23,724 & 28 & 512 & 6,704 & 821 & 12 & 2,752 & 3 & 124 & 2 & 8 & 65 & 6,138 & 0.71 & 107,952 \\
\hline 12 & 55 & 14,780 & 83,580 & 23,724 & 28 & 512 & 6,704 & 821 & 12 & 2,752 & 3 & 124 & 2 & 8 & 70 & 8,184 & 0.57 & 107,952 \\
\hline 13 & 55 & 14,780 & 68,178 & 22,790 & 33 & 443 & 5,249 & 684 & 13 & 2,136 & 3 & 96 & 2 & 8 & 70 & 6,138 & 0.60 & 89,012 \\
\hline 14 & 55 & 14,780 & 112,202 & 26,471 & 24 & 1,626 & 12,342 & 2,912 & 24 & 5,845 & 5 & 643 & 5 & 11 & 50 & 9,838 & 0.63 & 143,149 \\
\hline 15 & 55 & 14,780 & 74,350 & 21,333 & 29 & 1,774 & 8,922 & 2,560 & 29 & 2,979 & 4 & 357 & 4 & 12 & 50 & 3,839 & 1.16 & 96,602 \\
\hline 16 & 55 & 14,780 & 60,168 & 26,581 & 44 & 1,182 & 4,813 & 2,126 & 44 & 1,816 & 3 & 145 & 3 & 8 & 50 & 3,670 & 0.66 & 79,163 \\
\hline 17 & 55 & 14,780 & 51,440 & 19,179 & 37 & 2,513 & 8,745 & 3,260 & 37 & 2,200 & 4 & 374 & 4 & 17 & 50 & 3,872 & 1.13 & 68,430 \\
\hline 18 & 55 & 14,780 & 42,286 & 18,081 & 43 & 2,513 & 7,189 & 3,074 & 43 & 1,650 & 4 & 281 & 4 & 17 & 50 & 3,872 & 0.93 & 57,173 \\
\hline 19 & 55 & 14,780 & 127,782 & 28,340 & 22 & 1,921 & 16,612 & 3,684 & 22 & 6,780 & 5 & 881 & 5 & 13 & 50 & 9,838 & 0.84 & 162,308 \\
\hline 20 & 255 & 14,780 & 56,980 & 19,844 & 35 & 776 & 4,574 & 1,042 & 23 & 2,110 & 4 & 76 & 2 & 8 & 55 & 6,079 & 0.41 & 75,242 \\
\hline 21 & 255 & 14,780 & 46,580 & 19,868 & 43 & 1,081 & 3,943 & 1,453 & 37 & 1,590 & 3 & 86 & 2 & 8 & 55 & 5,882 & 0.37 & 62,453 \\
\hline 22 & 255 & 14,780 & 58,180 & 20,422 & 35 & 614 & 4,520 & 848 & 19 & 1,302 & 2 & 78 & 2 & 8 & 55 & 6,108 & 0.41 & 76,718 \\
\hline 23 & 255 & 14,780 & 91,592 & 20,157 & 22 & 1,774 & 10,991 & 2,419 & 22 & 3,841 & 4 & 461 & 4 & 12 & 53 & 8,042 & 0.72 & 117,805 \\
\hline 24 & 55 & 14,780 & 107,114 & 21,243 & 20 & 1,921 & 13,925 & 2,762 & 20 & 4,617 & 4 & 600 & 4 & 13 & 50 & 8,042 & 0.87 & 136,892 \\
\hline \multicolumn{6}{|c|}{ *HPMS New Data } & \multicolumn{13}{|c|}{ K-Factor=Design Hour (taken here to mean the Peak Hour) Volume as \% of AADT } \\
\hline \multirow{2}{*}{\multicolumn{6}{|c|}{$\begin{array}{l}\text { AADT=Average Annual Daily Traffic, vehicles per day } \\
\text { PHV=AADT*K=Peak Hour Volume, vehicles per hour }\end{array}$}} & \multirow{2}{*}{\multicolumn{13}{|c|}{$\begin{array}{l}\text { V/SF=Volume to Service Flow Ratio = AADT*K*D/Peak Capacity } \\
\mathrm{D}=\text { Directional Distribution; \% PHV in peak direction }\end{array}$}} \\
\hline & & & & & & & & & & & & & & & & & & \\
\hline \multicolumn{6}{|c|}{ VHT=Vehicle Hours of Travel } & \multicolumn{13}{|c|}{ VMT=Vehicle Miles of Travel } \\
\hline
\end{tabular}


The values for the future AADT in the Diversion file were calculated by means of a linear regression equation developed from the AADT and the future AADT forecasts in the original HPMS file. An $\mathrm{R}^{2}$ (r-squared) of 0.96 indicated that the forecasted $\mathrm{y}$-values can be reliably estimated from the $\mathrm{x}$-values using the equation--in other words the equation is a good fit to the data. The new, calculated AADT after the diversion was input as the $\mathrm{x}$-value in the equation and the Future AADT (y-value) was developed and input to the Diversion file. Figure 22 shows the trend line developed, the equation, and the $\mathrm{R}^{2}$.

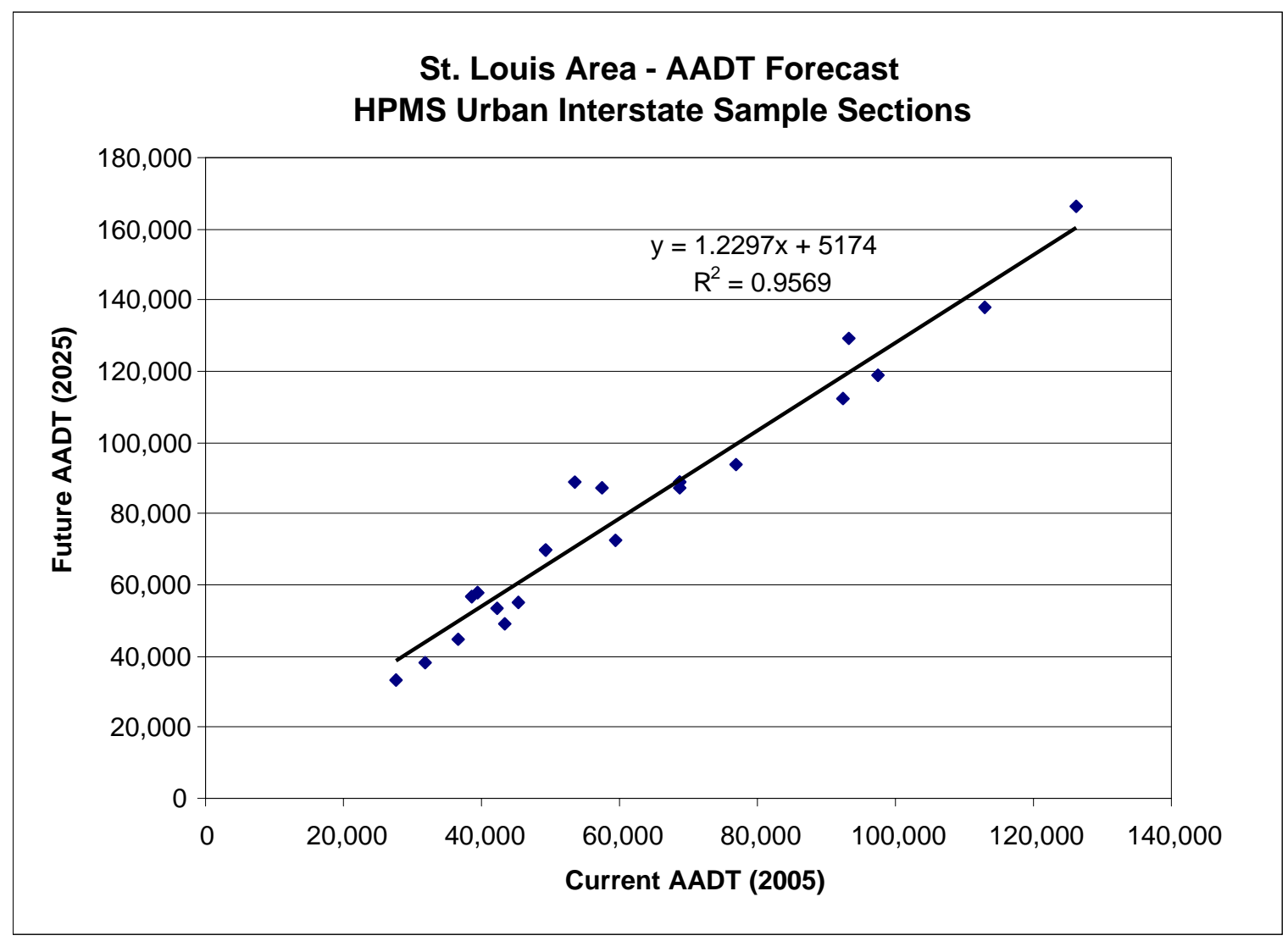

Figure 22. St. Louis Urban Interstate AADT Forecast.

\section{Results}

The HERS-ST output is very rich and detailed and is optimized for up to four funding periods of five years each, or a 20-year outlook. The maximum length of each funding period is seven years, so a 10-year outlook consisting of two funding periods, Funding Period 1 (FP1) and Funding Period 2 (FP2) was considered proper for this analysis. FP1 is for the time frame 0-5 years out and FP2 includes 5-10 years out.

Each of the two files, "Current" and "Diversion”, was input to HERS-ST and each was run under two types of analyses. The first analysis used the minimum BCR type, which was set to 1.0, in order to evaluate highway conditions and public investment required in FP1 and FP2. The second analysis used the Constraint by Funds type with the level of funding available for improvements in both funding periods set to zero. The objective was to evaluate the 
uncompensated deterioration of highway conditions first without and then with diversion of the waterborne freight.

The output of the two minimum BCR runs consisted of System Conditions, System Deficiencies, and Improvement Statistics. The output of the two Constraint by Funds runs consisted of System Conditions and System Deficiencies only; since no funds were allocated, no improvements were implemented in either funding period. The output was rearranged and grouped in a meaningful manner for proper comparison of the various classifications of results given occurrence of a diversion or not, and given available funding or not.

\section{With Improvements - Minimum BCR}

Table 20 shows the System Conditions under the Current and Diversion scenarios, initially and at the end of each of the two funding periods, assuming that funds are available and HERSrecommended improvements with minimum BCR ratios of 1.0 have been implemented. This is the reason why some system condition indicators may not show significant changes between funding periods, or others (e.g., user costs) may show a decrease. In other words, the output can be thought of in terms of "What must be done, when must it be done, what will the benefits be, and what will be the cost to maintain or improve the system's performance given increased demand?”

Comparison of the initial category values to the values at the end of FP2 provides the best basis for contextual evaluation within each scenario as well as between them. In Table 20 the following categories are of interest:

- Category 2: Lane-Miles will only have to increase by 3 in 10 years' time under the Current scenario. They will have to increase by 37, or by more than 12 times $(1,200 \%)$ under the Diversion scenario.

- $\quad$ Category 11: Total delay under Diversion is initially more than three times the Current and this ratio continues through FP2, a steady 300\% difference.

- $\quad$ Category 14: VMT (Vehicle Miles Traveled) by Combination Trucks under Diversion is almost three times (300\%) the Current due to the additional trucks, both initially and by FP2.

- $\quad$ Category 18: VHT (Vehicle Hours Traveled) by Combination Trucks under Diversion is more than three times (300\%) the Current, both initially and by FP2. This reflects the increase in travel time, and increase in delay due to the congestion created by the additional truck traffic.

- Category 31: Infrastructure Maintenance Costs under Diversion are more than double (200\%) those under Current, initially and by FP2.

- Category 32: Emissions Costs under Diversion are initially almost double (200\%) the Current. By FP2 the difference drops and they are about 50\% higher than the Current scenario. 
Table 20. HERS Results: Current and Diversion System Conditions - with Improvements.

\begin{tabular}{|c|c|c|c|c|c|c|c|}
\hline \multirow{2}{*}{\multicolumn{2}{|c|}{ Category }} & \multicolumn{3}{|c|}{ CURRENT } & \multicolumn{3}{|c|}{ DIVERSION } \\
\hline & & \multirow{2}{*}{$\begin{array}{c}\text { Initial } \\
96.2\end{array}$} & \multirow{2}{*}{$\begin{array}{c}\text { FP 1 } \\
96.2\end{array}$} & \multirow{2}{*}{$\begin{array}{c}\text { FP } 2 \\
96.2\end{array}$} & \multirow{2}{*}{$\begin{array}{c}\text { Initial } \\
96.2\end{array}$} & \multirow{2}{*}{$\begin{array}{c}\text { FP 1 } \\
96.2\end{array}$} & \multirow{2}{*}{$\begin{array}{c}\text { FP 2 } \\
96.2\end{array}$} \\
\hline 1 & Miles & & & & & & \\
\hline 2 & Lane-Miles & 636.6 & 639.4 & 639.4 & 636.6 & 642.6 & 673.8 \\
\hline 3 & Average PSR & 3.43 & 3.68 & 3.60 & 3.40 & 3.27 & 3.49 \\
\hline 4 & Average IRI & 90.8 & 72.0 & 74.9 & 92.5 & 99.4 & 81.5 \\
\hline 5 & Average Speed - Peak (mph) & 69.9 & 69.9 & 69.1 & 67.7 & 67.2 & 65.5 \\
\hline 6 & Average Speed - Off Peak (mph) & 70.8 & 70.8 & 70.7 & 70.7 & 70.7 & 70.6 \\
\hline 7 & Average Speed - Overall (mph) & 70.5 & 70.5 & 70.2 & 69.8 & 69.6 & 68.9 \\
\hline 8 & Delay - Zero Volume (hrs per 1000 VMT) & 0 & 0 & 0 & 0 & 0 & 0 \\
\hline 9 & Delay - Incident (hrs per 1000 VMT) & 0.06 & 0.08 & 0.12 & 0.19 & 0.23 & 0.29 \\
\hline 10 & Delay - Other (hrs per 1000 VMT) & 0.01 & 0.01 & 0.02 & 0.07 & 0.08 & 0.15 \\
\hline 11 & Delay - Total (hrs per 1000 VMT) & 0.07 & 0.08 & 0.14 & 0.26 & 0.31 & 0.44 \\
\hline 12 & VMT - 4-Tire Vehicle (millions) & 1,834 & 1,967 & 2,095 & 1,839 & 1,964 & 2,116 \\
\hline 13 & VMT - Single Unit Trucks (millions) & 111 & 119 & 127 & 107 & 114 & 123 \\
\hline 14 & VMT - Combination Trucks (millions) & 283 & 306 & 328 & 802 & 861 & 930 \\
\hline 15 & VMT - All (millions) & 2,229 & 2,393 & 2,551 & 2,748 & 2,940 & 3,170 \\
\hline 16 & VHT - 4-Tire Vehicle (millions) & 26 & 27 & 29 & 26 & 28 & 30 \\
\hline 17 & VHT - Single Unit Trucks (millions) & 1 & 1 & 1 & 1 & 1 & 1 \\
\hline 18 & VHT - Combination Trucks (millions) & 3 & 4 & 4 & 11 & 12 & 13 \\
\hline 19 & VHT - All (millions) & 31 & 33 & 36 & 39 & 42 & 45 \\
\hline 20 & Travel Time Costs - 4-Tire Vehicle (\$ per 1000 VMT) & 280 & 281 & 283 & 286 & 287 & 290 \\
\hline 21 & Travel Time Costs - Trucks (\$ per 1000 VMT) & 458 & 459 & 463 & 483 & 487 & 496 \\
\hline 22 & Travel Time Costs - All (\$ per 1000 VMT) & 312 & 312 & 315 & 351 & 354 & 359 \\
\hline 23 & Operating Costs - 4-Tire Vehicle (\$ per $1000 \mathrm{VMT}$ ) & 309 & 297 & 299 & 305 & 310 & 298 \\
\hline 24 & Operating Costs - Trucks (\$ per 1000 VMT) & 767 & 732 & 733 & 793 & 783 & 752 \\
\hline 25 & Operating Costs - All (\$ per 1000 VMT) & 390 & 375 & 376 & 467 & 467 & 449 \\
\hline 26 & Crash Costs (\$ per $1000 \mathrm{VMT})$ & 74 & 75 & 75 & 75 & 76 & 76 \\
\hline 27 & Total User Costs (\$ per 1000 VMT) & 777 & 763 & 767 & 894 & 897 & 884 \\
\hline 28 & Crash Rate (per 100 million VMT) & 154.7 & 155.2 & 155.8 & 156.5 & 157.2 & 157.7 \\
\hline 29 & Injury Rate (per 100 million VMT) & 75.9 & 76.1 & 76.5 & 76.8 & 77.2 & 77.4 \\
\hline 30 & Fatality Rate (per 100 million VMT) & 0.6 & 0.6 & 0.6 & 0.6 & 0.6 & 0.6 \\
\hline 31 & Maintenance Costs (\$ per 1000 miles) & 790,891 & 430,964 & 498,640 & $1,749,975$ & $1,418,868$ & $1,421,410$ \\
\hline 32 & Emissions Costs (\$ per $1000 \mathrm{VMT})$ & 32.88 & 19.96 & 12.28 & 57.27 & 32.56 & 18.68 \\
\hline 33 & BCR of Last Improvement & -- & 2.7 & 1.2 & -- & 1.8 & 1.1 \\
\hline \multicolumn{8}{|c|}{ Notes: } \\
\hline $\begin{array}{l}\text { PSF } \\
\text { IRI } \\
\text { V/C } \\
\text { VM } \\
\text { VH } \\
\text { BC } \\
\text { An }\end{array}$ & $\begin{array}{l}\mathrm{R}=\text { Present Serviceability Rating. The higher the PSR } \mathrm{t} \\
\text { = International Roughness Index. The higher the IRI } \\
\text { Ratio or VCR = Volume to Capacity Ratio; traffic jams } \\
\mathrm{IT}=\text { Vehicle Miles of Travel } \\
\mathrm{T}=\text { Vehicle Hours of Travel } \\
\mathrm{R}=\text { Benefit Cost Ratio } \\
\text { y discrepancies in calculations due to intermediate rou }\end{array}$ & $\begin{array}{l}\text { better th } \\
\text { worse th } \\
\text { system fa }\end{array}$ & $\begin{array}{l}\text { pavement. } \\
\text { pavement. } \\
\text { res) occur }\end{array}$ & New pa & ments at m & $\mathrm{xPSR}=4.5$ & \\
\hline
\end{tabular}

Table 21 shows selected categories from the System Deficiencies output of HERS. Deficiencies in Pavement Serviceability Rating, Volume-to-Capacity (V/C) Ratio, and Shoulder Surface are reported in percent miles and percent vmt that are deficient, initially and at the end of each funding period.

Under the Current scenario all three categories are remedied by FP2, given implementation of improvements, since the percent deficient miles and vmt both drop substantially by FP2. 
Under the Diversion scenario, only PSR and shoulder deficiencies are remedied by FP2. The V/C ratio deficiencies however, worsen by FP2 despite improvements. Both the deficient percent miles and the deficient percent vmt more than double from initial to FP2, from 6 to 12 and from 5 to 13 respectively. FP2 V/C ratio deficiencies are roughly 15 times the FP2 levels under Current, 12.3 vs. 0.8 percent miles and 12.7 vs. 0.7 percent vmt.

Table 21. HERS Results: Current and Diversion System Deficiencies - with Improvements.

\begin{tabular}{|c|c|c|c|c|c|c|c|}
\hline & \multirow{2}{*}{ Deficiency Category } & \multicolumn{3}{|c|}{ CURRENT } & \multicolumn{3}{|c|}{ DIVERSION } \\
\hline & & Initial & FP 1 & FP 2 & Initial & FP 1 & FP 2 \\
\hline & \% MILEAGE & & & & & & \\
\hline 1 & $\operatorname{PSR}(<3.4)$ & 47.9 & 15.3 & 11.2 & 47.9 & 70.9 & 14.5 \\
\hline 2 & V/C Ratio (>0.9) & 1.7 & 0.8 & 0.8 & 6.1 & 11.4 & 12.3 \\
\hline 3 & Shoulder Surface Type* & 43.2 & -- & -- & 43.2 & -- & -- \\
\hline & $\% \mathrm{VMT}$ & & & & & & \\
\hline 1 & $\operatorname{PSR}(<3.4)$ & 36.3 & 25.3 & 13.8 & 38.5 & 69.3 & 21.2 \\
\hline 2 & V/C Ratio (>0.9) & 2.0 & 0.7 & 0.7 & 4.9 & 12.3 & 12.7 \\
\hline 3 & Shoulder Surface Type* & 27.3 & -- & -- & 30.3 & -- & -- \\
\hline
\end{tabular}

Table 22 shows selected improvement statistics output by HERS. The three categories of improvements identified are:

- $\quad$ Resurfacing, including adding new lanes - or major widening

- $\quad$ Resurfacing the existing lanes, including the shoulders

- $\quad$ Resurfacing the existing lanes only

These improvements are estimated to cost four times as much in FP2 under the Diversion by comparison to the Current ( $\$ 479 \mathrm{~m}$ vs. $\$ 119 \mathrm{~m}$ ). The total lane-miles to be improved by FP2 under Diversion are almost three times as many as under Current (584 vs. 202). The total miles to be improved, by FP2 under Diversion are also almost three times as many as under Current (80 vs. 30). 
Table 22. HERS Results: Current and Diversion Improvement Statistics.

\begin{tabular}{|c|c|c|c|c|}
\hline \multirow{2}{*}{ Category } & \multicolumn{2}{|c|}{ CURRENT } & \multicolumn{2}{|c|}{ DIVERSION } \\
\hline & FP 1 & FP 2 & FP 1 & FP 2 \\
\hline \multicolumn{5}{|l|}{1 Cost (\$ 000s) } \\
\hline Resurface and add Normal-Cost Lanes (major widening) & 19,265 & -- & 40,596 & 235,568 \\
\hline Resurface and Improve Shoulders & 157,007 & -- & 152,092 & -- \\
\hline Resurface & 49,530 & 119,242 & 49,530 & 243,744 \\
\hline Total & 225,803 & 119,242 & 242,219 & 479,312 \\
\hline \multicolumn{5}{|l|}{2 Lane-Miles Improved } \\
\hline Resurface and add Normal-Cost Lanes (major widening) & 10 & -- & 19 & 170 \\
\hline Resurface and Improve Shoulders & 218 & -- & 212 & - \\
\hline Resurface & 95 & 202 & 95 & 413 \\
\hline Total & 323 & 202 & 327 & 584 \\
\hline \multicolumn{5}{|l|}{3 Miles Improved } \\
\hline Resurface and add Normal-Cost Lanes (major widening) & 1 & -- & 3 & 15 \\
\hline Resurface and Improve Shoulders & 41 & -- & 39 & -- \\
\hline Resurface & 14 & 30 & 14 & 64 \\
\hline Total & 57 & 30 & 57 & 80 \\
\hline
\end{tabular}

\section{Without Improvements - Constraint by Funds}

Table 23 shows the System Conditions under the Current and the Diversion scenarios, initially and at the end of each of the two funding periods, assuming that no funds are available and no improvements have been implemented. This output can be thought of in terms of "What will the system's condition and performance be if nothing is done?”

Comparison of the initial category values to the values at the end of FP2 provides the best basis for contextual evaluation within each scenario as well as between them. In Table 23 the following categories are of interest:

- Category 2: Lane-Miles do not increase under either scenario; since no funds are available, no construction has taken place.

- Category 11: Total delay under Diversion is roughly three times the Current from initial through to FP2, a steady 300\% difference.

- Category 14: VMT (Vehicle Miles Traveled) by Combination Trucks under Diversion is almost three times (300\%) the Current due to the additional trucks, both initially and by FP2.

- Category 18: VHT (Vehicle Hours Traveled) by Combination Trucks under Diversion is more than three times (300\%) the Current from initial to FP2. This reflects the increase in travel time, and increase in delay due to the congestion created by the additional truck traffic.

- Category 31: Infrastructure Maintenance Costs under Diversion are more than double (200\%) those under Current scenario, initially and by FP2.

- Category 32: Emissions Costs under Diversion are initially almost double (200\%) the Current. By FP2 the difference drops to about 1.4 times the Current scenario (40\% higher). 
Table 23. HERS Results: Current and Diversion System Conditions - w/o Improvements.

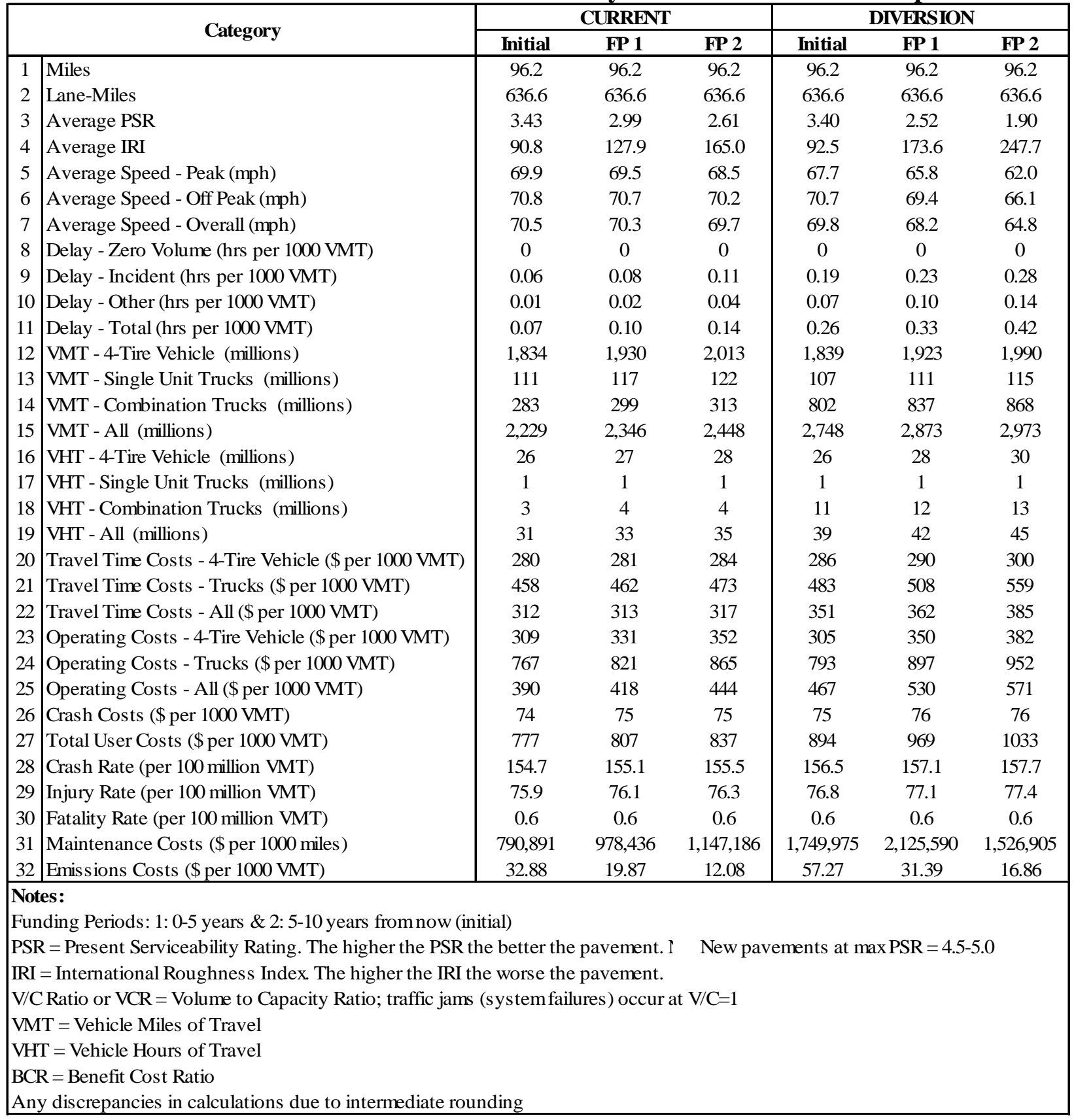

Table 24 shows selected categories from the System Deficiencies output of HERS. Deficiencies in Pavement Serviceability Rating, Volume-to-Capacity Ratio, and Shoulder Surface are reported in percent miles and percent vmt that are deficient, initially and at the end of each funding period.

Under the Current scenario the percent miles and percent vmt that are deficient in V/C ratio and shoulder surface increase modestly from initial to FP2. However, PSR deficiency at FP2 is at least 1.5 times the initial levels, from 48 to 72 percent miles and from 36 to 67 percent vmt. 
Under the Diversion scenario, no change is shown in percent miles or vmt that are deficient in shoulder surface. PSR deficiency however, almost doubles by FP2, from 48 to 93 percent miles and more than doubles in percent vmt, from 39 to 90 . Overall vmt deficiencies are roughly $200 \%$ the initial levels or a $100 \%$ increase.

V/C ratio deficiencies under Diversion from initial to FP2 more than double in percent miles (6 to 15), and more than triple in percent vmt (5 to 16). By comparison to FP2 under the Current scenario, the V/C ratio deficiencies in percent miles and percent vmt are over six times as much.

Table 24. HERS Results: Current and Diversion System Deficiencies - w/o Improvements.

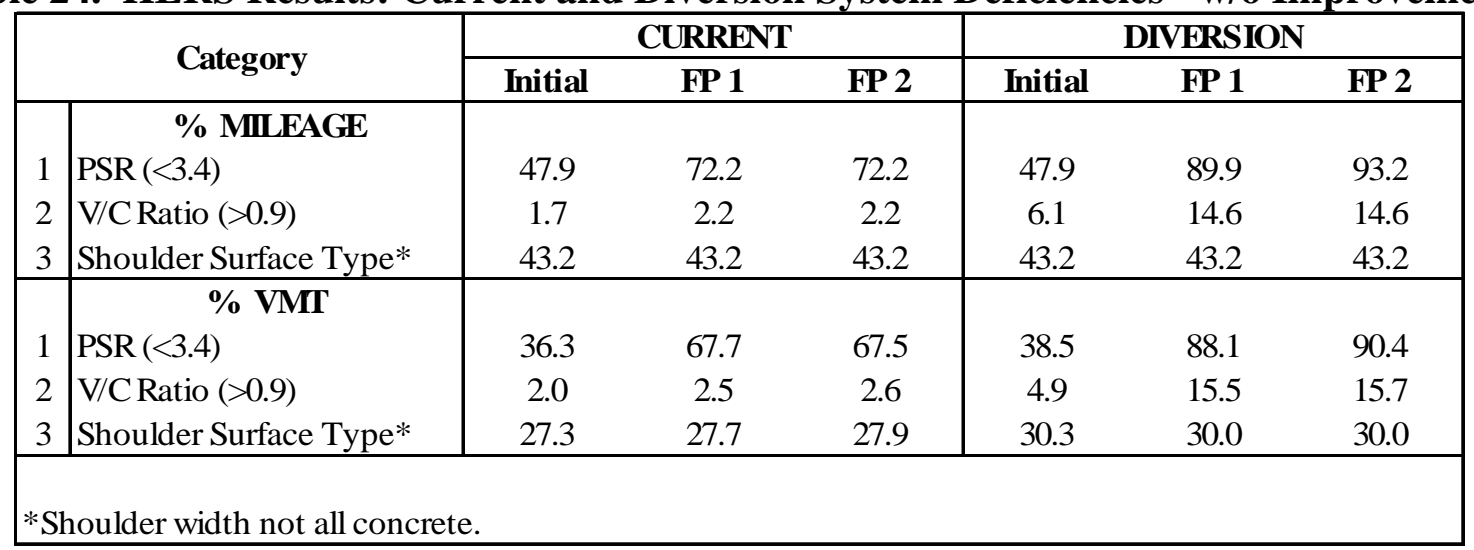

Table 25 consolidates the wide spectrum of impacts on the interstate system that would be expected in case of a diversion of the Mississippi river freight traffic through the St. Louis area. The comparison focuses on selected categories, with and without improvements, under the current and the diversion scenarios, initially and 10 years hence. 
Table 25. Summary of HERS Results - Engineering.

\begin{tabular}{|c|c|c|c|c|c|}
\hline \multirow{2}{*}{ IMPACT } & \multirow{2}{*}{ IMPROVEMENTS } & \multicolumn{2}{|c|}{ CURRENT } & \multicolumn{2}{|c|}{ DIVERSION } \\
\hline & & Initial & In 10 Years & Initial & In 10 Years \\
\hline \multirow{2}{*}{$\begin{array}{l}\text { New Construction } \\
\text { (lane-miles) }\end{array}$} & Yes & 636.6 & 639.4 & 636.6 & 673.8 \\
\hline & No & 636.6 & 636.6 & 636.6 & 636.6 \\
\hline \multirow{2}{*}{$\begin{array}{c}\text { Delay } \\
\text { (hrs/1,000 VMT) }\end{array}$} & Yes & 0.07 & 0.14 & 0.26 & 0.44 \\
\hline & No & 0.07 & 0.14 & 0.26 & 0.42 \\
\hline \multirow{2}{*}{$\begin{array}{l}\text { VMT Combination } \\
\text { Truck (millions) }\end{array}$} & Yes & 283 & 328 & 802 & 930 \\
\hline & No & 283 & 313 & 802 & 868 \\
\hline \multirow{2}{*}{$\begin{array}{l}\text { VHT Combination } \\
\text { Truck (millions) }\end{array}$} & Yes & 3 & 4 & 11 & 13 \\
\hline & No & 3 & 4 & 11 & 13 \\
\hline \multirow{2}{*}{$\begin{array}{l}\text { Maintenance Costs } \\
\text { (\$000s/1,000 VMT) }\end{array}$} & Yes & 791 & 499 & 1,750 & 1,421 \\
\hline & No & 791 & 1,147 & 1,750 & 1,527 \\
\hline \multirow{2}{*}{$\begin{array}{l}\text { Emissions Costs } \\
(\$ / 1,000 \mathrm{VMT})\end{array}$} & Yes & 33 & 13 & 57 & 19 \\
\hline & No & 33 & 12 & 57 & 17 \\
\hline \multirow{2}{*}{$\begin{array}{l}\text { \% VMT with } \\
\text { Deficient PSR }\end{array}$} & Yes & 36.3 & 13.8 & 38.5 & 21.2 \\
\hline & No & 36.3 & 67.5 & 38.5 & 90.4 \\
\hline \multirow{2}{*}{$\begin{array}{c}\text { \% VMT with } \\
\text { Deficient V/C Ratio }\end{array}$} & Yes & 2.0 & 0.7 & 4.9 & 12.7 \\
\hline & No & 2.0 & 2.6 & 4.9 & 15.7 \\
\hline \multirow{2}{*}{$\begin{array}{l}\text { Improvement Costs } \\
\text { (\$ million) }\end{array}$} & Yes & \multicolumn{2}{|c|}{345} & \multicolumn{2}{|c|}{722} \\
\hline & No & \multicolumn{2}{|c|}{--} & \multicolumn{2}{|c|}{--} \\
\hline
\end{tabular}

Table 26 further consolidates the wide spectrum of impacts on the interstate system that would be expected in case of a diversion of the Mississippi river freight traffic through the St. Louis area. The comparison focuses on 10 selected categories deemed to be the items of greatest interest to the general public. It shows present conditions (from Current initial output), as well as conditions in 10 years (end of FP2) under the Diversion scenario, both with and without costeffective improvements to account for the additional traffic. The present conditions serve as the baseline values on which the percent change has been calculated. Assuming all cost-effective improvements (benefits exceed costs) were undertaken, the analysis concluded that highway improvement costs over 10 years would increase from \$345 million to \$722 million. Truck traffic would almost triple. Traffic delays would increase by almost 500\%. Injuries and fatalities on these highway segments would increase by $36-45 \%$. Maintenance costs would 
increase by $80-93 \%$. While a permanent shutdown of the waterway certainly cannot be anticipated, this case study demonstrates how beneficial the waterways are to the overall freight transportation system.

Table 26. Summary of Significant Impacts - General Public.

\begin{tabular}{|c|c|c|c|c|c|c|}
\hline \multirow{2}{*}{\multicolumn{2}{|c|}{ Category }} & \multirow{2}{*}{$\begin{array}{c}\text { CURRENT } \\
\text { Initial }\end{array}$} & \multicolumn{4}{|c|}{10 YEARS AFTER WATERWAY CLOSURE } \\
\hline & & & w/o Improvements & \% Change & w Improvements & \% Change \\
\hline 1 & Combination Trucks per Lane-Mile per Day* & 1218 & 3736 & $207 \%$ & 3781 & $210 \%$ \\
\hline 2 & Average Speed - Peak (mph) & 69.9 & 62.0 & $-11 \%$ & 65.5 & $-6 \%$ \\
\hline 3 & Average Speed - Off Peak (mph) & 70.8 & 66.1 & $-7 \%$ & 70.6 & $0 \%$ \\
\hline 4 & Delay - Total (hrs per 1000 VMT) & 0.07 & 0.42 & $466 \%$ & 0.44 & $495 \%$ \\
\hline 5 & Crashes (annual) & 3448 & 4688 & $36 \%$ & 4999 & $45 \%$ \\
\hline 6 & Injuries (annual) & 1692 & 2301 & $36 \%$ & 2454 & $45 \%$ \\
\hline 7 & Fatalities (annual) & 13 & 18 & $36 \%$ & 19 & $45 \%$ \\
\hline 8 & Maintenance Costs (\$ million per 1000 miles) & 0.79 & 1.53 & $93 \%$ & 1.42 & $80 \%$ \\
\hline & Emissions Costs (\$ per $1000 \mathrm{VMT})^{* *}$ & 12.28 & 16.86 & $37 \%$ & 18.68 & $52 \%$ \\
\hline & Improvement Costs (\$ million)*** & 345.0 & -- & -- & 721.5 & $109 \%$ \\
\hline
\end{tabular}

